Florida International University FIU Digital Commons

FIU Electronic Theses and Dissertations

University Graduate School

7-25-1996

\title{
Developing brownfields ranking models using decision analytic methods
}

Adjo A. Amekudzi

Florida International University

DOI: $10.25148 /$ etd.FI14032305

Follow this and additional works at: https://digitalcommons.fiu.edu/etd

Part of the Civil and Environmental Engineering Commons

\section{Recommended Citation}

Amekudzi, Adjo A., "Developing brownfields ranking models using decision analytic methods" (1996). FIU Electronic Theses and Dissertations. 1277.

https://digitalcommons.fiu.edu/etd/1277

This work is brought to you for free and open access by the University Graduate School at FIU Digital Commons. It has been accepted for inclusion in FIU Electronic Theses and Dissertations by an authorized administrator of FIU Digital Commons. For more information, please contact dcc@fiu.edu. 
FLORIDA INTERNATIONAL UNIVERSITY

Miami, Florida

DEVELOPING BROWNFIELDS RANKING MODELS

USING DECISION ANALYTIC METHODS

A thesis submitted in partial fulfilment of the

degree requirements for

MASTER OF SCIENCE

IN

CIVIL ENGINEERING

by

Adjo A. Amekudzi

1996 
This thesis, written by Adjo A. Amekudzi, and entitled Developing Brownfields Ranking Models Using Decision Analytic Methods, having been approved in respect to style and intellectual content, is referred to you for judgement.

We have read this thesis and recommend that it be approved.

Dr. O. Attoh-Okine

Dr. Shonali Laha

○

Dr. L. David Shen

Date of Defense: July 25, 1996

This thesis of Adjo A. Amekudzi is approved.

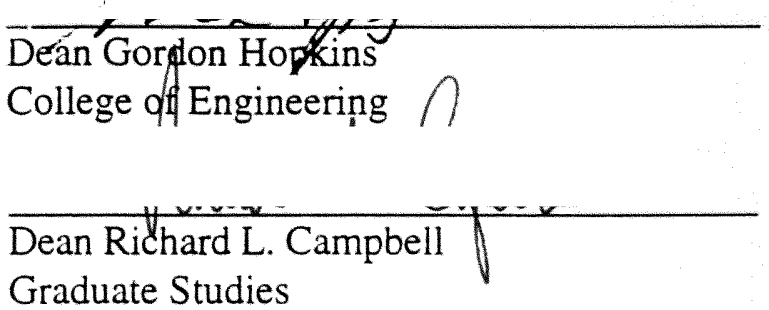

Florida International University, 1996 
${ }^{\circ}$ COPYRIGHT 1996 Amekudzi

All rights reserved. 
This thesis is dedicated to my parents who have given me the valuable gifts of formal and informal education, and to all sincere seekers of Brownfields Redevelopment. 


\section{ACKNOWLEDGMENTS}

Gratitude goes to the One Divine Love for life, thought and wisdom, to my major professor Dr. Attoh-Okine for his consistent desire to share and apply his knowledge and new ideas, to Dr. Shonali Laha for her perusal of the manuscript and unwavering attention to detail, and to Dr. Shen for his continual accessibility. 


\section{ABSTRACT OF THE THESIS \\ DEVELOPING BROWNFIELDS RANKING MODELS \\ USING DECISION ANALYTIC METHODS}

by

Adjo A. Amekudzi

Florida International University, 1996

Professor N. O. Attoh-Okine, Major Professor

The redevelopment of Brownfields has taken off in the 1990s, supported by federal and state incentives, and largely accomplished by local initiatives. Brownfields redevelopment has several associated benefits. These include the revitalization of inner-city neighborhoods, creation of jobs, stimulation of tax revenues, greater protection of public health and natural resources, the renewal and reuse existing civil infrastructure and Greenfields protection. While these benefits are numerous, the obstacles to Brownfields redevelopment are also very much alive. Redevelopment issues typically embrace a host of financial and legal liability concerns, technical and economic constraints, competing objectives, and uncertainties arising from inadequate site information. Because the resources for Brownfields redevelopment are usually limited, local programs will require creativity in addressing these existing obstacles in a manner that extends their limited resources for returning Brownfields to productive uses. Such programs may benefit from a structured and defensible decision framework to prioritize sites for redevelopment: one that incorporates the desired objectives, corresponding variables 
and uncertainties associated with Brownfields redevelopment. This thesis demonstrates the use of a decision analytic tool, Bayesian Influence Diagrams, and related decision analytic tools in developing quantitative decision models to evaluate and rank Brownfields sites on the basis of their redevelopment potential. 


\section{TABle OF Contents}

CHAPTER

PAGE

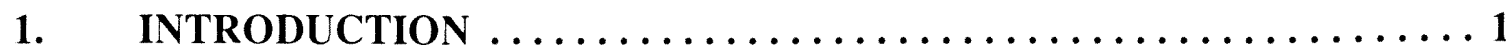

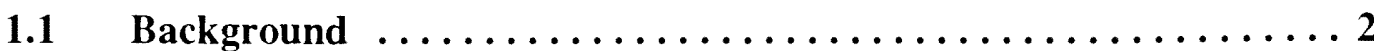

1.2 Problem Statement $\ldots \ldots \ldots \ldots \ldots \ldots \ldots \ldots \ldots \ldots \ldots \ldots$

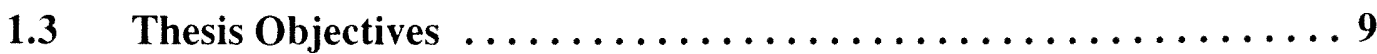

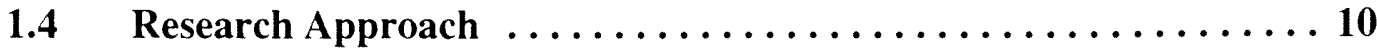

1.5 Thesis Organization $\ldots \ldots \ldots \ldots \ldots \ldots \ldots \ldots \ldots \ldots \ldots \ldots$

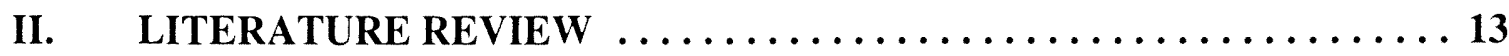

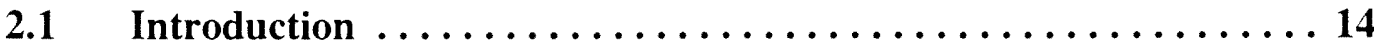

2.2 Major Issues in the Brownfields Redevelopment Process . . . . . . 15

2.3 Brownfields Redevelopment - The Actual Process ........... 19

2.4 State and Local Level Brownfields Initiatives ............ 23

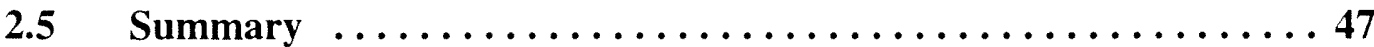

1II. DECISION ANALYSIS IN BROWNFIELDS REDEVELOPMENT . . . 49

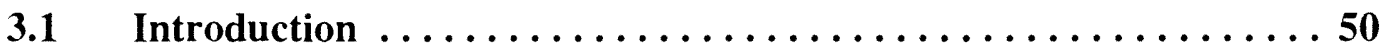

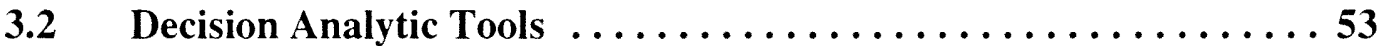

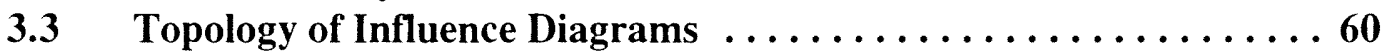

3.4 Evaluation of Influence Diagrams $\ldots \ldots \ldots \ldots \ldots \ldots \ldots \ldots \ldots 61$

3.5 Influence Diagrams in Brownfields Redevelopment ........6 63

3.6 Benefits of Influence Diagrams for Brownfields Redevelopment . . 8 85

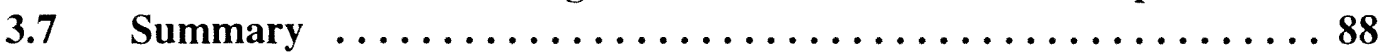

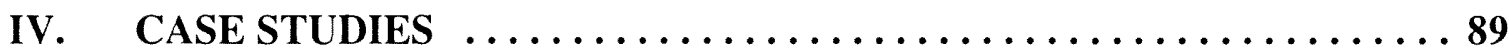

4.1 Introduction to Dade County and its Brownfields Program .... 90

4.2 Need for Brownfields Redevelopment in Dade County ........94

4.3 Current Issues in Brownfield Redevelopment in Dade County . . . 97

4.4 Available and Potential Resources for Brownfields Redevelopment 98

4.5 Liberty City and the Poinciana Industrial Center Sites . . . . . . 100

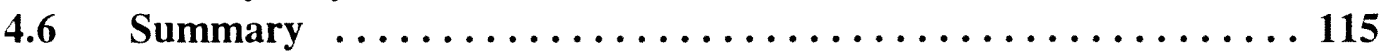

V. MODEL DEVELOPMENT \& RANKING OF SITES $\ldots \ldots \ldots \ldots \ldots 117$

5.1 Decision Model Development for the PIC Sites $\ldots \ldots \ldots \ldots \ldots 118$

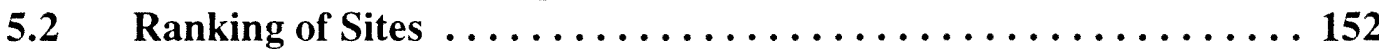

5.3 Note on Value of Information $\ldots \ldots \ldots \ldots \ldots \ldots \ldots \ldots \ldots \ldots$

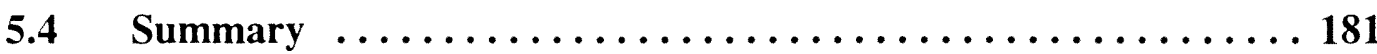




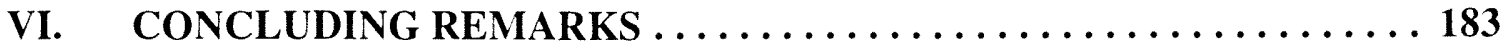

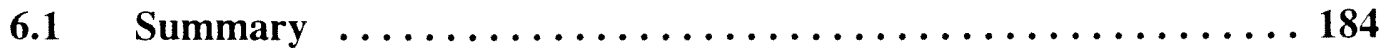

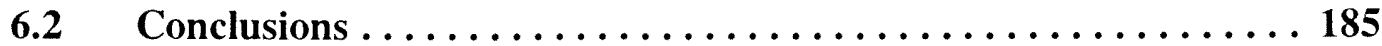

6.3 Suggestions for Further Research $\ldots \ldots \ldots \ldots \ldots \ldots \ldots \ldots 188$

VII. REFERENCES $\ldots \ldots \ldots \ldots \ldots \ldots \ldots \ldots \ldots \ldots \ldots \ldots \ldots \ldots$ 


\section{LIST OF TABLES}

Table 2.1 Funding Sources for Brownfields Redevelopment $\ldots \ldots \ldots \ldots \ldots 31$

Table 2.2 State Level Brownfields Initiatives $\ldots \ldots \ldots \ldots \ldots \ldots \ldots$

Table $2.3 \quad$ Local Level Brownfields Strategies $\ldots \ldots \ldots \ldots \ldots \ldots \ldots \ldots \ldots$

Table 4.1 Database for PIC Sites $\ldots \ldots \ldots \ldots \ldots \ldots \ldots \ldots \ldots \ldots \ldots \ldots \ldots$

Table 5.1 Summary of Independent Variables $\ldots \ldots \ldots \ldots \ldots \ldots \ldots \ldots$

Table 5.2 Independent Variables, States and Values $\ldots \ldots \ldots \ldots \ldots \ldots$

Table $5.3 \quad$ Site Ranking Information for Case 1 Scenario $\ldots \ldots \ldots \ldots \ldots$

Table 5.4 Site Expected Values for Case 1 Scenario $\ldots \ldots \ldots \ldots \ldots \ldots \ldots$

Table $5.5 \quad$ Site Ranking Information for Case 2 Scenario $\ldots \ldots \ldots \ldots \ldots 2$

Table 5.6 Site Expected Values for Case 2 Scenario . . . . . . . . . . . . 169

Table $5.7 \quad$ Site Ranking Information of Case 3 Scenario $\ldots \ldots \ldots \ldots \ldots$

Table 5.8 Site Expected Values and Risk Information for Case 3 Scenario . 170 


\section{List OF Figures}

Figure 2.1 Significant Relationships in Brownfields Redevelopment $\ldots \ldots \ldots 22$

Figure 3.1.1 Symmetric Decision Tree $\ldots \ldots \ldots \ldots \ldots \ldots \ldots \ldots \ldots \ldots$

Figure 3.1.2 Asymmetric Decision Tree $\ldots \ldots \ldots \ldots \ldots \ldots \ldots \ldots \ldots \ldots \ldots \ldots \ldots \ldots \ldots$

Figure $3.2 \quad$ Simple Influence Diagram $\ldots \ldots \ldots \ldots \ldots \ldots \ldots \ldots \ldots$

Figure $3.3 \quad$ Node Relationships in Influence Diagrams $\ldots \ldots \ldots \ldots \ldots \ldots$

Figure 3.4 Technical Issues in Brownfields Redevelopment (Type 1) . . . . 67

Figure 3.5 Technical Issues in Brownfields Redevelopment (Type II) . . . . . 70

Figure 3.6 Legal Liability Issues in Brownfields Redevelopment (Type I) . . 72

Figure 3.7 Legal Liability Issues in Brownfields Redevelopment (Type II) . . . 73

Figure 3.8 Financial Issues in Brownfields Redevelopment (Type I) . . . . . 75

Figure 3.9 Financial Issues in Brownfields Redevelopment (Type II) . . . . 76

Figure 3.10 Community Concerns in Brownfields Redevelopment (Type I) . . 78

Figure 3.11 Community Concerns in Brownfields Redevelopment (Type II) . . 79

Figure 3.12 Brownfields Redevelopment Prospects $\ldots \ldots \ldots \ldots \ldots \ldots$

Figure 3.13 Overall Brownfields Redevelopment Potential (Type I) .......83

Figure 3.14 Overall Brownfields Redevelopment Potential (Type II) . . . . . 84

Figure 3.15 Improved Process for Brownfields Redevelopment $\ldots \ldots \ldots \ldots 87$

Figure 4.1 Map of Florida Showing Metropolitan Dade County ......... 91

Figure 4.2 Metropolitan Dade County - Urban Development Area ........ 95

Figure 4.3 Metropolitan Dade County - Urban Infill Area $\ldots \ldots \ldots \ldots \ldots$ 
Figure 4.4 County Map Showing Model Cities Area $\ldots \ldots \ldots \ldots \ldots \ldots 101$

Figure $4.5 \quad$ Study Area Location Map $\ldots \ldots \ldots \ldots \ldots \ldots \ldots \ldots \ldots \ldots$

Figure 4.6 Site and Area Number - Location Map .............. 104

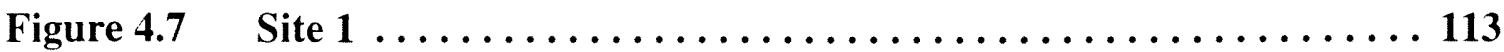

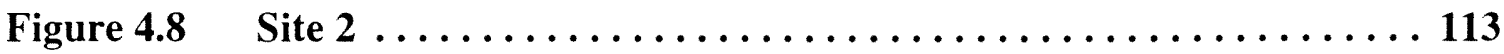

Figure $4.9 \quad$ Site $3 \ldots \ldots \ldots \ldots \ldots \ldots \ldots \ldots \ldots \ldots \ldots \ldots \ldots \ldots \ldots \ldots$

Figures 5.0-A Components of Brownfields Ranking Model ......... 119

Figures 5.0-B Dependent \& Independent Variables ............ 123

Figures 5.0-C Implicit and Explicit Inter-Variable Relationships $\ldots \ldots 128$

Figures 5.0-D Functional Relationships Between Model Variables . . . . . 129

Figures $5.1 \quad$ Preliminary Model $\ldots \ldots \ldots \ldots \ldots \ldots \ldots \ldots \ldots \ldots \ldots \ldots \ldots$

Figures $5.2 \quad$ Refined Model I $\ldots \ldots \ldots \ldots \ldots \ldots \ldots \ldots \ldots \ldots \ldots \ldots \ldots$

Figures $5.3 \quad$ Refined Model II $\ldots \ldots \ldots \ldots \ldots \ldots \ldots \ldots \ldots \ldots \ldots \ldots \ldots \ldots$

Figures $5.4 \quad$ Final Model $\ldots \ldots \ldots \ldots \ldots \ldots \ldots \ldots \ldots \ldots \ldots \ldots \ldots$

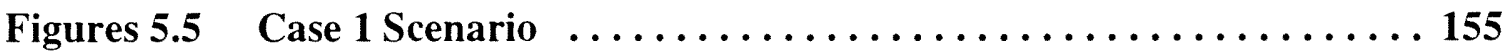

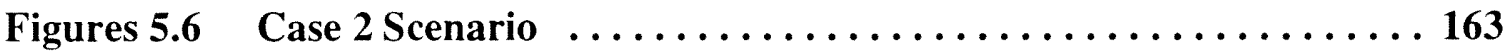

Figures 5.7 Case 3 Scenario $\ldots \ldots \ldots \ldots \ldots \ldots \ldots \ldots \ldots \ldots \ldots \ldots \ldots$

Figures $5.8 \quad$ Best Case Scenario $\ldots \ldots \ldots \ldots \ldots \ldots \ldots \ldots \ldots \ldots \ldots \ldots \ldots$ 
Chapter 1

INTRODUCTION 


\subsection{Background}

Brownfields are vacant, abandoned or under-utilized commercial and industrial sites and facilities where real or perceived environmental contamination is an obstacle to redevelopment. These sites lie somewhere between significantly contaminated sites (Superfund Sites) and pristine Greenfields (unused land parcels or farmlands outside urban borders). An estimated 130,000 to 400,000 such sites exist, according to the U.S. General Accounting Office [Maldonado, 1996]. Once the might of the U.S. economy, several Brownfields are now found in the older industrial and commercial urban centers of the United States that are now part of declining or depressed neighborhoods. Many of these sites are concentrated in the Northeast and Midwest where much of the economy was historically based on heavy industrial activity. However, they are also common in the South and West and represent a wide variety of past industrial and commercial uses.

Over the last two decades, federal, state and local environmental regulations, designed to protect public health and natural resources, have unintentionally hampered the redevelopment of contaminated sites. The hazardous waste management era began with the passage of the Resource Conservation and Recovery Act (RCRA) of 1976 which clearly differentiated between hazardous and non-hazardous wastes and sought to protect public health and the environment. In 1980, the Comprehensive Environmental Response, Compensation and Liability Act (CERCLA), also known as Superfund, was enacted to facilitate the clean up of heavily contaminated sites nationwide. Administered by the United States Environmental Protection Agency (USEPA), the Superfund process was designed to 
establish an inventory of hazardous waste sites nationwide, (known as the National Priorities List or NPL), and to transfer the costs of cleaning up these sites to the producers of the waste. Needless to say, the Superfund process quickly orphaned many contaminated sites. The USEPA rapidly evolved an ardent watchdog role, and demonstrated a strong desire to see the contaminated sites cleaned up at all costs. Where producers of the waste could not be easily located, cleanup costs were indiscriminately passed on the current users or owners of the site, lenders or any other such individual(s) who could be reasonably linked to these sites. This state of affairs scared off potential property buyers who could wind up exposing themselves to liability for prohibitively expensive cleanup costs. The Superfund process soon became fraught with litigation and extensive delays.

In 1986, the Superfund Amendments and Reauthorization Act (SARA) established a fund, derived from taxes on the chemical manufacturing industry, to provide for cleanup of contaminated sites whose generators could not be determined. However, litigation and the fear of liability kept remediation and redevelopment of the majority of these sites at a standstill. Indeed, the Congressional Budget Office has reported that each site on the National Priority List requires 12 years and 30 million dollars to clean up, with eight of those years and 36 percent of that money going to the litigation process [Maldonado, 1996]. Moreover, several developers and businesses found the federal Superfund program complicated and unable to provide risk assessments and immunity from further environmental liability once the sites had been cleaned up. Thus, the very Superfund process that was created to eliminate contaminated sites, seemed to result in an indefinite preservation of the 
contaminated status of a majority of these sites.

As long as these contaminated sites remained unaltered, their obvious health and environmental hazards also lingered. In addition, they negatively affected the overall economic and social health of the communities surrounding them, a situation which made the sites even less attractive for redevelopment. As a result, many developers took their businesses to the suburbs, with housing developers and urban commuters following their suit. These contaminated sites have therefore created environmental, economic and social drawbacks for localities, regions, states and hence the nation at large. Locally, contaminated sites have contributed to blighted neighborhoods with declining central business districts, stigmatized by decaying and abandoned sites with little potential for attracting business. Regionally, increasing development at urban fringes has resulted in uncontained urban sprawl, with its associated encroachment on virgin Greenfields. In turn, the urban sprawl phenomenon has resulted in associated increases in travel demand and roadway congestion. This widespread increase in urban sprawl has emphasized the advantages of developing Brownfields rather than Greenfields. As Barnette [1995] points out:

1. Brownfields are properly zoned and thus well suited for industrial [and commercial] use;

2. The civil infrastructure and utilities necessary for industrial operations are already in place at several Brownfields sites;

3. Brownfields redevelopment preserves the nation's virgin land and natural resources. Thus, while the cleanup of site contamination seemed to fall squarely on the shoulders of the 
USEPA in the early 1980 s, the late 80 s and early 90 s have proven rather different. Local entities have come to realize and demonstrate that they have a significant stake in eliminating contaminated sites from their neighborhoods. Without any federal incentives, several municipalities, working with state level officials, began to develop plans to cleanup and reuse these stigmatized sites, increase their neighborhoods' water and air quality, and revitalize their economic and social climates: portraying yet another classic example where the maintenance of environmental integrity makes social and economic sense.

In recent years, these grassroots initiatives have crystallized into a clear federal commitment with supporting initiatives to remove prevailing obstacles, and develop much needed incentives that promote the redevelopment of contaminated sites. The first step in this direction has been the emergence of the expression "Brownfields" to replace the previously used term "Superfund Sites", a term that simply destroys the market value of any property. In addition, a new wave of federal regulations and programs have rapidly evolved to encourage widespread efforts in Brownfields redevelopment. To spearhead nationwide Brownfields redevelopment, the USEPA announced its Brownfields Economic Redevelopment Initiative in November 1993. The purpose of the Initiative is to identify contaminated, abandoned inner city properties [Connolly and Daddario, 1995], and promote their cleanup [Emerson, 1996]. The Initiative is funded through the Superfund budget and managed by USEPA. A new rule under this Initiative is expected to loosen funds for underground storage tank (UST) upgrades and cleanup, and dramatically reduce lender liability for properties housing USTs [Baker, 1995]. Following this Initiative, the USEPA 
announced its Brownfields Action Program in January 1995 [Shanoff, 1995]. The main objective of this program is to transfer sites from the Superfund tracking system to state Brownfields inventories, and provide funding incentives for their remediation and productive reuse. Under this program, the federal government has committed to provide funding for local governments to cleanup 50 pilot Brownfields projects by the end of 1996 . The projects are funded at up to $\$ 200,000$; they will test redevelopment models, direct special efforts toward removing regulatory barriers without sacrificing protectiveness, and facilitate coordinated public and private efforts at the federal, state and local levels [Brownfields Pilots, 1996]. Approximately 27,000 of the original 40,000 Superfund sites have been transferred from the National Priority List to state Brownfields inventories [Maldonado, 1996]. In addition, federal legislation has been drafted to reduce and clearly define the levels of liability for both existing and potential owners of contaminated sites [USEPA Guidance, 1995; USEPA Policy, 1995]. And most recently, the Clinton Administration has proposed a Brownfields tax incentive plan that will provide over two billion dollars in tax incentives over a seven-year period, specifically targeted to Brownfields pilot sites [ENR, 1996]. Inthisnew and fast improving environment, several state initiatives and local level efforts are underway to develop comprehensive programs with supporting tools for Brownfields remediation and redevelopment. State level initiatives attempt to create a more favorable framework for Brownfields redevelopment at the local level, with such incentives as risk and liability management, financial support and technical assistance programming. Examples of such state level programs are Minnesota's Voluntary Investigation and Cleanup Program, 
Pennsylvania's Land Recycling Program and Orphan Sites Program, and Ohio's Voluntary Action Program. Local level initiatives take advantage of both state and federal incentives and programs to develop adequate tools for the actual clean up and redevelopment of these sites. Examples of such local level initiatives are the Duwamish (Washington) initiative to develop a decision-tree model for risk evaluation and remedy selection, and the City of Pittsburgh's pilot project to inventory existing sites with redevelopment potential and use financial incentives to stimulate site redevelopment. Collectively, these initiatives are expected to revitalize inner-city neighborhoods, renew and reuse existing civil infrastructure, create jobs, stimulate tax revenues, ensure greater protection of public health and natural resources, reduce encroachment on virgin Greenfields and curb urban sprawl.

\subsection{Problem Statement}

While the potential benefits of Brownfields redevelopment are substantial, so also are the obstacles. Despite the growing enthusiasm and debate for Brownfields redevelopment, the remediation and redevelopment process still faces strong environmental and socio-economic constraints. In addition to costly site assessments and cleanups, the financial challenge for redevelopment is very much alive, especially in declining neighborhoods where a significant number of Brownfields happen to be located.

Parallel to these pervasive constraints are a host of fundamental issues that must also be considered for Brownfields redevelopment. Decision making for Brownfields remediation and redevelopment typically embraces the following five basic issues: technical (relating to 
the availability of feasible and cost-effective remediation technologies), legal liability (relating to the varying degrees of uncertainty over the level and extent of liability), financial (relating to the availability of viable options for financing site assessment, remediation and redevelopment), community concerns (related to public health and environmental resource protection), and site redevelopment prospects (relating to socioeconomic and planning variables that influence the demand of the site and its potential profitability, once contamination and the potential for legal liability are removed).

These multiple issues bring into play a wide variety of groups with an interest in Brownfields redevelopment. Stakeholders include existing and potential property owners, developers and commercial investors, bankers, environmental and engineering consultants, insurance providers, environmental organizations, community development organizations, regulators at the local, state and federal levels, and attorneys. While these parties unite in their common desire to see the restoration of Brownfields to more productive uses, they each come with their specific objectives, sometimes divergent.

Finally, the decision-making phase for Brownfields remediation and redevelopment is itself typically fraught with uncertainty. Environmental and redevelopment information on abandoned sites is often unavailable. In cases where such information is found, it is likely to be highly deficient for the purposes of thoroughly evaluating viable remediation and redevelopment alternatives for selected sites, and ranking these sites for redevelopment in a way that optimizes usually limited resources.

To be successful therefore, Brownfields redevelopment programs will require 
creativity in addressing the existing environmental and socioeconomic constraints, amidst the complex framework of pertinent issues, and multiple stakeholders with sometimes divergent objectives. Consequently, the major challenge centers on creating sound and yet simple Brownfields redevelopment programs that make use of feasible technical, legislative and financial tools to extend limited resources for returning contaminated sites to more productive uses. Such programs could benefit from a formally structured and defensible decision analytic framework incorporating the pertinent objectives, variables and prevailing values and uncertainties in Brownfields redevelopment.

\subsection{Thesis Objectives}

This thesis demonstrates the use of Bayesian Influence Diagrams, a formal decision analytic tool, in developing comprehensive and logical frameworks for evaluating and ranking Brownfields sites for redevelopment. The objectives are as follows:

1. To develop a formal and structured Brownfields decision model that incorporates the multiple fundamental issues, stakeholder objectives and prevailing values and uncertainties in Brownfields redevelopment decision-making;

2. To demonstrate the usefulness of this decision model and associated tools for determining which variables are significant for Brownfields decision-making, and clarifying the relationships between these variables;

3. To demonstrate the functionality of this model in defining the relationships between competing objectives in Brownfields decision-making; and, 
4. To demonstrate the effectiveness of this model as a structured, defensible and easily reproducible methodology for using actual site data to compare the redevelopment potential of different sites, (from the point of view of predetermined redevelopment objectives), to enable the ranking of these sites in a manner that makes the best use of available resources for site redevelopment.

The primary significance of this study is that it adds a structured and consistent formal decision framework to existing Brownfields redevelopment tools. Such a framework will support risk-based assessments for prioritization of both remediation and redevelopment activities to facilitate the optimal use of limited resources.

\subsection{Research Approach}

This research begins with a thorough review of the existing literature on Brownfields redevelopment for the purpose of characterizing the current state of affairs and trends in Brownfields redevelopment, at the federal, state and local levels, and demonstrating the practical benefits of a formal decision analytic tool for the existing processes. The next stage involves the development of a number of qualitative Influence Diagram models that depict the generic relationships between the basic objectives and associated variables in Brownfields decision-making. This section will also serve as a basis for developing quantitative models to assess the redevelopment potential and risks associated with developing different Brownfields. The third stage will involve the development of a number of case studies for selected Brownfields sites in the state of Florida to characterize issues of local interest in 
redeveloping the sites. Finally, the last stage will demonstrate the use of actual site data in Influence Diagram models to optimally rank these selected sites for redevelopment, (from the point of view of predetermined objectives obtained in the previous step). This stage will involve performing Sensitivity Analyses on preliminary model variables, determined from the case study, to identify which variables are indispensable for optimally ranking the. This stage will also demonstrate the solution of Influence Diagrams to yield expected value and riskrelated information, and the analysis of this information to generate meaningful information for sounder decisions for ranking the Brownfields sites for redevelopment.

\subsection{Thesis Organization}

Following this introduction, the second Chapter of this study provides a literature review on Brownfields redevelopment in the United States. Chapter 3 introduces formal methods in Decision Analysis and demonstrates how Bayesian Influence Diagrams may be used to develop standardized decision models that depict relationships between Brownfields decision objectives and associated variables. Chapter 4 then develops a case study for a number of Brownfields sites in a selected City in Metropolitan Dade County, Florida. Case studies are developed both for the City and its sites, for the purpose of identifying the important decision objectives (and associated variables) to be used in prioritizing the City's Brownfields sites for redevelopment. In Chapter 5, relationships between these objectives and variables are defined and modeled using Influence Diagrams. Sensitivity Analyses are then performed to determine which of these variables are actually critical in determining the optimal ranking of sites for 
redevelopment, (from the point of view of the predefined decision objectives). The preliminary Influence Diagram model is then refined to reflect the significant variables identified in the previous step. Using actual site data, the Influence Diagram model is then solved for each site, and the results are analyzed to determine the optimal ranking for the selected Brownfields. Finally, Chapter 6 provides a summary with concluding remarks. 
Chapter 2

LITERATURE REVIEW 


\subsection{Introduction}

The objectives of this literature review are as follows:

- To provide an overview of the current state of affairs and trends in Brownfields redevelopment in the United States, with special emphasis on state and local level initiatives;

- To demonstrate that Brownfields remediation and redevelopment is a complex and dynamic process with many interrelated variables;

- To illustrate that state level Brownfields initiatives provide broad incentives relating to legal liability assurances, financial and technical assistance incentives;

- To illustrate that, in several cases, local level initiatives form the actual mechanisms for site cleanup and reuse, and that while different localities may have unique needs in redeveloping their Brownfields, they nonetheless make use similar tools in achieving their different agendas; and finally,

- To provide an inventory of existing tools, techniques and methodologies being used in local level Brownfields redevelopment initiatives, and point out ways in which these efforts could be enhanced by a formal decision analytic framework.

It is worth mentioning that since Brownfields redevelopment is a rapidly growing domain, information may change significantly or become obsolete within short periods of time. Therefore, rather than attempt to provide any exhaustive summary of the ongoing issues and activities related to Brownfields redevelopment, this Chapter will seek to provide a strong 
sense of general trends in Brownfields redevelopment. The Chapter must therefore not be looked upon as an untimely document concurrent with the Brownfields redevelopment process. Rather, it is more likely to serve as a useful document with respect to highlighting historic and present trends in the scopes of state and local level initiatives, and providing useful examples of multi-level strategies and tools being used to accomplish Brownfields redevelopment nationwide.

\subsection{Major Issues in the Brownfields Redevelopment Process}

The are five major issues in Brownfields remediation and redevelopment as discussed below:

\subsubsection{Technical Issues}

Technical issues in Brownfields redevelopment revolve around accurately assessing the type and extent (or absence) of contamination at a site, and deciding on which cleanup standards and procedures must be followed. Typically, developers are concerned about soil and groundwater contamination, water conservation and air quality [Emerson, 1996]. These issues are closely related to issues of legal liability. Uncertainty about the exact nature of a site's contamination, and the process through which it may be addressed, is associated with unknown and potentially high costs for remediation. This creates disincentives for parties who are potentially interested in Brownfields redevelopment. In addition, the inability of prospective developers to predict future liability that may result from involvement at Brownfield sites is an 
obstacle to redevelopment.

\subsubsection{Liability Issues}

Issues of legal liability are a major controlling factor in Brownfields redevelopment because they largely determine whether or not contaminated sites will be returned to productive use(s). The legal liability framework will promote (or retard) Brownfields redevelopment as it is simple and straightforward (rather than complex), and able to provide clearly defined types and levels of liability for potential site developers. Where there are few assurances at the federal or state level to protect private parties from future liability, the redevelopment of contaminated sites is simply not a viable option.

\subsubsection{Financial Issues}

Financial issues are particularly complicated at Brownfields sites primarily due to the following three interrelated factors:

(1) Potential risk of legal liability,

(2) Uncertainty regarding the ultimate costs of assessment and remediation, and

(3) Depressed or declining neighborhoods surrounding Brownfields sites.

The initial investment in site assessments may be prohibitive and, in some cases, may only be justified by the economic gains anticipated from future site redevelopment. However, in depressed areas where several Brownfields exist, there is little economic 
incentive for the redevelopment of contaminated sites. In addition to this, the remediation costs associated with environmental contamination can be quite high, ranging from thousands of dollars to millions of dollars for particularly hazardous sites. Coupled with the high clean up costs and economically depressed surroundings of Brownfields, the uncertainties surrounding existing and future liability for site contamination undo the few remaining incentives for investing in Brownfields redevelopment. This combination of factors frequently results in limited fiscal resources for Brownfields redevelopment.

\subsubsection{Community Concerns}

Brownfields sites hardly exist in isolation. They are often located in the heart of depressed or declining urban communities and may be in close proximity to retail districts and residential areas. Community concerns are fueled by the desire to protect human and environmental health. Existing contaminated properties may pose direct threats to human and environmental health where they are located. For this reason, community groups are usually interested in promoting the clean up and redevelopment of such sites in their neighborhoods. However, almost without exception, they demand some assurances that the remediation procedure(s) used will protect human health and that of the environment. In several communities as well, certain individuals and private parties may seek an active role in deciding on the future use(s) of specific

sites. For these and other reasons, community members have varying degrees of 
involvement with their neighborhood's Brownfields.

\subsubsection{Redevelopment Prospects}

Redevelopment prospects are the issues that determine the marketability of Brownfields once site contamination has been removed and the type and extent of legal liability have been clarified. Redevelopment prospects are crucial because they determine whether there will be demand for the property if the problem of contamination and the potential for liability are removed. These prospects make it clear that concerns about site contamination are only one aspect of the Brownfields remediation and redevelopment process, namely the remedial aspect. The other major aspect of Brownfields redevelopment revolves around the important socioeconomic variables that determine the site's marketability once remediation is complete. Brownfields sites, many of which are located in distressed communities, pose problems for redevelopment. In many cases their supporting civil infrastructure is old and obsolete, property access may be limited, and other socio-economic variables such as crime, high taxes, traffic congestion, low-quality amenities and racial tensions may be strong obstacles to the redevelopment of these sites. With these existing impediments for Brownfields redevelopment, the development of Greenfields becomes increasingly attractive, contributing to urban sprawl with its associated destruction of farmlands and increase in travel demands. 


\subsection{Brownfields Redevelopment - The Actual Process}

While different Brownfields redevelopment programs may be tailored to suit specific needs and objectives of different localities, most Brownfields programs seem to follow a generic process involving the following four basic steps:

(1) Site Identification,

(2) Site Assessment,

(3) Site Remediation, and

(4) Site Redevelopment.

\subsubsection{Site Identification}

A number of sites that have been designated as Brownfields possess the stigma of being contaminated rather than any actual site contamination. While the USEPA has estimated about 450,000 Brownfields sites nationwide [Angelo, 1995], many of these sites may not be contaminated at all but are merely perceived to be so [Maldonado, 1996]. Thus, the first step in any Brownfields redevelopment initiative is to identify contaminated Brownfields and develop an inventory of these sites. This stage usually involves a Phase I site assessment in which environmental consultants are engaged to provide an analysis of government and other historical records, perform site reconnaissance studies, interview owners, occupants and others associated with the site, in order to determine if there is evidence of contamination.

The legal liability framework for contaminated sites strongly influences 
whether or not site identification will be pursued by parties interested in Brownfields redevelopment. Uncertainty over the extent and types of legal liabilities attached to contaminated sites acts as a barrier to site remediation and redevelopment. Legal liabilities must be clearly defined and certified by relevant authorities to provide incentives for site redevelopment. Along the same lines, redevelopment prospects also strongly influence the redevelopment potential of existing sites. Redevelopment prospects may contribute incentives or disincentives to site remediation. Site identification for redevelopment is unlikely to occur in depressed areas with no promises of economic revitalization, and no other public incentives for site redevelopment.

\subsubsection{Site Assessment}

If the Phase I assessment reveals evidence of contamination, a Phase II level assessment may then be conducted. This includes actual sampling of the soil and groundwater, and results in a determination of the actual type and extent of site contamination. This phase also involves the determination of appropriate clean up standards, the identification of feasible site remediation technologies for cleaning up the contamination, and an estimation of site remediation costs. Determination of a feasible plan and level of cleanup is based on a host of criteria including toxicity, exposure pathways and associated risk, surrounding land uses, economic considerations and future land use(s). The decision to proceed with site assessment 
will involve some levels of legal liability and financial assurances, as well as favorable socio-economic factors. In cases where a number of sites are to be redeveloped, an attempt may be made to prioritize the redevelopment of sites in an order that makes the best use of usually limited resources.

\subsubsection{Site Remediation}

Site remediation involves the actual remediation of the site to clean up levels established in the previous phase. This phase brings into play all the basic five issues relevant to Brownfields redevelopment. Specifically, feasible technical methods and tools, legal liability assurances, financial incentives, community concerns and promising redevelopment prospects will strongly factor in the decision to remediate the site. The targeted cleanup levels will be largely determined by the acceptable laws for site cleanup in a particular locality, as well as the anticipated future land use(s) of the site.

\subsubsection{Site Redevelopment}

With site cleanup accomplished, the site then undergoes redevelopment for some viable socioeconomic use that is compatible with the local land use and transportation plan.

As depicted in Figure 2.1, these four stages in the Brownfields redevelopment process 


\section{Remediation/Redevelopment Process}

Site Identification

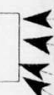

Site Assessment

Site Remediation $\underline{\mathfrak{s}}$

Site Redevelopment

\section{Major Issues}

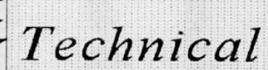

$>$

$$
\text { Liability }
$$

Financial

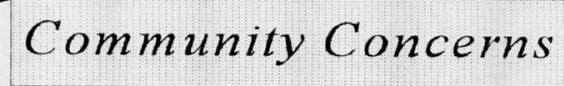

Redevelopment Prospects

Figure 2.1: Significant Relationships in the Brownfields Redevelopment Process 
dynamically interact with each other and address the five fundamental Brownfields issues discussed in section 2.2.

\subsection{State and Local Level Brownfields Initiatives}

Whereas state (and federal) Brownfields programs tend to be focused on providing a universally conducive (or occasionally enforcement-driven) environment for remediation and redevelopment, public and private entities at the local level tend to constitute the actual mechanisms for the cleanup and redevelopment of Brownfields. State level programs are characteristically strong in their provision of liability assurances, funding and technical assistance incentives for remediation and redevelopment; local level programs, on the other hand, tend to be more focused on the redevelopment and community-related issues surrounding Brownfields redevelopment. Programs on both levels may make use of strategies for prioritizing the cleanup of sites with higher redevelopment potential.

\subsubsection{State Level Programs}

There are several ongoing state efforts to clarify cleanup standards and processes, define and clarify the levels of legal liability involved in Brownfields cleanup, and offer financial incentives to promote their cleanup and redevelopment. These initiatives may also make available some level of technical assistance through government oversight. Because NPL (National Priority List) sites (under federal action) are far outnumbered by non-NPL sites (under state action), much of the "Brownfields" 
activities have historically taken place at the state level. From the initiation of Superfund and related environmental laws, states have addressed non-NPL sites in their jurisdiction through any number and combination of the following three most common approaches: (1) State Superfund Programs, (2) Property Transfer Laws, and (3) State Voluntary Programs [State of the States, 1995].

\subsubsection{State Superfund Programs [State of the States, 1995]}

Some states still address Brownfields sites through state Superfund programs. Such Superfund programs are an offshoot of the federal Superfund program, and are operated through enforcement-driven activities. In many cases they were created to address sites not considered hazardous enough to be placed on the NPL. Approximately 45 states operate their own Superfund programs in the United States.

While few generalizations may be made about state Superfund procedures, many operate like the federal Superfund program in which the site identification and cleanup process is driven by enforcement activities. Cleanup standards are largely determined by USEPA guidelines. As of 1993, 34 of these states reported the use of USEPA guidelines for deciding on cleanup standards, and 42 states employed risk assessment techniques to set standards and determine goals, (with many relying on EPA risk assessment guidance for direction). Many of these programs also attempt to prioritize 
sites for remediation; sites which pose higher risks for human health and the environment tend to receive high priority. In today's emerging Brownfields scenario however, site prioritization may be more related to the redevelopment potential of existing sites, since Brownfields are generally low priority sites from an environmental point of view: i.e., Brownfields tend to lie somewhere between highly contaminated Superfund sites and pristine Greenfields.

With respect to legal liability, most states consider a wide range of stakeholders as responsible parties at non-NPL sites. As of 1993, 32 states applied strict, and joint and several liability to responsible parties, four allowed proportional liability and 14 had no established standards for determining liability.

On the subject of funding site cleanups, these Superfund programs authorize the state to bring enforcement actions against responsible parties associated with hazardous wastes; the funds raised through enforcement actions go toward site cleanup and to supplement other program activities. In addition, the states have access to state and federal funds designated by law to support cleanup activities.

With regard to community concerns, about fifty percent of these programs have provisions for some level of public participation in the process. This normally takes the form of public meetings with the opportunity for 
review and comment on remediation proposals.

It is worth noting that these Superfund programs do not have a predetermined agenda with respect to site redevelopment, after site identification and remediation have been accomplished. Moreover, the prioritization of sites for remediation is solely based on the health and environmental risks posed by the contaminated sites, which is one major difference between Superfund programs and innovative Voluntary Cleanup Programs, as is seen later.

\subsubsection{Property Transfer Laws [State of the States, 1995]}

Property transfer provisions exist in states as laws, regulations or policies that make the transfer, ownership or control of real property contingent on one or more of the following: discovery, identification, investigation, cleanup, or disclosure of the existence of hazardous waste contamination. Property Transfer Laws are an indirect method for identifying and initiating site cleanup activities. While some states simply require full disclosure of the environmental condition of a site, others require a more advanced level of site investigations, and a few states require complete cleanup before a transfer can occur. New Jersey established the first property transfer law in the country in 1983. Known as the Environmental Cleanup Responsibility Act (ECRA), the law required that certain industries intending to close, sell, or transfer 
operations must investigate and clean up hazardous waste contamination before a transaction could occur [New State, 1993]. Other states with comprehensive property transfer laws include Connecticut and Illinois. Property transfer laws are significant because they do not only deal with existing Brownfields, but also attempt to prevent the development of future Brownfields. As of 1994, 18 states had some form of property transfer requirements [Geltman, 1994].

\subsubsection{Voluntary Cleanup Programs [State of the States, 1995]}

In today's evolutionary Brownfields climate, State Voluntary Cleanup Programs (VCPs) are increasingly the preferred alternative, and the fastest growing programs for Brownfields remediation and redevelopment. More and more, they are viewed as a preferred alternative to enforcement-driven Superfund programs which are often characterized as confrontational and demanding of time and other valuable resources. VCPs are innovative. They differ from other programs because they involve site owners or developers voluntarily approaching the state to cooperatively work out a process for site remediation and redevelopment. VCPs are in direct contrast to enforcementdriven programs in that they involve cooperative agreements between private and public parties and are more likely to consider future uses in deciding on remediation plans. According to Maldonado [1996], 30 state voluntary 
cleanup programs had been implemented in the country as of May 1996, five to which the USEPA deferred. Commonly, non-NPL sites with no or low to medium contamination problems enter into VCPs. VCPs usually operate on a fee-for-service basis with the voluntary party responsible for all costs associated with the cleanup.

State VCPs are favorable because they avoid some of the significant costs and delays associated with enforcement-driven programs. Commonly, they work to overcome many of the obstacles to site cleanup and redevelopment. They usually offer some combination of technical assistance, financial support and liability assurances to private parties. In addition, they may offer the much needed information management services for valuable information sharing, opportunities for public/private partnerships and active community involvement in the Brownfields redevelopment process. While many VCPs employ the same cleanup standards that are used under the state Superfund program, others have developed their own specific remediation standards. VCPs provide indirect financial incentives; there is evidence that financial institutions may be more inclined to lend on properties that have gone though voluntary programs than on independently cleaned up sites. From the perspective of governments, states are also interested in promoting VCPs because they typically require fewer government resources, and assure that site cleanups can continue with some level of official oversight despite 
dwindling funds for enforcement-driven programs.

\subsection{Legal Liability Assurances through VCPs}

VCP legal liability assurances reduce the uncertainty related to legal liability by specifying the parties who would not be held liable at a site, or by defining government interest in the condition of a site. Examples of liability protection offered by some states are letters of "no association" to the contamination (either as innocent or involuntary owner, prospective purchaser or neighbor to the site); absorption of private liability by the state or a municipality; liability exemption for some public entities such as city or county governments and port authorities; covenants not to sue for any actions related to the site; certificates of completion or partial completion for a cleanup; and letters of "no further action" or "no further interest" in a site. These assurances reduce the likelihood that any enforcement action will be pursued at a future date.

\subsection{Funding Support through VCPs}

While many state VCPs are operated on a fee-for-service basis, a number of them still offer financial incentives for participation. Funding assistance for initial site assessment, cleanup or 
redevelopment is typically disbursed as public grants, loans or loan guarantees and tax incentives. It is common to offer public financial assistance for Brownfields cleanup activities based on fairly stringent criteria including demonstrated need, the relationship of the volunteer to site contamination, (some states will not assist responsible parties), and demonstrated potential of the site for economic development. Table 2.1 provides a cross-section of Brownfields Funding alternatives.

\subsection{Technical Support through VCPs}

Technical support is usually made available through public technical oversight for site activities from the initial site assessment through remediation. Technical oversight is a means of ensuring that predetermined remediation standards are being met. This results in more clearly defined liabilities and/or liability assurances for the site owner after cleanup has been completed. 
Table 2.1: Cross-Section of Funding Sources for Brownfields Redevelopment

\begin{tabular}{|c|c|}
\hline Source & Description \\
\hline Revolving Funds & $\begin{array}{l}\text { Source of money providing loans to specified parties. The parties } \\
\text { reimburse the fund for the loan amount plus interest, so that the fund is } \\
\text { able to maintain the same or increased levels of funding. Revolving funds } \\
\text { are typically developed through revenue disbursement from a trust fund. }\end{array}$ \\
\hline Trust Funds & $\begin{array}{l}\text { Trust funds are special accounts developed to receive and disburse } \\
\text { revenues from taxes and/or fees for dedicated purposes. These differ from } \\
\text { revolving funds in that they do not maintain the funding capacity through } \\
\text { payback of loans, but through new injections of revenue though taxes } \\
\text { and/or fees. }\end{array}$ \\
\hline $\begin{array}{l}\text { Real Estate } \\
\text { Investment Trust }\end{array}$ & $\begin{array}{l}\text { Real Estate Investment Trusts (REITs) are funds comprised of revenues } \\
\text { from private investors. REITs act as primary investors when purchasing } \\
\text { property. Applied to Brownfields, the REIT acts as the owner, thereby } \\
\text { shielding investors from liability in excess of the investors' initial } \\
\text { monetary input. }\end{array}$ \\
\hline $\begin{array}{l}\text { Tax Increment } \\
\text { Financing }\end{array}$ & $\begin{array}{l}\text { Tax increment financing is created through a local government's } \\
\text { assessment of property values. Special assessments are made on } \\
\text { properties that are expected to accrue particular benefits from a general } \\
\text { improvement, or from an environmental activity, such as a clean up. The } \\
\text { incremental difference in tax revenues between the original assessment } \\
\text { rate and the new, higher assessed rate is then used to finance the } \\
\text { improvement activity. }\end{array}$ \\
\hline Tax Incentives & $\begin{array}{l}\text { Tax incentives include a wide variety of mechanisms used to encourage } \\
\text { redevelopment of Brownfields through the use of public taxation tools. } \\
\text { These often take the form of tax credits or tax deferrals. By deferring } \\
\text { taxes to be paid on property, income or sales, governments can provide } \\
\text { businesses with the needed incentives to create redevelopment } \\
\text { opportunities for Brownfields. }\end{array}$ \\
\hline State Grants & $\begin{array}{l}\text { State grants can provide communities with funding needed for cleanup or } \\
\text { redevelopment incentive packages within Brownfields programs. Grants } \\
\text { may also be made from state trust funds for the establishment of local } \\
\text { revolving funds. }\end{array}$ \\
\hline
\end{tabular}

Source: NE-MW Economic Review [1995] 


\subsubsection{Examples of State Voluntary Cleanup Programs}

While several states have ongoing voluntary Brownfields programs [Maldonado, 1996; State of the States, 1995], the following three examples are selected to illustrate how state programs may successfully provide broad liability assurances, financial incentives and technical assistance to ease the burden of redeveloping Brownfields. Together these programs demonstrate ways to manage the basic issues in Brownfields redevelopment. It is noteworthy that while these programs may not make direct efforts to link site remediation with redevelopment, the incentives they provide may mitigate some of the largest obstacles to Brownfields redevelopment, and serve as a clear incentive for local entities and individuals to undertake site cleanup for redevelopment.

2.4.1.4.1 Minnesota [Maldonado, 1996; State of the States, 1995] Begun in 1988, Minnesota's Voluntary Investigation and Cleanup (VIC) program is one of the oldest and most respected in the country. The program is administered by the Minnesota Pollution Control Agency (MPCA), on a fee for service basis, and manages about 700 sites. Minnesota's program provides strong liability assurances, financial and technical incentives, as well as higher level public-private partnerships for Brownfields cleanup. Both the state's Department of 
Trade and Economic Development and the Metropolitan Council offer grants to cities or counties participating in the VIC program. The program is also provides an exemplary example of public-private collaboration for Brownfields redevelopment. Fifty percent of a $\$ 100,000$ grant by the Ford Foundation and Harvard's Kennedy School of Government has been used in establishing a grant for nonprofit organizations. As recipient organizations obtain grants, the money is then matched by local corporations, and a team of attorneys and environmental consultants are engaged to work for the public good. As of June 1995, about 450 companies and local agencies in the Twin Cities area had invested tens of millions of dollars under the VIC program to clean up about 3,000 contaminated acres [Josi, 1995]. The program also offers 10 different types of liability protection from Superfund Laws, through a unique incremental liability protection system, in which liability protection is offered approximately commensurate with the amount of information disclosed by property owners. Finally, MPCA staff offer a high level of technical assistance and oversight for the entire cleanup process. Specifically, they are involved in the approval of cleanup plans, and the certification of completion in the final stage of remediation. The program has proven very successful. As of May 1995, over 100 sites 
had been cleaned up through the program, and over 300 had obtained closure through a written assurance. The USEPA defers to Minnesota's VIC program.

2.4.1.4.2 Ohio [State of the States, 1995; RMT Regulatory Updates, 1996]

Contrary to Minnesota's VIC, Ohio`s Voluntary Action Program (VAP) is one of the newer ones in the country, and still rapidly evolving. Like several others it was established through legislative reform. Ohio's VAP came into being when the state passed the "Real Estate Reuse and Cleanup Law" in June 1994. Collateral with the recent trend in the Brownfields debate. this law makes an effort to link the reuse potential of sites to their priority for cleanup. Administered by the Ohio EPA, the program is valid only for sites that are not on the federal National Priority List (NPL) or regulated by other federal and state environmental laws. It is designed to encourage people to redevelop and reuse land contaminated by hazardous materials or petroleum. Like Minnesota's VIC. Ohio's VAP offers not only liability assurances, but also technical assistance and avenues for public/private partnership. Indeed, there are plans to privatize the entire cleanup process. The amount of cleanup required for a 
particular piece of property depends on the future end use of the property. Ohio's VAP provides protection from liability for any volunteer who complies with the applicable program standards. The program also provides lender and fiduciary liability protection for cleanup contractors and local governments. In addition, the program offers financial assistance to program participants through state lowinterest loans and tax incentives that allow volunteers to forgo paying taxes for 10 years on any increases in property values resulting from remediation. Participants may also request an additional tax abatement for 10 years on real and personal property taxes from their local government. Ohio's program is known for expediting the permit process for sites undergoing voluntary cleanup. As of June 1995, one cleanup had been conducted through the program.

\subsection{Michigan [RMT Regulatory Updates, 1996]}

Although Michigan's program is also in its infant stages, it is a good example of a state level program that provides more direct links between remediation and redevelopment, a more recent trend in the Brownfields process. Michigan's Brownfields Program came into being with the passage of the Natural Resources Environmental Protection Act, in June 1995. The Act is intended to promote the 
redevelopment and reuse of vacant manufacturing facilities and abandoned industrial sites that have economic development potential, provided that redevelopment or reuse assures the protection of public health and safety, and the welfare of the environment. This program may be different from several others because it relaxes not only liability standards, but also provides for relaxed cleanup standards commensurate with the intended use of the site after cleanup. Cleanup standards for different land use categories depend on algorithms incorporating exposure scenarios that would be in effect during site use. These algorithms assume that exposure to on-site contamination is greatest under residential uses, less under industrial uses and least under various types of specified commercial uses. Legal liability has been relaxed for owners of contaminated sites, and new owners are protected from liability from any pre-existing contamination once they conduct a Baseline Environmental Assessment (BEA). A BEA determines the nature of existing contamination and ensures that new owners are held responsible only for exacerbating any existing contamination or causing new contamination. The program also includes the preparation and submittal of a Proposed Use Plan (PUP) so that the scope of the BEA is closely tied to the nature of the new business planned on the site. 


\subsubsection{Concluding Remarks on State Voluntary Cleanup Programs}

The above examples illustrate the fact that state level programs, like federal programs, are support-oriented and set the stage for local level Brownfields activities. They are able to offer broader liability assurances, financial incentives for cleanup and redevelopment. and technical assistance for remediation. State Voluntary Cleanup Programs are usually initiated through reformative laws that clear up the uncertainties related to legal liability, and remove one of the largest obstacles for parties interested in redeveloping Brownfields. In doing so, these programs provide a more favorable environment for local level activities that culminate in the reclamation of Brownfields for more productive and healthful uses. State level programs may also provide the information management services needed for successful management of existing Brownfields in the state. This involves the identification and inventory of existing Brownfields sites, and the maintenance updated information on these sites as redevelopment proceeds. In addition, state level programs may provide risk management and prioritization related to site redevelopment potential, with the objective of stretching limited resources to ensure the continuance of Brownfields redevelopment activities. Clearly, the USEPA still retains a supervisory role over state Brownfields programs to ensure that ultimately, USEPA standards are met during site cleanups. It does this by deferring to programs that are found adequate under 
USEPA standards for the remediation of contaminated sites. States which achieve this level of independence in their Brownfields activities may effectively speed up their Brownfields cleanup process and attract more interested parties for Brownfields redevelopment. Table 2.2 provides a feature summary of selected state level Brownfields initiatives showing the different types of liability assurances, financial and technical incentives made available through these programs. 


\section{Table 2.2: Overview of State Initiatives for Brownfields Remediation and Redevelopment}

\begin{tabular}{|c|c|c|c|}
\hline $\begin{array}{c}\text { State } \\
\text { Initiatives/Programs }\end{array}$ & Liability Incentives & Financial Incentives & Technical Incentives \\
\hline Minnesota VIC & $\begin{array}{l}\text { No Action Letters } \\
\text { Limited No Action Letters } \\
\text { Land Recycling Certificates of Completion } \\
\text { Offsite Source Determination letters } \\
\text { No Association Determinations }\end{array}$ & $\begin{array}{l}\text { Contamination Cleanup Grants } \\
\text { Tax Incentives }\end{array}$ & $\begin{array}{l}\text { Technical Assistance and Oversight for } \\
\text { remediation process }\end{array}$ \\
\hline Ohio VAP & $\begin{array}{l}\text { Covenant not to sue under state law } \\
\text { Lender and fiduciary liability protection } \\
\text { Liability protection for cleanup contractors and } \\
\text { local governments }\end{array}$ & $\begin{array}{l}\text { Low interest loans to help finance site } \\
\text { cleanup costs } \\
\text { Tax incentives }\end{array}$ & $\begin{array}{l}\text { Certification program for environmental } \\
\text { consultants qualified to conduct site } \\
\text { investigations }\end{array}$ \\
\hline $\begin{array}{l}\text { Michigan Brownfields } \\
\text { Initiatives }\end{array}$ & $\begin{array}{l}\text { Recent legislation that requires proof of cause } \\
\text { for contamination in order to find parties liable } \\
\text { Establishment of land-use-based standards for } \\
\text { cleanup in } 8 \text { categories including commercial } \\
\text { and industrial. }\end{array}$ & $\begin{array}{l}\text { Public grants to cities for initial site } \\
\text { assessment and reclamation } \\
\text { Financial assistance for areawide site } \\
\text { investigation }\end{array}$ & N/A \\
\hline New Jersey VCP & N/A & $\begin{array}{l}\text { Low interest loans to help finance site } \\
\text { cleanup costs }\end{array}$ & N/A \\
\hline California VCP & $\begin{array}{l}\text { Certificate of Completion } \\
\text { No Further Action Letter }\end{array}$ & N/A & $\begin{array}{l}\text { Technical Assistance at any stage from } \\
\text { initial site investigation to full site cleanup }\end{array}$ \\
\hline $\begin{array}{l}\text { Wisconsin Brownfields } \\
\text { Initiatives }\end{array}$ & $\begin{array}{l}\text { Wisconsin Spill Law for limited purchaser } \\
\text { liability } \\
\text { Limited lender liability } \\
\text { Cleanup exemption for sites acquired through } \\
\text { tax delinquency } \\
\text { Protection transferable to successive owners }\end{array}$ & $\begin{array}{l}\text { Clean Up Cost Cap } \\
\text { Limited lender liability }\end{array}$ & N/A \\
\hline
\end{tabular}

Sources: Miscellaneous, 1994, 1995, 1996 


\subsubsection{Local Level Brownfields Initiatives}

Supported by federal and state incentives and programs. lical Brownfields efforts are not only evolved to trigger and support Brownfields cleanup and reuse; they usually serve as the actual mechanisms for accomplishing the cleanup and reuse of individual Brownfields sites. Administered by municipalities (cities and counties). these programs are developed to address the unique needs of different localities. As such, their scopes tend to be varied and their foci revolve specifically around prevailing local needs. However, these programs tend to be similar in the tools and strategies they employ in accomplishing their goals. Specifically, they tend to involve the formulation of Brownfields remediation and redevelopment methodologies, the use of some form of risk-management and site redevelopment potential assessments to identify and rank high priority sites for cleanup and redevelopment, the formation of effective public/private partnerships to accomplish the cleanups, and the transfer of this knowledge to potential stakeholders and the general public for use in developing other Brownfields sites. Below, the goals and objectives of six selected local programs are given to illustrate the above mentioned similarities and differences. All of these programs have been initiated through the provision of federal grants by the Brownfields Action Initiative. 


\subsubsection{Examples of Local Brownfields Pilots}

[Brownfields Regional Pilots, 1996; Brownfields National Pilots, 1996]:

\subsection{Bridgeport, Connecticut:}

Bridgeport's goal is to identify and tackle existing contamination and the environmental obstacles prohibiting redevelopment in the City. Although this City plans to focus on environmental obstacles, it is clear that Brownfields redevelopment obstacles mily be as much socio-economic as environmental. Funding for Bridgeport s pilot program will be used to accomplish the following objectives:

- $\quad$ Categorize and prioritize site cleanups;

- Develop timeline estimates for cleanup duration and methods, with associated costs;

- Select two to six model sites based on incentives relating to effective property assessment, cleanup and redevelopment for each model site; and,

- Coordinate with the Housatonic Community and Technical College to offer environmental icience courses to students to prepare them to assist in future redevelopment efforts. 


\subsection{Emeryville. California:}

The City of Emeryville's main goal is to encourage Brownfields redevelopment by building stakeholder confidence in emerging state regulatory policy by using an area-wide. risk-management based approach for environmental cleanup. Planned pilot activities include the following: - Compiling existing site information, conducting additional assessments and creating a geographic information system model;

- Developing a Mitigation/Risk Management Plan; and,

- Convening a broad-based Community Task Force to serve as a forum for community participation in decision making.

\subsection{Houston. Texas:}

Houston's overall goals are to establish a permanent organizational infrastructure for future Brownfields redevelopment, revitalize inner-city properties and increase jobs. Planned pilot objectives include:

- Identifying candidate sites within the city's Federal Urban Enhanced Enterprise Community:

- Developing a Land Redevelopment Committee that involves stakeholders in decision making; and,

- Developing a model for the redevelopment process encompassing financial incentives, community outreach, targeted job 
opportunities, and the new Texas Voluntary Cleanup Program.

\subsection{Knoxville, Tennessee:}

Knoxville's goal is to identify potentially responsible parties for contamination, and to develop a cleanup implementation plan that ensures activities which do not aggravate existing environmental threats. Two major planned activities are as follows:

- A feasibility evaluation on the relevelopment of the Center City Business Park which encompalsics many acres of abandoned or underutilized commercial and industrial property;

- Investigating sites that are thought to be contaminated and determining the most cost-effective method for remediation.

\subsection{Lawrence, Massachusetts:}

Lawrence's overall goal is to provide long-term stability and a safe environment for its downtown industrial, commercial and residential centers by employing the existing public/private partnerships created to redevelop three significant contaminuled sites in the City. The City's plans include:

- Creating an inventory of Brownfields within the City's Canal Industrial Corridor; 
- Expanding the existing advisory committees to encourage meaningful involvement of stakcholders; and,

- Creating a one stop guidance manual for Brownfields redevelopment.

\subsection{New Orleans, Louisiana}

New Orleans will use pilot funding to develop a Brownfields Management and Monitoring System that encourages redevelopment efforts. Planned activities will do the following:

- Identify the city's Brownfields:

- Maintain an inventory of sites on a government information system for data analysis;

- Develop criteria for ranking the redevelopment potential of sites; and,

- Sponsor meetings with redevelopment stakeholders to explore remediation funding mechanisms.

While these programs illustrate that Brownfields programs have unique objectives at the local level, it is clear that most of these programs rely on some form of Information Management tools, Risk Management strategies, Prioritization techniques. Community Outreach, and 
Public/Private Partnerships, to accomplish their ultimate goal of cleaning up and redeveloping their existing Brownfields. Table 2.3 provides a feature summary of local programs hinwing their use of the above mentioned strategies and tools for Brounfields redevelopment. 
Table 2.3: Common Local Level Brownfields Techniques and Tools

\begin{tabular}{|c|c|c|c|c|}
\hline $\begin{array}{r}\text { Activity } \\
\text { Municipality }\end{array}$ & Goal & Information Management & Risk Management / Prioritization Methods & $\begin{array}{c}\text { Public / Private Partnerships \& Outreach } \\
\text { Programs }\end{array}$ \\
\hline Duwamish, WA & $\begin{array}{l}\text { Developing comprehensive guidelines } \\
\text { for contaminated sites. }\end{array}$ & $\begin{array}{l}\text { Development of a new Washington } \\
\text { Department of Ecology guidance } \\
\text { document for contaminated sites }\end{array}$ & $\begin{array}{l}\text { Development of a Decision Tree Methodology } \\
\text { as a model for risk evaluation and remedy } \\
\text { selection. } \\
\text { Adaptation of national efforts regarding the } \\
\text { risk-based corrective guidance action. }\end{array}$ & $\begin{array}{l}\text { Backed by a group of commercial, } \\
\text { environmental and community representatives } \\
\text { known as the Duwamish Committee. }\end{array}$ \\
\hline Phoenix ville, PA & $\begin{array}{l}\text { Cleanup of abandoned Phoenix Iron } \\
\text { and Steel Company Site }\end{array}$ & Produce a video journal of the project & Determining feasibility of redevelopment & $\begin{array}{l}\text { Building a land community consensus on site } \\
\text { reuse }\end{array}$ \\
\hline Portland, OR & $\begin{array}{l}\text { Encourage Cleanup and } \\
\text { Redevelopment of specific sites within } \\
\text { Enterprise Community \& along } \\
\text { Williamette River }\end{array}$ & $\begin{array}{l}\text { Developing an Internet-accessible } \\
\text { online computer information system to } \\
\text { provide data on site assessments, } \\
\text { cleanup and development. }\end{array}$ & N/A & $\begin{array}{l}\text { Education and Outreach to involve citizens } \\
\text { Crafting parnership agreements with affected } \\
\text { neighborhoods. }\end{array}$ \\
\hline Richmond, VA & $\begin{array}{l}\text { Developing a systematic and cost- } \\
\text { effective means to inventory and } \\
\text { market Brownfields sites }\end{array}$ & N/A & $\begin{array}{l}\text { Evaluating commercial and industrial market } \\
\text { reuse options }\end{array}$ & $\begin{array}{l}\text { Creating a program to bring host residential } \\
\text { communities into the reuse decision-making } \\
\text { process }\end{array}$ \\
\hline Rochester, NY & $\begin{array}{l}\text { Develop and Initiate Cleanup } \\
\text { Mechanism for high priority sites. }\end{array}$ & N/A & $\begin{array}{l}\text { Preparation of marketability criteria for } \\
\text { Brownfields site selection } \\
\text { Selection of four to five priority sites eligible for } \\
\text { a revolving loan/grant program }\end{array}$ & $\begin{array}{l}\text { Creation of strategies that will rely on } \\
\text { partnerships with current and future site owners, } \\
\text { government, regulatory agencies and } \\
\text { development slaff. }\end{array}$ \\
\hline Sacramento, CA & $\begin{array}{l}\text { Developing an automated land use } \\
\text { permitting process and monitoring } \\
\text { system to geographically overlay } \\
\text { environmental information onto land } \\
\text { use maps }\end{array}$ & $\begin{array}{l}\text { Development of an automated } \\
\text { Information System }\end{array}$ & N/A & $\begin{array}{l}\text { Develop a cooperative process among federal, } \\
\text { state and local agencies go involve the } \\
\text { community in redevelopment }\end{array}$ \\
\hline St Louis, MO & $\begin{array}{l}\text { Developing a transferable model for } \\
\text { Brownfields remediation and } \\
\text { redevelopment }\end{array}$ & $\begin{array}{l}\text { Transfer knowledge gained from } \\
\text { business park efforts to a Brownfields } \\
\text { redevelopment model for wide } \\
\text { implementation }\end{array}$ & $\begin{array}{l}\text { Selection of Cleanup Criteria and development } \\
\text { of risk-based cleanup standards }\end{array}$ & $\begin{array}{l}\text { Form a Citizens Advisory Council to ensure } \\
\text { community involvenent with the process }\end{array}$ \\
\hline Trenton, NJ & $\begin{array}{l}\text { Establishing the Brownfields } \\
\text { Environmental Solutions for Trenton } \\
\text { (BEST) }\end{array}$ & N/A & $\begin{array}{l}\text { Identifying key commercial/industrial } \\
\text { Brownfields sites }\end{array}$ & $\begin{array}{l}\text { Raising public awareness of possible issues at } \\
\text { sites in residential areas }\end{array}$ \\
\hline
\end{tabular}

Sources: Miscellaneous, 1994, 1995, 1996. 


\subsubsection{Preventing the Formation of Future Brownfields}

Although there are several local efforts to remediate and redevelop Brownfields, few localities have begun to address the ultimale sive of preventing the formation of Brownfields. The West Central Municipal (inference (WCMC) in Illinois is unique for its curative as well as preventative goals for Brownfields. It is one of the few municipalities with a well articulated goal to identify and eliminate the source of its Brownfields. The WCMC program is also funded by the federal Brownfields Action Initiative. It has parallel objectives to clean up and redevelop existing Brownfields sites as well as eliminatc the source of Brownfields. The program objectives are to:

- Establish a Brownfields Prevention Program to identify ongoing industrial activities that pose a risk of creating new Brownfields.

- Create a "Rapid Response Team" " provide timely expertise on Brownfields Redevelopment;

- Support the redevelopment of at least two public and two private Brownfields lands parcels, and,

- Distribute information about the pilot projects to the public.

\subsection{Summary}

Local Brownfields initiatives are a practical engine for eridlicating existing Brownfields and preventing the formation of future Brownfields, although the latter activity has yet to gain 
importance in the Brownfields debate. Whereas federal and stite level programs tend to focus on providing broad incentives (liability, financial and technical) for Brownfields remediation and redevelopment, local level programs tend to provide the actual tools, techniques and strategies for Brownfields redevelopment. As human, technical and financial resources for Brownfields redevelopment are usually limited, local level programs are also ふেyonsible for providing creative solutions that maximize limited resources for Brownfields rekvelopment. To this end, many municipalities seek intelligent strategies for decision-making that prioritize sites for redevelopment. Such strategies will benefit from repeatable techniques in identifying the redevelopment potential of sites, and in managing the risks involved in site cleanup and redevelopment. In this regard, formal decision analytic touls may be useful for developing defensive and duplicative techniques to manage Brownfields retevelopment. The next Chapter presents an overview of selected decision analysis tools and demonstrates how these may be applied to develop standardized Brownfields decision frameworks. 
CHAPTER 3

DECISION ANALYSIS IN BROWNFIELDS REDEVELOPMENT 


\subsection{Introduction}

Decision making is complicated by conflicting objectives, competing alternatives, unavailable and incomplete data, and uncertain consequences. The development of increasingly complex systems has been associated with a corresponding increase in the complexity of decision problems. This has resulted in rapid growth in the development of quantitative models for decision-making. From these efforts, decision analysis has emerged as a science that uses quantitative methodologies to incorporate viable alternatives, values and uncertainties into a logical framework for sounder decision making. The objective of decision analysis is to enable the decision-maker to perform a more thorough job at sorting out the important factors relating to a specific problem, structuring them in a meaningful manner, quantitatively evaluating decision alternatives, and selecting the one that best meets his or her objectives. The decision analysis process is typically iterative and may be broken down into the following five phases (DPL, 1995):

\section{Problem Structuring}

The objective of problem structuring is to develop a clear statement of the decision maker's alternatives, uncertainties and values. This phase provides a clear statement of the major issues and usually results in a better understanding of the nature of the problem to be modeled. 


\section{Deterministic Analysis}

The deterministic phase has two major objectives. The first is to develop a value model that links input variables to outputs, and may be used in comparing alternatives. The second objective is to perform a sensitivity analysis in order to determine the sensitivity of the model to variations in input variables in order to reduce the number of variables that need to be formally treated in the probabilistic assessment phase.

\section{Probabilistic Analysis}

Once sensitivity analysis has identified a list of the important variables, probabilistic relationships may be defined among the uncertain variables and probabilistic data collected from historical and judgmental sources. The purpose of this phase is to develop a complete probability distribution for each uncertain variable.

\section{Evaluation}

This phase involves linking the components of the model into a fully specified decision modeling tool, (such as an Influence Diagram or Decision Tree), and formally evaluating the problem. Common outputs from this phase are an optimal decision policy as well as risk profiles which indicate the uncertainty associated with that decision policy and others. These risk profiles allow risk analyses to be performed with an ensuing trade-off between the expected utility and level of risk. The evaluation step usually includes additional sensitivity analysis, both deterministic and 
probabilistic, to establish confidence in the results.

Evaluation may also involve value of information and control analyses. The expected value of perfect information is the change in expected value if the state of one or more uncertainties in the model could be observed before decisions are made. The expected value of complete control, on the other hand, is the change in the expected value if one or more uncertainties could be controlled in order to guarantee a particular outcome. The value of information (or control) is measured by the difference between the expected value with information (or control) and the expected value without it. While it is always tempting to insist on more information to resolve uncertainties, the concept of value of information provides the benefit of acquiring additional information and sets an upper bound on the value of new information. Similarly, the concept of value of control provides a basis for evaluating hypothetical decision options or scenarios that are not part of the current analysis but could very well be incorporated, for example, the incorporation of insurance mechanisms in Brownfields Redevelopment.

\section{Communication}

This phase involves coherent communication of the decision analysis results in a manner that provides clear and useful insights for better decision making. 


\subsection{Decision Analytic Tools}

Although decision problems may be modeled with a variety of tools, such as Probability Tables, Decision Trees and Bayesian Influence Diagrams, Decision Trees are traditionally and widely known for modeling decision problems under uncertainty. In a number of more current applications however, Influence Diagrams have emerged as a more adequate communicative tool for decision modeling under uncertainty. Influence Diagrams are especially effective where the decision framework is large and complex, and must be communicated to a variety of practitioners, as is the case with Brownfields redevelopment. Since these tools have a wide variety of applications, the purpose of this Chapter is not so much to explain how they are each used [see DPL, 1995 and Clemen, 1991]; it is more to provide an overview of Influence Diagrams and its relative merits (and demerits) with respect to the more widely used Decision Trees, and to demonstrate how the former may be used in developing qualitative and comprehensive Brownfields decision frameworks. (Chapter 5 provides details of how quantitative Influence Diagram models may be developed for specific localities and used to rank individual Brownfields for redevelopment).

Decision Trees and Influence Diagrams are both graphical tools for representing decision problems. They are both useful for modeling decisions under uncertain conditions. Decision Trees represent decision problems with both graphical and numerical levels of detail, and display more of the problem structure than do Influence Diagrams [Figure 3.1.1]. This is advantageous when the problem is small but becomes less practical as the problem becomes larger. The Decision Tree graphically represents decisions, values and uncertainties in a 


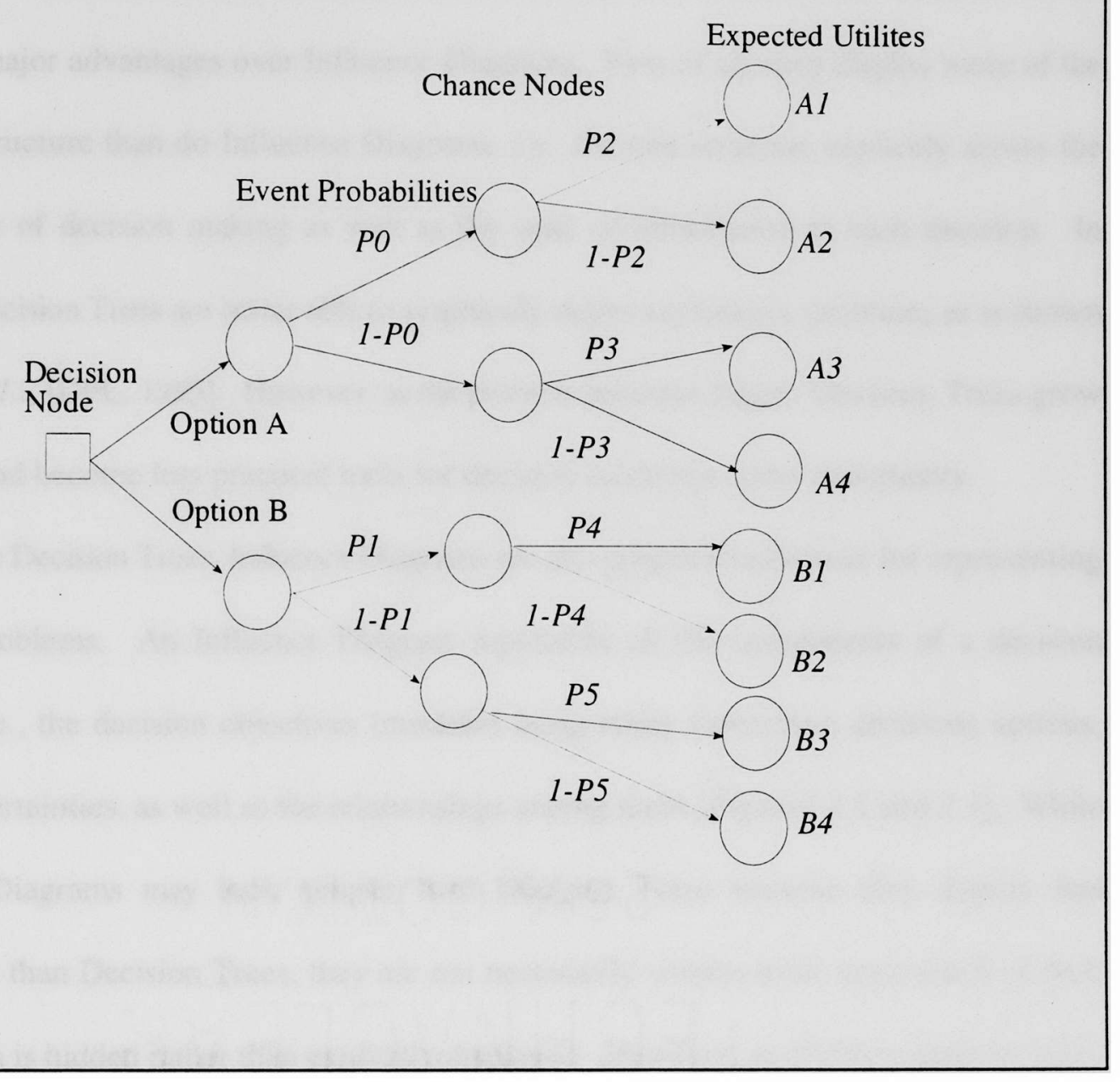

Figure 3.1.1: Symmetric Decision Tree 
problem to be solved, and allows the expected value, a measure of relative utility, to be calculated for all the different decision options or alternatives. The purpose of this tool is to enable the decision maker to select the optimal decision alternative taking into consideration the expected values and risks associated with all the decision alternatives. Decision Trees have two major advantages over Influence Diagrams. First of all, they display more of the problem structure than do Influence Diagrams, i.e., the tree structure explicitly shows the chronology of decision making as well as the state of information at each decision. In addition, Decision Trees are better able to graphically depict asymmetric problems as is shown in Figure 3.1.2 [DPL, 1995]. However, as the problem becomes larger, Decision Trees grow unwieldy and become less practical tools for decision modeling under uncertainty.

Like Decision Trees, Influence Diagrams are also graphical structures for representing decision problems. An Influence Diagram represents all the components of a decision problem, i.e., the decision objectives (modeled using utility functions), decisions options, values, uncertainties, as well as the relationships among them [Figures 3.2 and 3.3]. While Influence Diagrams may look simpler than Decision Trees because they display less information than Decision Trees, they are not necessarily simpler tools since much of their detailed data is hidden rather than explicitly displayed. However, as decision analytic tools, Influence Diagrams have several advantages over Decision Trees. The major advantage is that Influence Diagrams may be used to clearly define decision objectives and explicitly reveal probabilistic and value dependencies in information flow. An Influence Diagram can always represent distributions in the form they are assessed which may not be possible in a Decision 


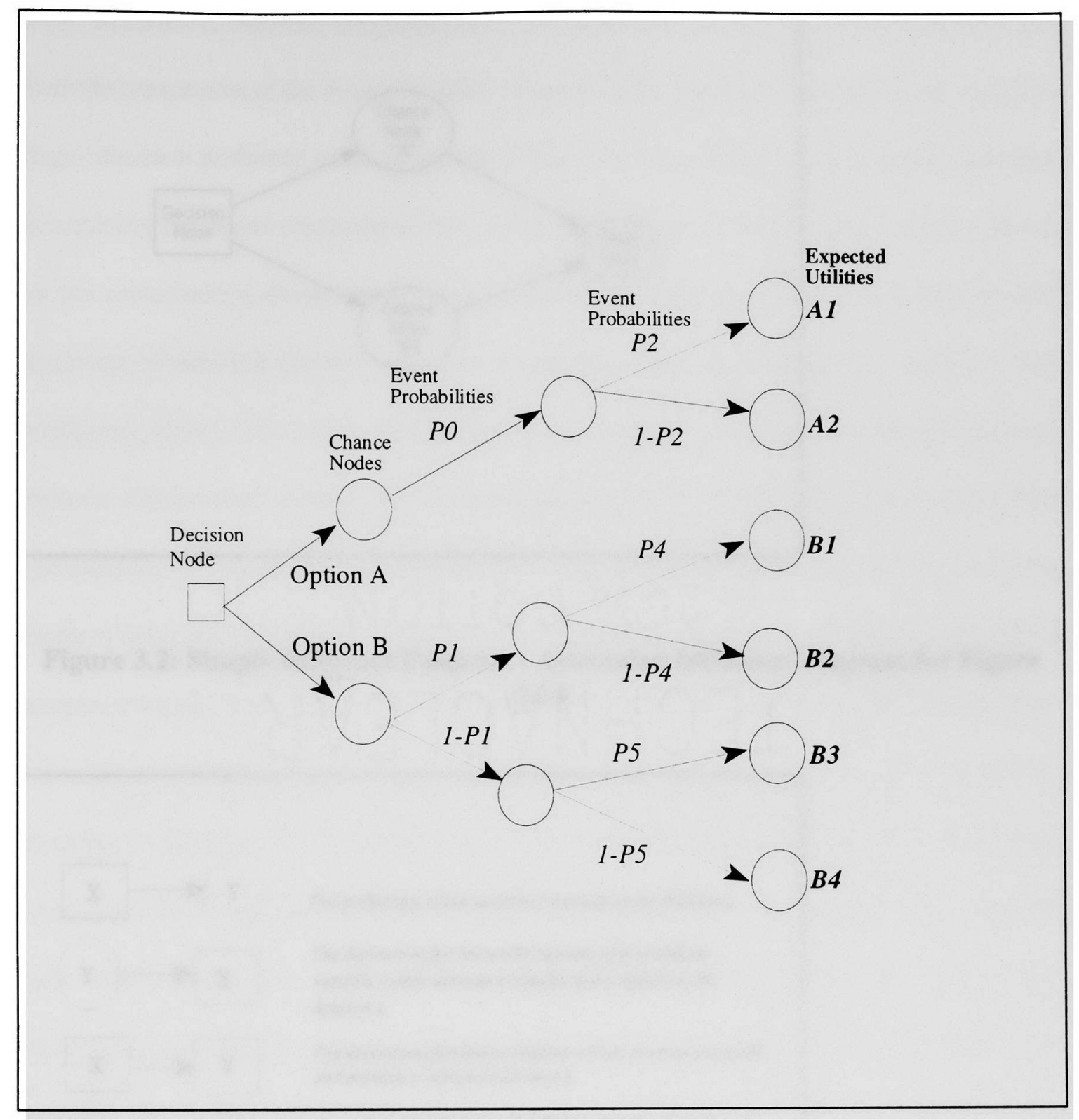

Figure 3.1.2: Asymmetric Decision Tree 


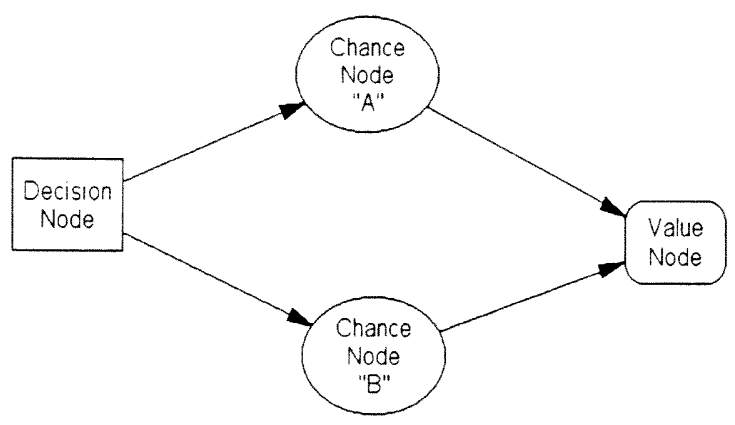

Figure 3.2: Simple Influence Diagram - Associated Influence Diagram for Figure

\subsection{1}

The probability of the variable $y$ depends on the decision $x$.
$\begin{aligned} & \text { The decision-maker knows the outcome of probabilistic. } \\ & \text { variable } y \text { when decision } x \text { is made, and } y \text { influences the } \\ & \text { decision } x \text {. }\end{aligned}$
The decision-maker knows decision $x$ when decision $y$ is made,
and decision $x$ influences decision $y$.
$\mathrm{X}$
The probabilities associated with the variable $y$ depend on the
outcome of the random variable $x$.
$\mathrm{Y}$

Figure 3.3: Fundamental Node Relationships in Influence Diagrams 
Tree. In addition, Influence Diagrams are more successful in representing decision problems from the perspective of the decision-maker. Thirdly, Influence Diagrams graphically represent larger decision problems more compactly than do Decision Trees. The detailed data about the variables are stored within the nodes, so that the diagram is compact and focuses attention on the relationships among the variables. Moreover, Influence Diagrams enable symbolic modeling of decision problems without necessarily requiring in-depth knowledge of their underlying theory, hence their potential utility and appeal to analysts, experts and decisionmakers. And last but not least, the solution algorithm for Influence Diagrams is more direct and can lead to considerable computational savings [Shachter, 1986], especially where the problem structure is symmetric. The Influence Diagram model has a convenient structure for computer manipulation and solution procedures. As Kirkwood [1992] points out, algebraic formulation methods allow Influence Diagrams to represent decision models that are too complex to handle with Decision Trees. However, Influence Diagrams are intrinsically symmetric and do not graphically depict asymmetric problems. The reduction algorithm has been widely tested and is currently the acceptable method for the solution of Influence Diagrams, [see Shachter, 1986; Shachter, 1988 and Clemen, 1991]. This algorithm takes advantage of the inherent symmetry of Influence Diagrams. Therefore, as Shachter [1986] points out, there are some problems for which Decision Trees may be more efficient. Specifically, the reduction algorithm may not be advantageous for problems in which most of the computational savings are gained through asymmetric processing. Nevertheless, as the problem grows larger, the problem size may neutralize or even negate any gains in 
computational savings that could accrue from using Decision Trees to model asymmetric problems. Comprehensively therefore, Influence Diagrams may be a more practical tool for decision modeling under uncertainty. They have been found to improve communication among decision-makers and analysts about key dependencies in a decision under uncertainty. In summary then, Influence Diagrams are intuitive; they are better able to model larger decision problems, they emphasize the critical relationships among various variables, and communicate a complete value and probabilistic description of the problem from the decisionmaker's viewpoint [Shachter, 1986; Shachter, 1988; DPL, 1995]. Table 3.1 summarizes key comparison points for Influence Diagrams and Decision Trees. These advantages of Influence Diagrams will prove beneficial in the development of comprehensive Brownfields decision frameworks, as is seen later.

\section{Table 3.1: Attribute Comparison of Influence Diagrams and Decision Trees}

\begin{tabular}{|l|l|l|}
\hline \multicolumn{1}{|c|}{ Decision Analysis Enhancement Features } & \multicolumn{1}{|c|}{$\begin{array}{l}\text { Influence } \\
\text { Diagrams }\end{array}$} & \multicolumn{1}{|c|}{ Decision Trees } \\
\hline Representation of Larger Problems & Compact & Unwieldy \\
\hline Representation of Probabilistic Dependencies & Clear & Ambiguous \\
\hline Representation of Value Dependencies & Clear & Ambiguous \\
\hline Representation of Problem from Decision Maker's Viewpoint & Stronger & Weaker \\
\hline Computational Processing & Usually Shorter ${ }^{1}$ & Usually Longer \\
\hline Revision of the Problem once model is developed & Simpler & More Involved \\
\hline Communication of Critical Interrelationships between different variables & Stronger ${ }^{2}$ & Weaker \\
\hline $\begin{array}{l}\text { Communication of the State of Information at each Decision } \\
\text { Depiction of Asymmetric Problems }\end{array}$ & Indirect & Direct \\
\hline $\begin{array}{l}\text { The difference in computational savings between Influence Diagrams and Decision Trees increases exponentially as the problem } \\
\text { The communication power of Influence Diagrams becomes increasingly significant as the size of the problem increases. }\end{array}$ \\
\hline 2
\end{tabular}




\subsection{Topology of Influence Diagrams}

Topologically, an Influence Diagram is a finite non-cyclic graph made up of directed arcs (arrows) linking four kinds of nodes: decision nodes deterministic nodes, chance nodes and value nodes.

\subsubsection{Nodes}

Nodes represent variables. A node represents a choice among a set of alternatives. Each node contains a list of the possible values of the variable that the node represents. Chance or random variables are depicted by circles; decision variables by rectangles, deterministic nodes by concentric circles and value or utility nodes by rounded rectangles. Each chance node contains a probability distribution for its variable $\mathrm{X}$ for each configuration of its predecessor nodes. The probability distributions may be obtained from subjective assessments by experts, from maintenance records, statistical databases or experimental data. Each decision node contains a number of decision options and represents the choices available to the decision-maker. Deterministic nodes may be thought of as a special kind of chance node in which all the probabilities happen to be zero or one: i.e., a determinsitic node has a number of states and at any point in time, there is only one state (with an associated probability of 1) that may be assumed by the deterministic node. The value node may be viewed as a special kind of chance node whose value is needed to answer the question of interest to the analyst. This value node contains a mapping 
that specifies the value of its variable $X$ given values of all its predecessor nodes [Shachter, 1986; Agogino et al., 1992].

\subsubsection{Arcs}

Arcs linking two nodes indicate some kind of influence of one node on the other.

There are two kinds of arcs: informational and conditional arcs. Known as conditional arcs, arcs into chance or value nodes indicate that there may be probabilistic dependence. Arcs into decision nodes are called informational arcs and simply imply time precedence; they indicate that information from the predecessor nodes must be available at the time of decision [Shachter, 1986; Shafer, 1992]. Figures 3.3 illustrates fundamental node relationships in an Influence Diagram.

\subsection{Evaluation of Influence Diagrams}

In order to evaluate an Influence Diagram, there must be a question to be answered, i.e., some random variable(s) whose distribution(s) must be determined. The associated chance node is singled out as the value node. This value node then represents the objective to be optimized (maximized or minimized) in expectation. There may be single or multiple variables associated with the value node. The variable(s) associated with nodes having arcs into the value node are the attributes of the decision-maker's utility function. The random variable of the value node needs to be calculated in expectation. This expected value represents the utility of the outcome to the decision-maker. If there are decisions to be made 
then the expected utility may be used to compare alternatives. Given the state of information at the time of the decision, the alternative(s) selected should maximize the expected utility of the resulting outcome [Shachter, 1986].

Although a variety of algebraic algorithms are available for evaluating Influence Diagrams, the reduction algorithm had been widely tested and is currently used in the solution of Influence Diagrams [ see Shachter, 1986; Clemen 1991]. The reduction algorithm has been used in developing of several types of commercially available Influence Diagram software packages such as $D P L^{T M}$ (Decision Programming Language), InDia ${ }^{T M}$ (INfluence DIAgram processor) and $\operatorname{Demos}^{T M}$. These software tools generally run on widely used IBM compatibles and Macintoshes with graphical user-interfaces, and are reasonably easy to use once their basic decision analytic concepts are understood.

DPL, a windows-based IBM PC program, is selected as the software package for this study. DPL s a user-friendly package that provides Influence Diagram modeling capabilities with a well developed graphical user interface. There are two exceptions to the norm in DPL's node vocabulary: (I) it lacks an explicit non-value deterministic node; however a deterministic node can be computationally modeled using a value node; and, (II) a value node may be explicitly used to represent constants and complex functions of other variables [Maxwell, 1996], which proves to be a very useful feature in the development of Brownfields Ranking Models. 


\subsection{Influence Diagrams in Brownfields Redevelopment}

Influence Diagrams may be successfully used in modeling Brownfields redevelopment decision-making as is shown below. However, while the structure of Influence Diagrams makes them very appropriate for modeling the relevant issues in Brownfields redevelopment, the Brownfields redevelopment process remains challenging because of its environment of uncertainty, at least at the present time. Because of the general lack of information and data on several abandoned sites, there is a strong need to develop and use both cost and timeeffective strategies for the elicitation of meaningful information and data for site remediation and redevelopment [see Cooke, 1989]. Only then will these models be made effective and practical in the evaluation of Brownfields redevelopment alternatives.

\subsubsection{Developing Qualitative Brownfields Decision Frameworks}

Typically, decision-making in Brownfields redevelopment incorporates several issues as well as multiple interests, players and objectives. As discussed in Chapter 2, Brownfields redevelopment decision-making must deal with the following fundamental issues: technical (relating to the availability of feasible remediation technologies), legal liablilty (relating to uncertainties over the types and extents of legal liability associated with a site), financial (relating to the availability of viable options for financing site assessment, remediation and redevelopment), community concerns (relating to public health and environmental resource protection), and site redevelopment prospects. 
Site redevelopment prospects refer to the socioeconomic and planning variables that influence the demand for the site and its potential profitability once the contamination and the potential for liability are removed. Examples of socioeconomic variables are crime, accessibility to well qualified labor to support the future use(s) of Brownfields, prevailing levels of congestion, and the quality of social amenities. Social amenities will largely be determined by the availability of adequate civil infrastructure (and services), the existence of inadequate civil infrastructure for renewal and reuse, or the presence of conducive factors such as land area and land use regulations to provide for the required civil infrastructure. The land use and transportation planning environment, on the other hand, revolves around zoning laws and land use regulations, as well as long term growth management laws, that determine development patterns in the locality of the Brownfields site.

This host of issues brings into play a wide variety of groups for Brownfields decision-making. Significantly, these stakeholders are property owners, developers and investors, bankers, environmental and engineering consultants, insurance providers, environmental organizations, community development organizations, regulators at the local, state and federal levels, and attorneys. These parties each have their specific interests and objectives, sometimes conflicting.

Not only does Brownfields redevelopment have to deal with multiple issues and stakeholders, the redevelopment process may also be fraught with uncertainty. Environmental and redevelopment information on abandoned sites is often 
unavailable. In cases where some information is found it is likely to be highly deficient for the purposes of thoroughly evaluating viable redevelopment alternatives and selecting the optimal redevelopment scenario.

Given the many players in Brownfields redevelopment and their potentially conflicting objectives, decisions will have to be clearly defensible and easily communicated to all parties with a stake in redevelopment. In this complex environment, the comprehensive needs in Brownfields decision-making could be adequately captured using an Influence Diagram decision modeling approach. Influence Diagrams will provide a suitable framework for modeling and evaluating complex Brownfields redevelopment alternatives with multiple values under uncertainty. These models may be used to capture all the considerations viewed as important by the various Brownfields stakeholders. The following section develops and discusses a number of Influence Diagram models that incorporate the generic values, objectives and uncertainties relevant to determining the redevelopment potential of Brownfields sites.

\subsubsection{Discussion on Prototype Models for Brownfields Decision-Making}

In the first part of this section, separate single-attribute Influence Diagram models are built to capture the redevelopment potential of Brownfields from the perspectives of the five major issues discussed above. These models demonstrate how technical issues, legal liability, financial issues, community concerns and site redevelopment 
prospects each impact the redevelopment potential of Brownfields sites. The close relationships between variables in the different categories are also captured by these models.

The second part of the section then combines all the single-issue Influence Diagrams into two comprehensive multiple-issue Brownfields decision models. Collectively, these prototype models represent the generic decision framework for Brownfields redevelopment. They define the complex relationships that exist between critical issues in determining the redevelopment potential of Brownfields sites. In order to be made practically useful however, they may require adjustments to reflect the particular needs and characteristics of the localities using them (as is demonstrated in Chapter 5). Nevertheless, these models serve adequately to introduce and demonstrate the strengths of Influence Diagrams in modeling relationships between pertinent issues for determining the redevelopment potential of Brownfields sites.

Although a significant number of variables are selectively modeled as chance variables, it is important to note that these models are preliminary and will require sensitivity analyses to distinguish between those variables whose uncertainty significantly affects the expected value of the utility function and those that may be treated as constants without significant impact on the model's expected value. This step is likely to contribute to both time and money savings by decreasing amount of information that must be obtained prior to decision making, i.e., if a variable does not significantly impact the optimal policy of the decision model, it may just as well be 
treated as a constant with no serious consequences. Sensitivity analysis thus promises to be an especially useful tool for cost savings in Brownfields redevelopment, since Brownfields site data and information are usually unavailable or insufficient.

\subsubsection{Modeling Technical Issues in Brownfields Redevelopment}

Technical issues surrounding Brownfields redevelopment involve accurately assessing the type and extent (or absence) of contamination at the site, and deciding on the cleanup standards and procedures that must be followed. Figures 3.4 and 3.5 depict the critical variables and their interrelationships in determining the land redevelopment potential of Brownfields from the viewpoint of technical issues. Figure 3.5 is a slight variation of 3.4. The former model represents all laws pertaining to Brownfields redevelopment as deterministic rather than chance nodes. Figure 3.5 is therefore more applicable to advanced stages of Brownfields redevelopment where localities have clearly defined and established applicable laws for Brownfields remediation, from the existing repertoire of related federal, state and municipal environmental laws, and hence where remedial costs may be deterministically projected for each site. The main attributes of the utility value node, (i.e., the main issues impacting the expected value of the site from the viewpoint of technical feasibility), are the availability of affordable site assessment and remediation technologies. In addition, the type and extent of 
site contamination will largely influence the availability of cost-effective remediation technologies, and also impact on the adopted level of clean up standards for the site. Site clean up standards will also be influenced by the municipality's prevailing Brownfields-related laws as well as the viable future land uses permitted for the site. In cases where it is not economical to achieve feasible levels of clean up that permit pre-zoned land uses, land use(s) may be modified to suit clean-up levels and land use or engineering controls adopted to ensure that such sites retain the newly prescribed land use(s) indefinitely. In such cases, the influence arc will be reversed from the "Future Land Use" node to the "Clean Up Standards" node in both Figures 3.4 and 3.5. Finally, the site assessment and remedial methods to be used will necessarily be sensitive to the ever-important environmental issues of human health and natural resource protection. 


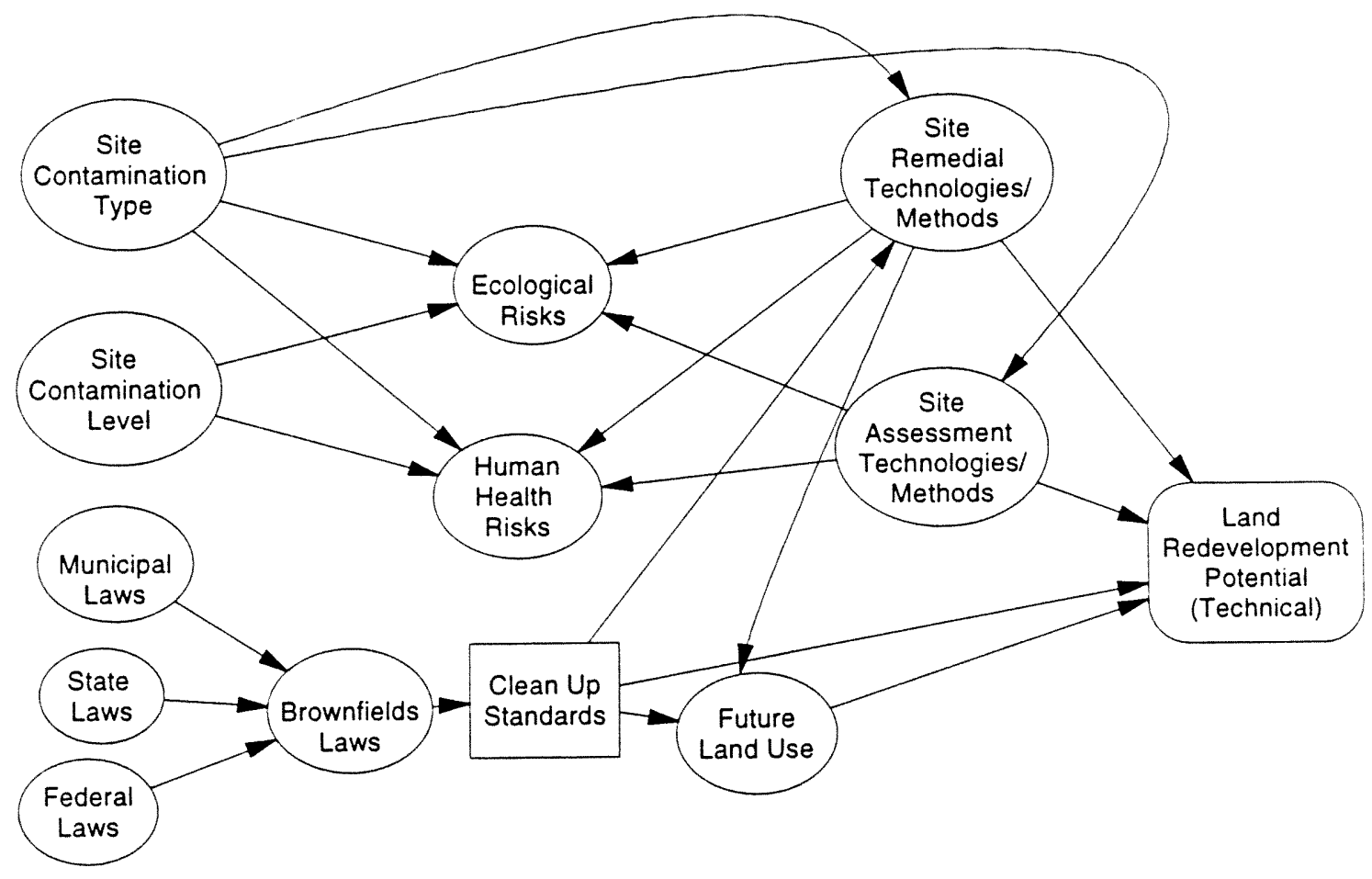

Figure 3.4: Technical Issues in Brownfields Remediation and Redevelopment

(Type I) 


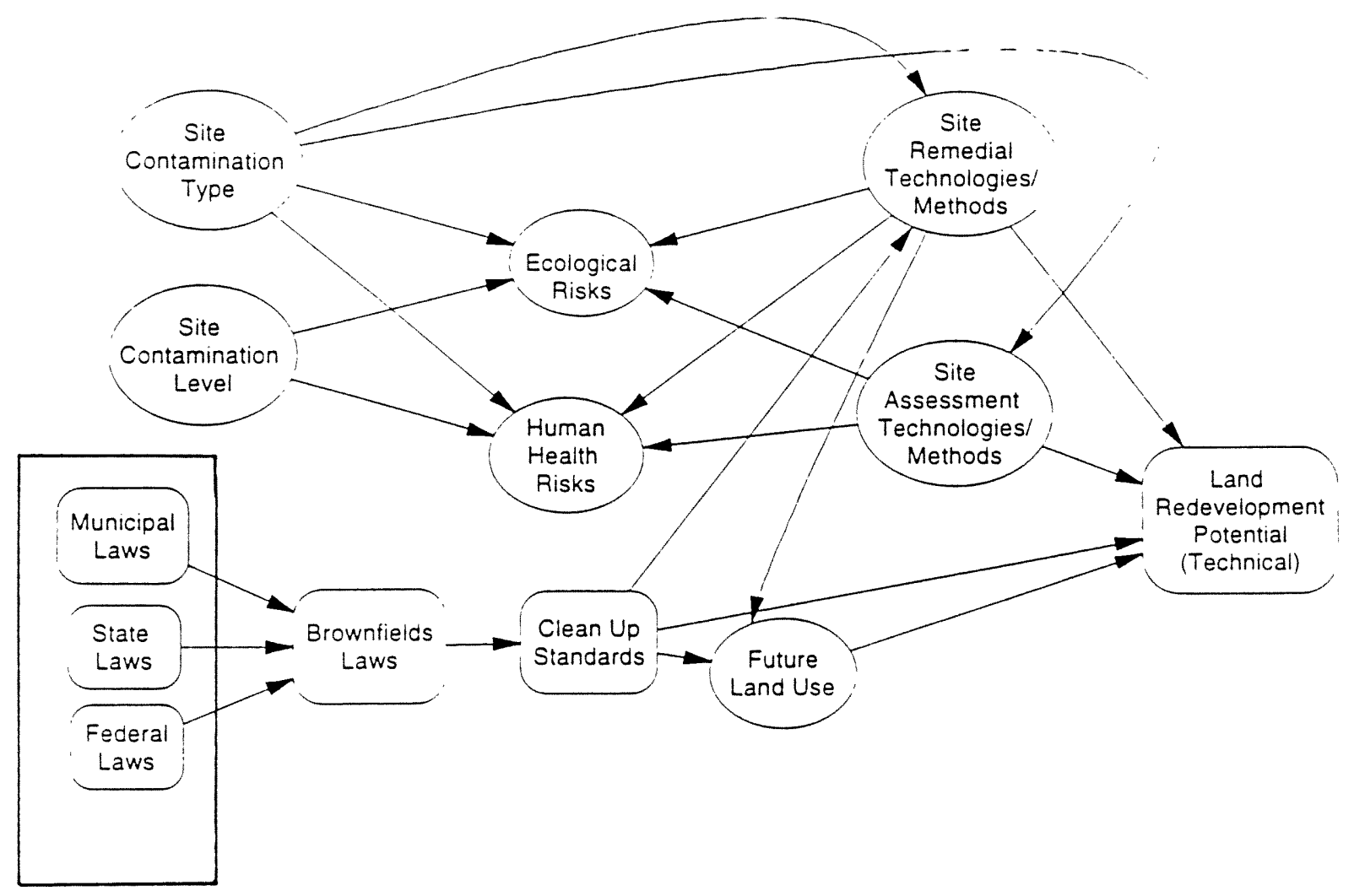

Figure 3.5: Technical Issues in Brownfields Remediation and Redevelopment

(Type II) 


\subsubsection{Modeling Legal Liability in Brownfields Redevelopment}

Legal liability is largely determined by prevailing laws and programs that support Brownfields remediation and/or redevelopment. Real or perceived threats of liability often deter interested parties form undertaking any transactions to clean up and redevelop a Brownfield site. More clearly defined laws relating to Brownfields redevelopment create an environment with less uncertainty and set the stage for redevelopment. However, assurances for private party protection from some types of liability provide even stronger incentives for Brownfields redevelopment. Thus, laws and programs that afford higher levels of protection against liability will be more successful in attracting interested parties for Brownfields redevelopment, and increase the land redevelopment potential from the liability viewpoint. Figures 3.6 and 3.7 depict this Brownfields redevelopment scenario from the viewpoint of legal liability. The decision attributes for the utility node are both legal and environmental. As in the previous example, Figure 3.7 represents a more advanced stage of Brownfields redevelopment programming where applicable Brownfields laws are clearly defined, and hence cost projections related to site remediation are deterministic. 


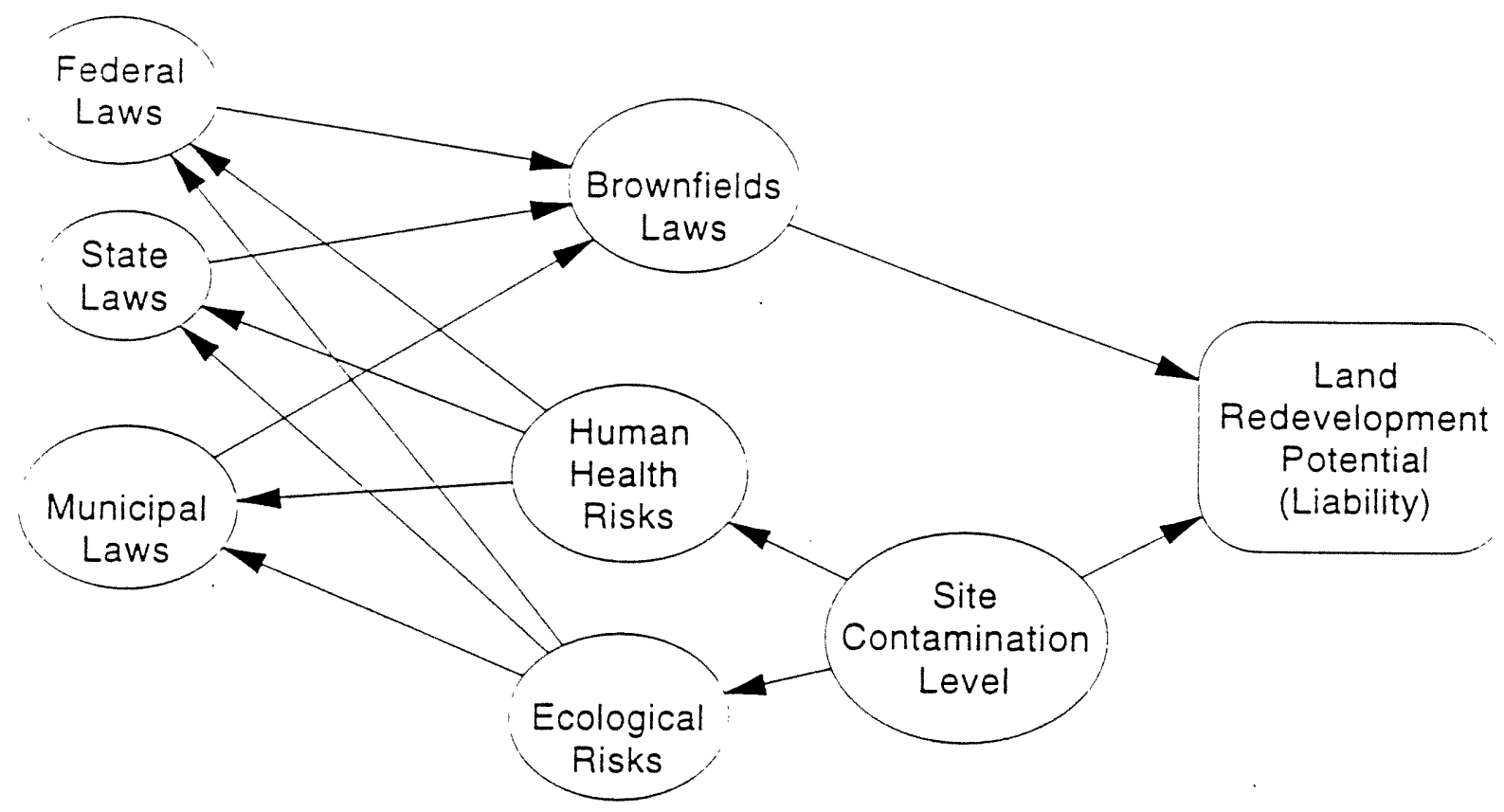

Figure 3.6: Legal Liability Issues in Brownfields Remediation and Redevelopment

(Type I) 


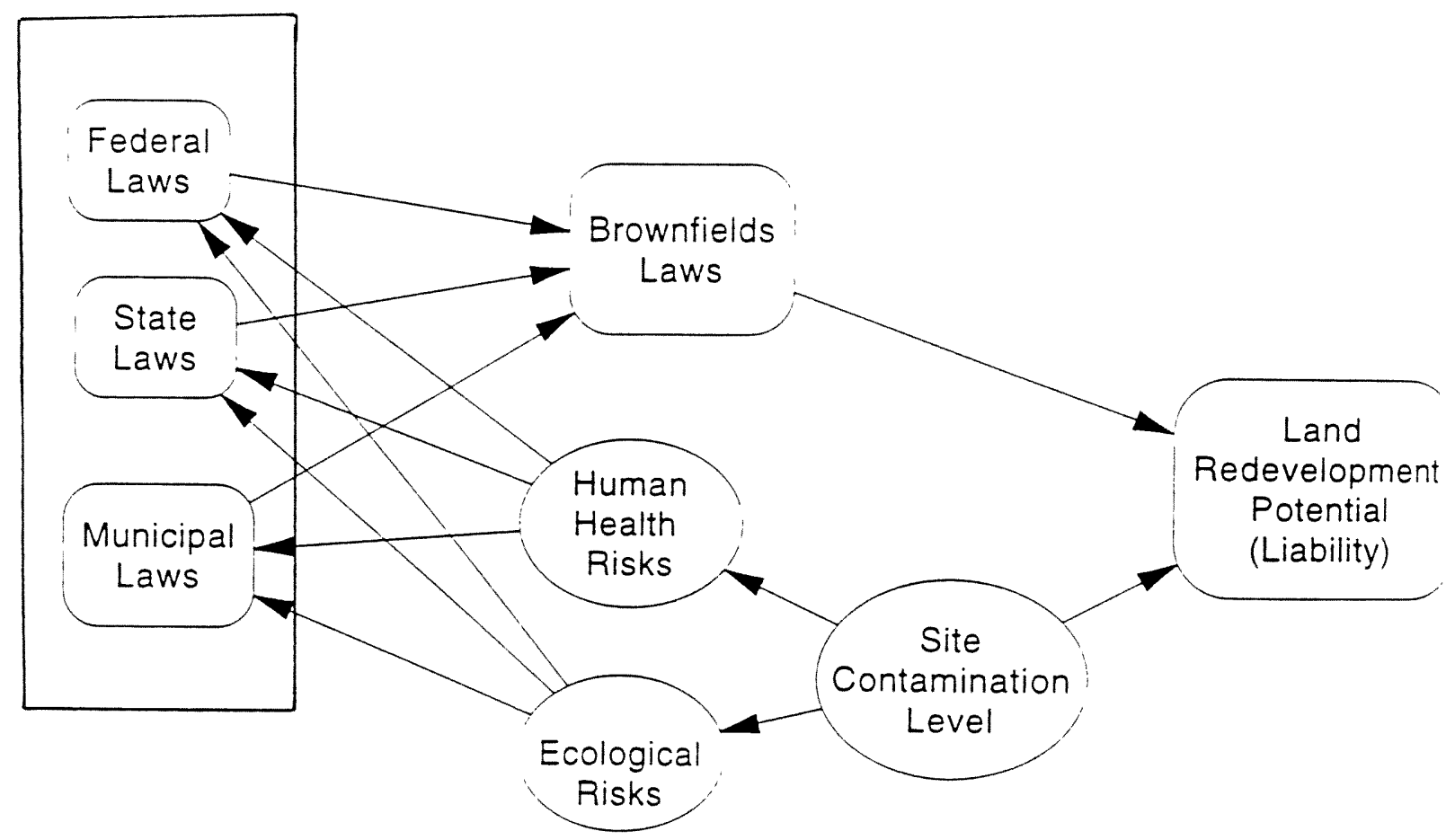

Figure 3.7: Legal Liability Issues in Brownfields Remediation and Redevelopment (Type II) 


\subsubsection{Modeling Financial Issues in Brownfields Redevelopment}

Financial issues are particularly complicated at Brownfields sites primarily due to the following three interrelated factors:

(1) The ultimate costs of assessment and remediation,

(2) The potential risk of legal liability, and

(3) The depressed socioeconomic conditions surrounding Brownfield sites.

Remediation costs associated with environmental contamination can be quite high, ranging from thousands of dollars to millions of dollars for particularly hazardous sites. Coupled with these high clean up costs, the uncertainties surrounding liability act as barricades against public and private investment in Brownfields redevelopment. Last but not least, the prevailing site redevelopment prospects also discourage potentially interested parties from investing in Brownfields. Figures 3.8 and 3.9 depict critical interrelationships among the variables affecting the financial redevelopment potential of Brownfields sites. Once again, Figure 3.9 depicts a Brownfields scenario in which issues of legal liability are deterministic rather than probabilistic. 


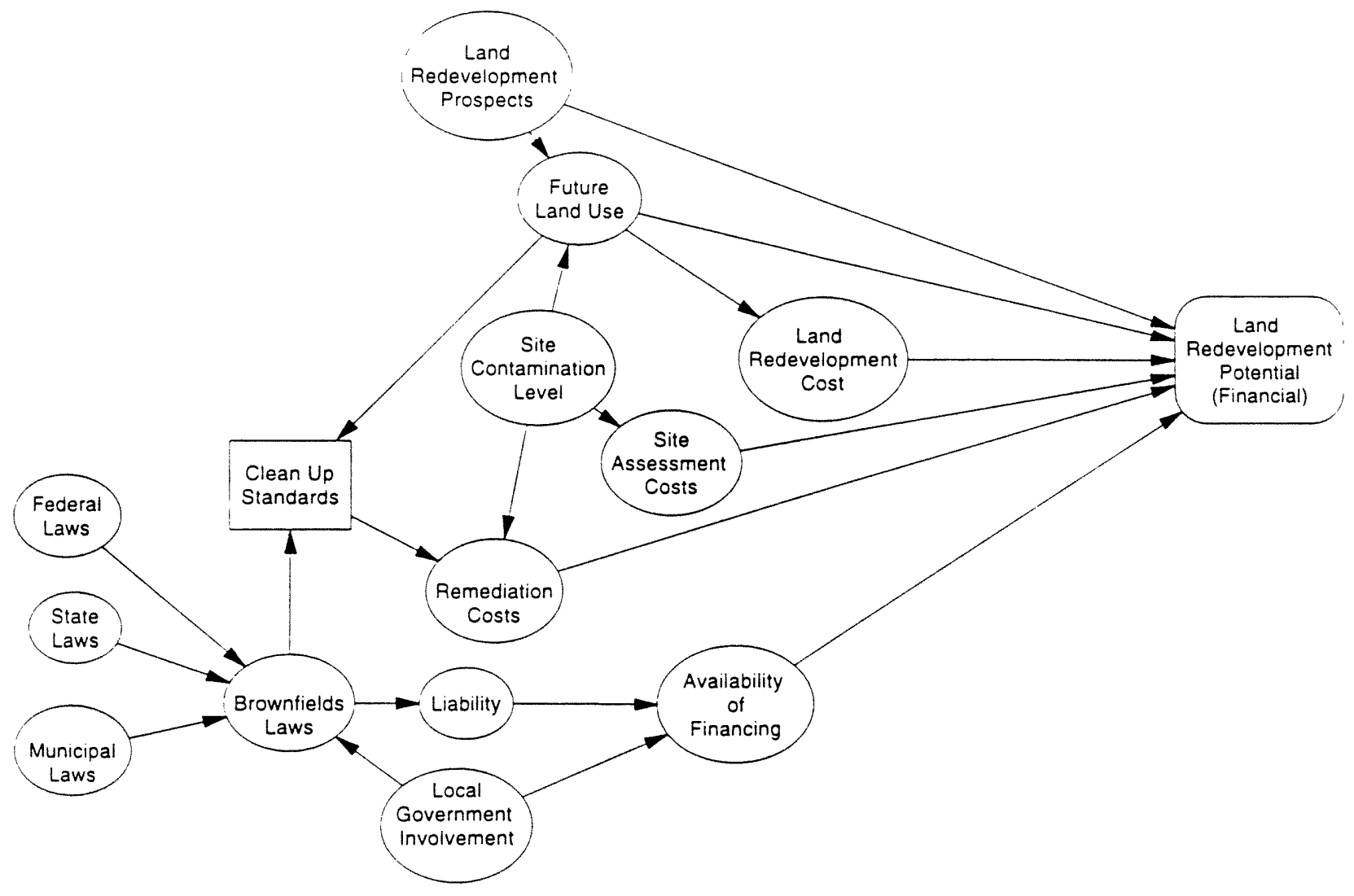

Figure 3.8: Financial Issues in Brownfields Remediation and Redevelopment

(Type I) 


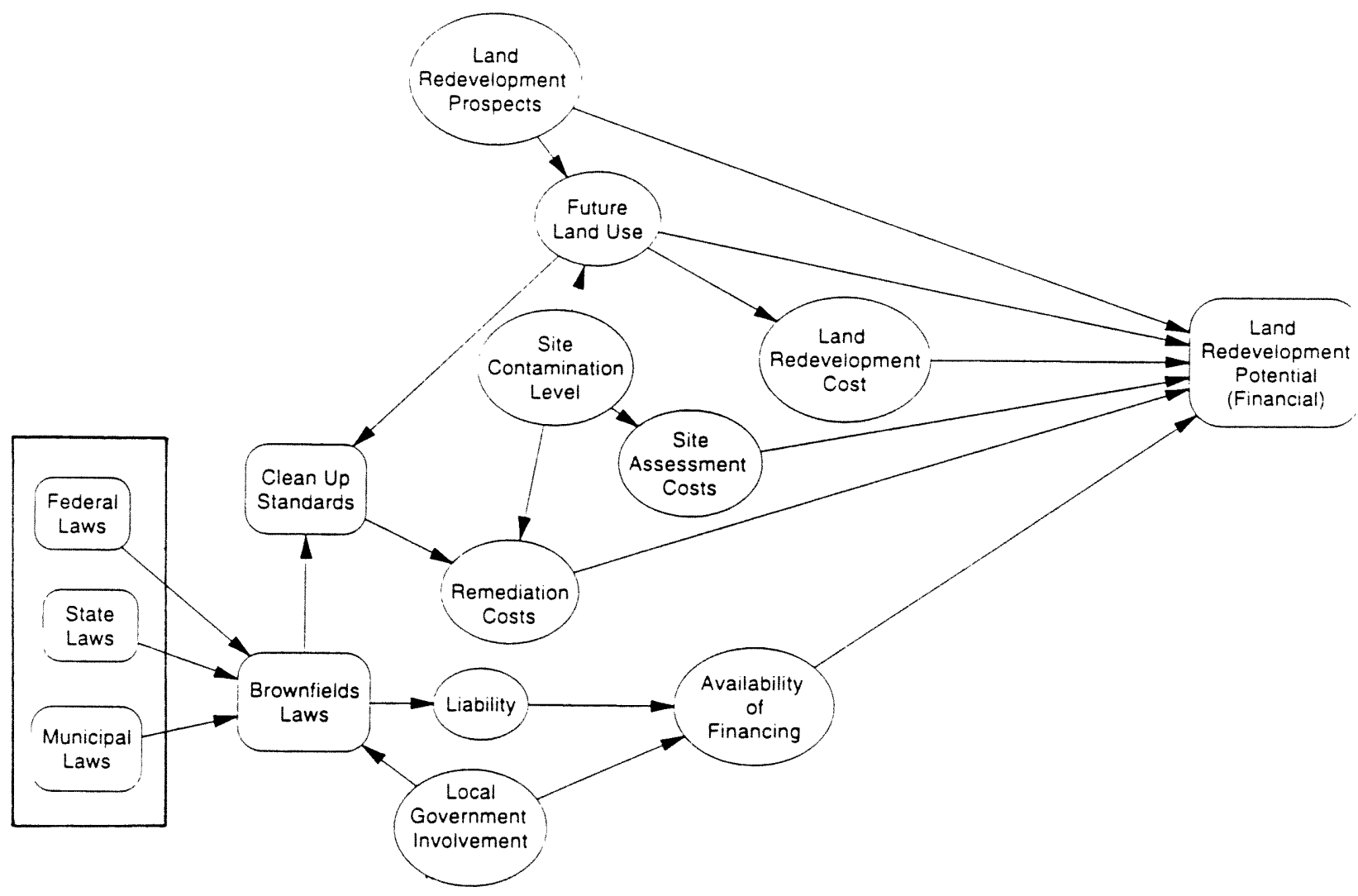

Figure 3.9: Financial Issues in Brownfields Remediation and Redevelopment

(Type II) 


\subsubsection{Modeling Community Concerns in Brownfields Redevelopment}

Brownfields sites hardly exist in isolation. They are often located in the heart of depressed communities and may be in close proximity to retail districts and residential areas. Community concerns are fueled by the desire to protect human and environmental health. Existing contaminated properties may pose direct threats to human and environmental health where they are located. For this reason, community groups are usually interested in promoting the clean up and redevelopment of Brownfields in their neighborhoods. However, almost without exception, they demand some assurances that the remediation procedure will protect their health and that of the environment. Hence community groups will tend to have a definite impact on the clean up standards and future land use(s) of Brownfields sites. Figures 3.10 and 3.11 capture the redevelopment potential of Brownfields from the viewpoint of community concerns. 


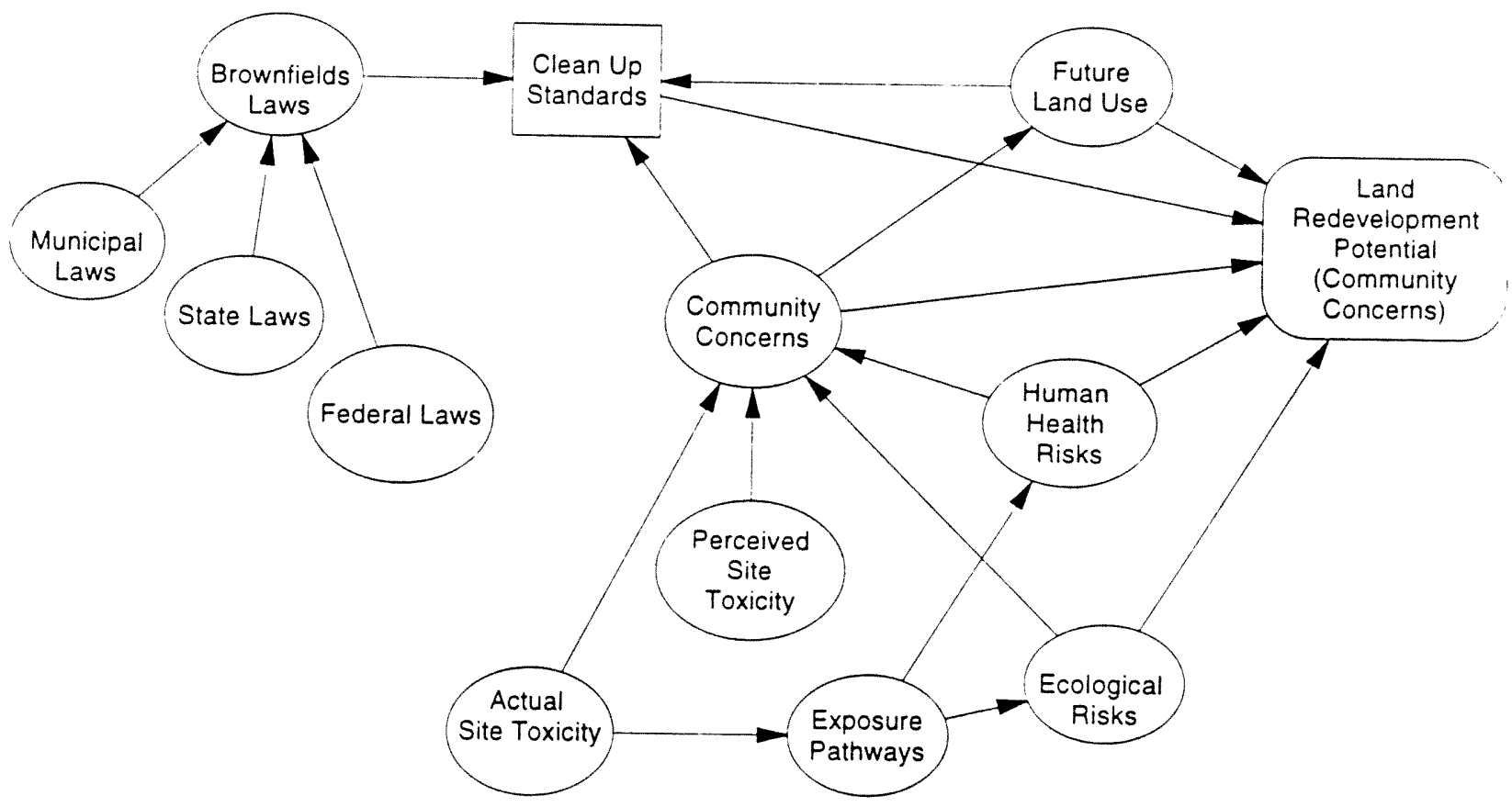

Figure 3.10: Community Concerns in Brownfields Remediation and Redevelopment

(Type I) 


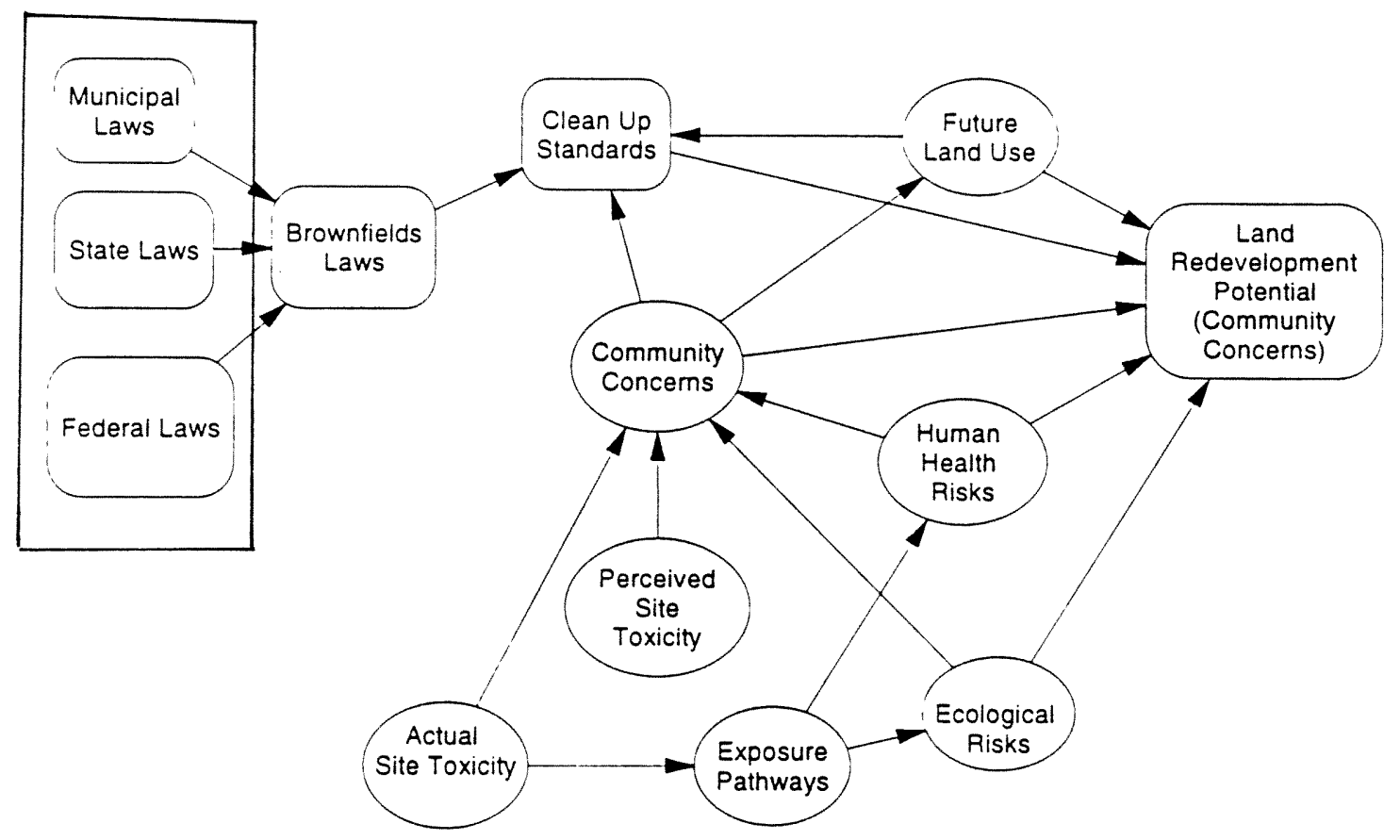

Figure 3.11: Community Concerns in Brownfields Remediation and Redevelopment

(Type II) 


\subsubsection{Modeling Redevelopment Prospects in Brownfields Redevelopment}

Redevelopment prospects are crucial for the marketability of Brownfields remediation and redevelopment because they determine whether there will be demand for the property if the problem of contamination and the potential for liability are removed. Redevelopment prospects make it clear that concern about environmental contamination is only one part of the problem in Brownfields redevelopment, namely the remedial aspect. The second major part of Brownfields redevelopment revolves around the socioeconomic and sociopolitical forces that largely determine the site's marketability. Brownfields sites, many of which are located in distressed communities, pose problems for redevelopment. In many cases their supporting civil infrastructure is old and obsolete, property access may be limited, and socioeconomic variables such as crime, high taxes, traffic congestion, lowquality amenities and racial tensions may be strong obstacles to the redevelopment of such sites. With such redevelopment barriers for Brownfields, the development of Greenfields (untouched land fringing urban areas), becomes increasingly attractive, contributing to urban sprawl and its associated destruction of farmlands. Figures 3.12 shows the important variables and critical relationships for determining the redevelopment prospects of Brownfields sites. 


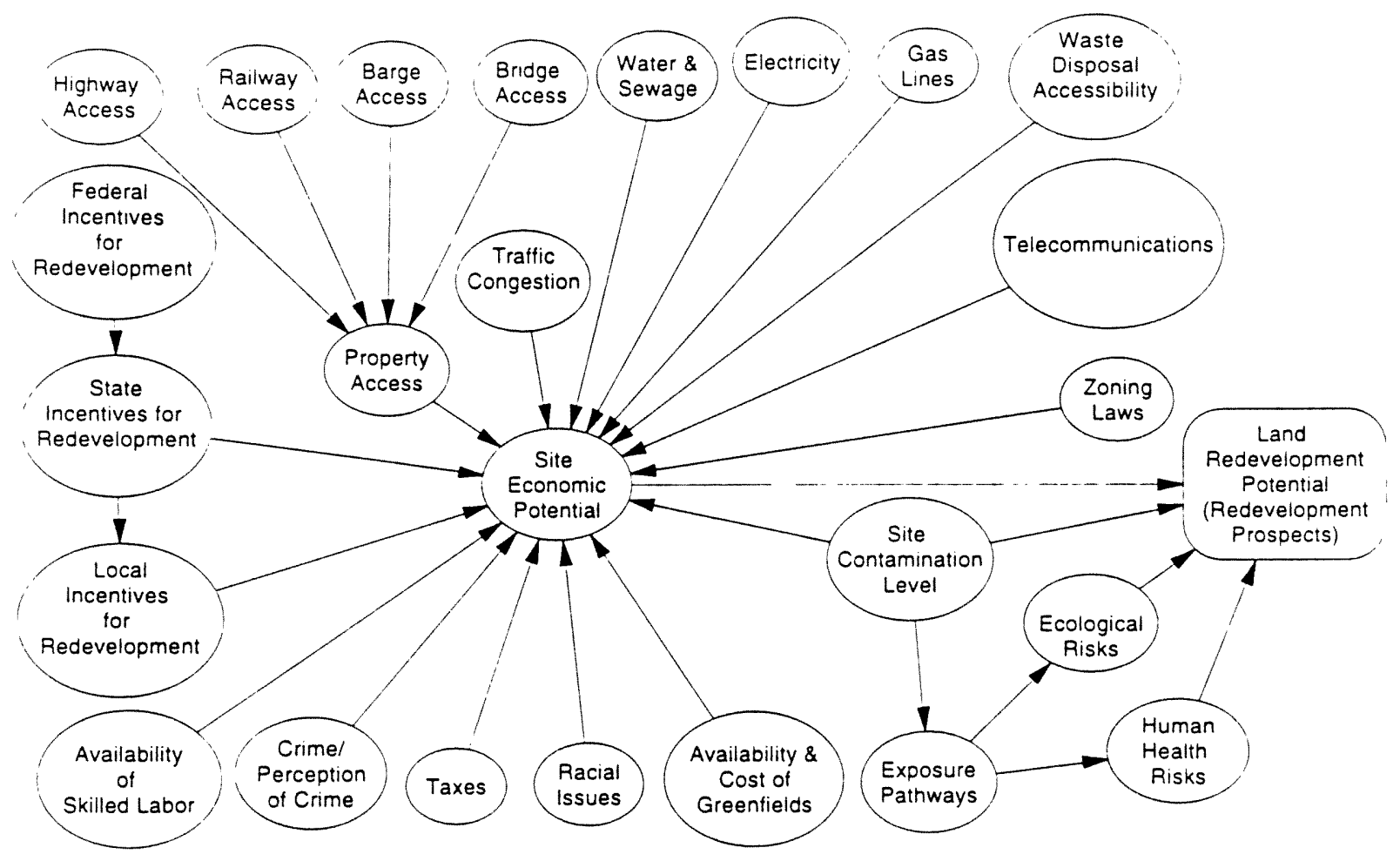

Figure 3.12: Redevelopment Prospects

in Brownfields Remediation and Redevelopment 
3.5.2.6 Comprehensive Decision Framework for Brownfields Redevelopment Complex as each of these issues may seem, each only scratches the surface of Brownfields redevelopment and describes a small portion of the overall picture of the Brownfields redevelopment framework. Figures 3.13 and 3.14 put together all the five types of previously discussed issues and models in a comprehensive Brownfields decision model that is undoubtedly complex and depicts the important relationships among competing objectives, values and uncertainties in Brownfields redevelopment. This model especially demonstrates the strengths of Influence Diagram modeling as the problem becomes larger. Despite the size of the problem, the model remains compact. In addition, the model clearly depicts the existing qualitative interrelationships among variables through probabilistic and value dependencies. 


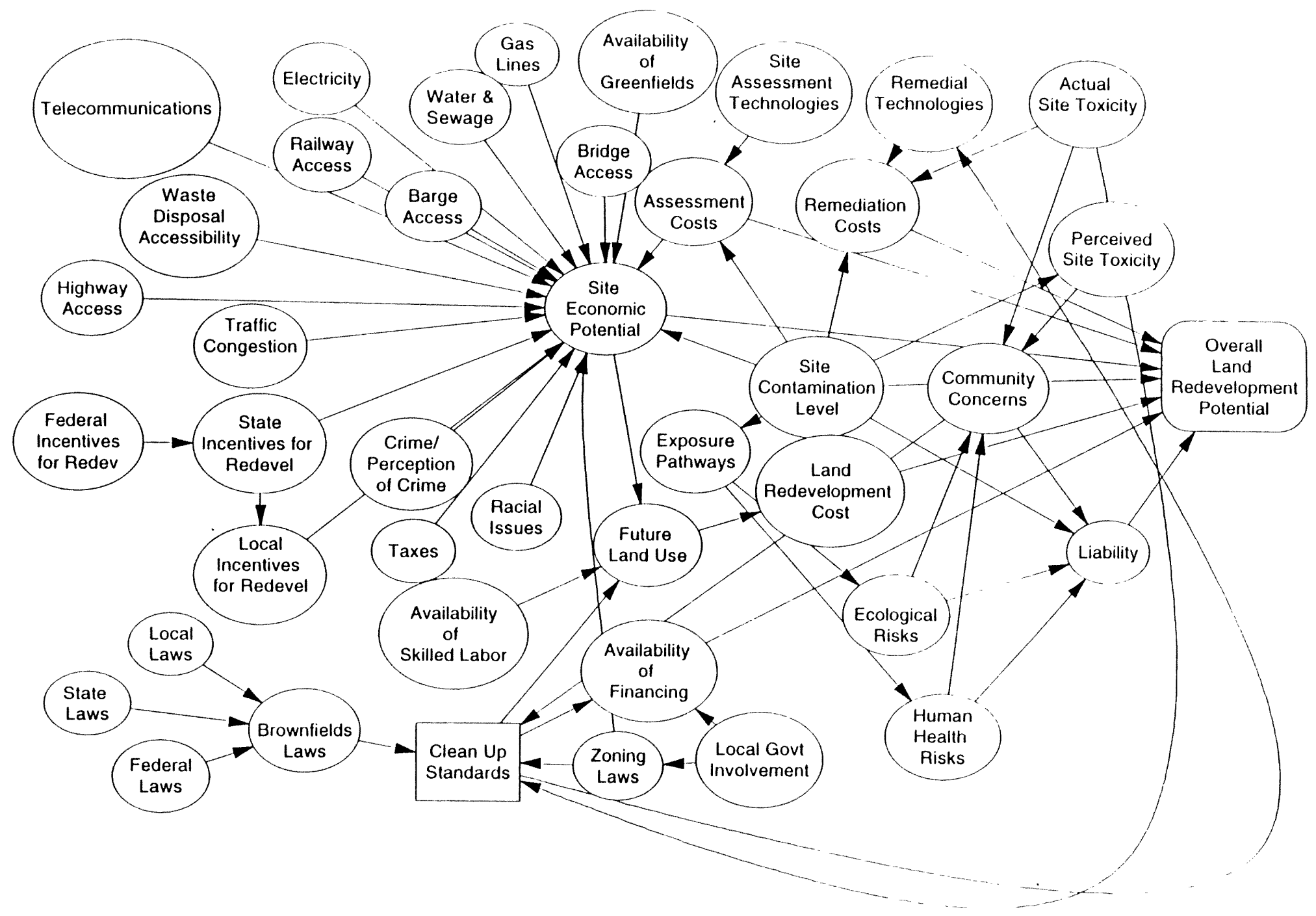

Figure 3.13: Overall Redevelopment Potential in Brownfields Remediation and Redevelopment

(Type I) 


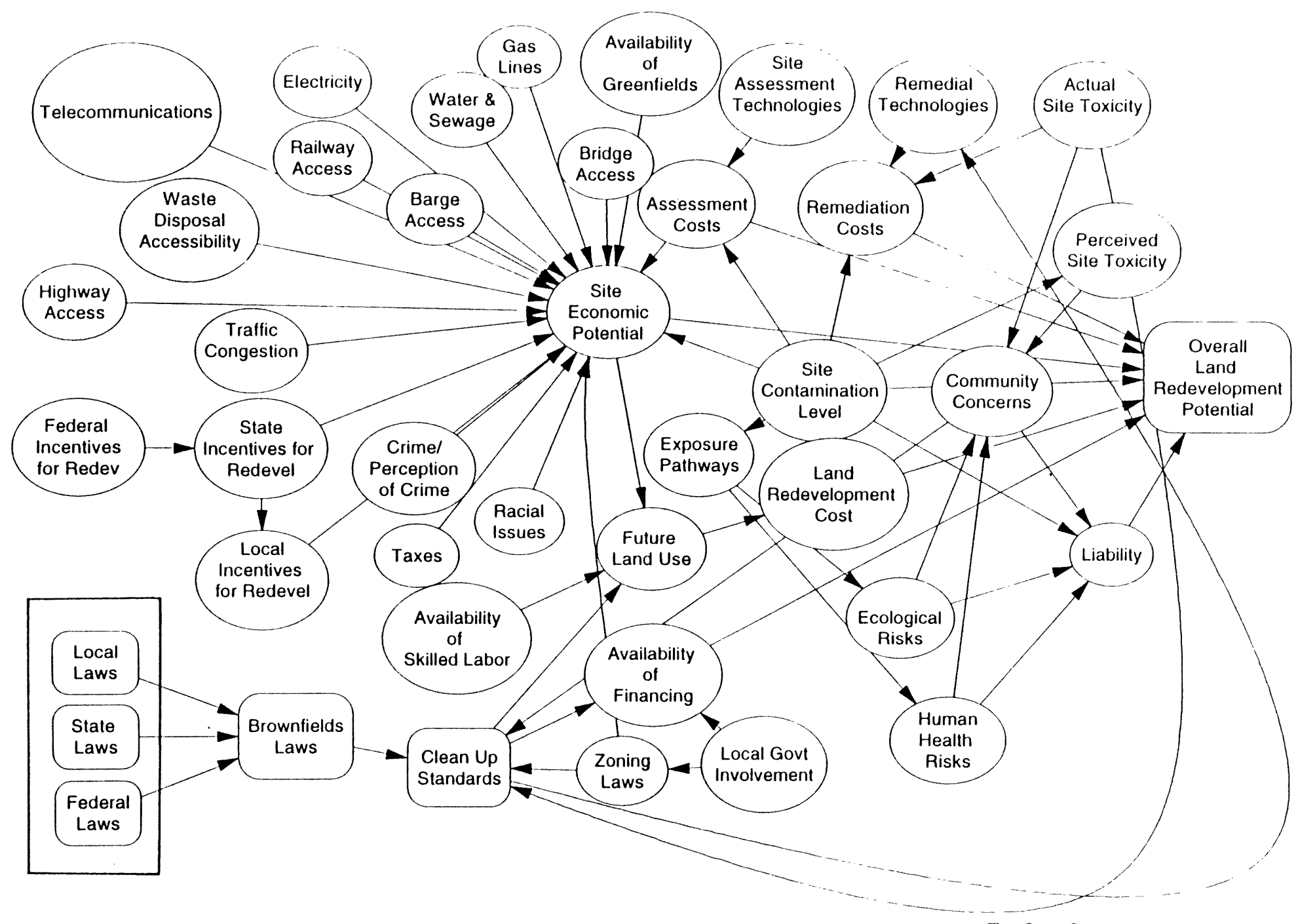

Figure 3.13: Overall Redevelopment Potential in Brownfields Remediation and Redevelopment

(Type II) 


\subsection{Benefits of Influence Diagrams for Brownfields Redevelopment}

As discussed in Chapter 2, Brownfields remediation and redevelopment activities typically involve the following four phases:

\section{(1) Site Identification}

(2) Site Assessment

(3) Site Remediation

(4) Site Redevelopment

With the high costs of remediation, the prevailing negative redevelopment prospects, and the limited availability of private and public funds for Brownfields redevelopment, Influence Diagrams promise an improvement to existing Brownfields redevelopment process as described above. With the introduction of a pre-evaluation phase, Influence Diagrams may be used, in cases where programs have been established to develop multiple sites over an extended period, to develop a methodology for ranking these sites in the order of their relative overall redevelopment potentials, (i.e., a point system of sorts). Influence Diagrams may be used to identify those sites that may require the least amount of cleanup and promise the greatest economic development impact, i.e. higher priority sites. This may include some prediction of time frames for turnover on the cleanup investment as well as profit gains on the future land development. Such a redevelopment framework is a strong basis for establishing Brownfields financial programs or funding mechanisms, such as a revolving funds, in which the gains from previous developments are put back into a common fund for the future redevelopment of other Brownfields. In such cases, an Influence Diagram approach will 
facilitate the best use of available resources for Brownfields redevelopment.

In addition, Influence Diagrams may be used with associated sensitivity analyses tools to determine which variables are indispensable to the decision-maker's predetermined decision objectives and to eliminate the need for obtaining other types of site-related information that were previously thought to be important. This is especially beneficial for today's Brownfields climate where environmental and redevelopment information is usually unavailable for Brownfields sites.

This proposed Influence Diagram planning framework is more strategy-oriented and promises more optimal uses of available resources. Figure 3.15 illustrates the new and improved Brownfields redevelopment process incorporating Influence Diagram preevaluation for site ranking for remediation and redevelopment. 
Site Identification [Phase I Site Assessment]

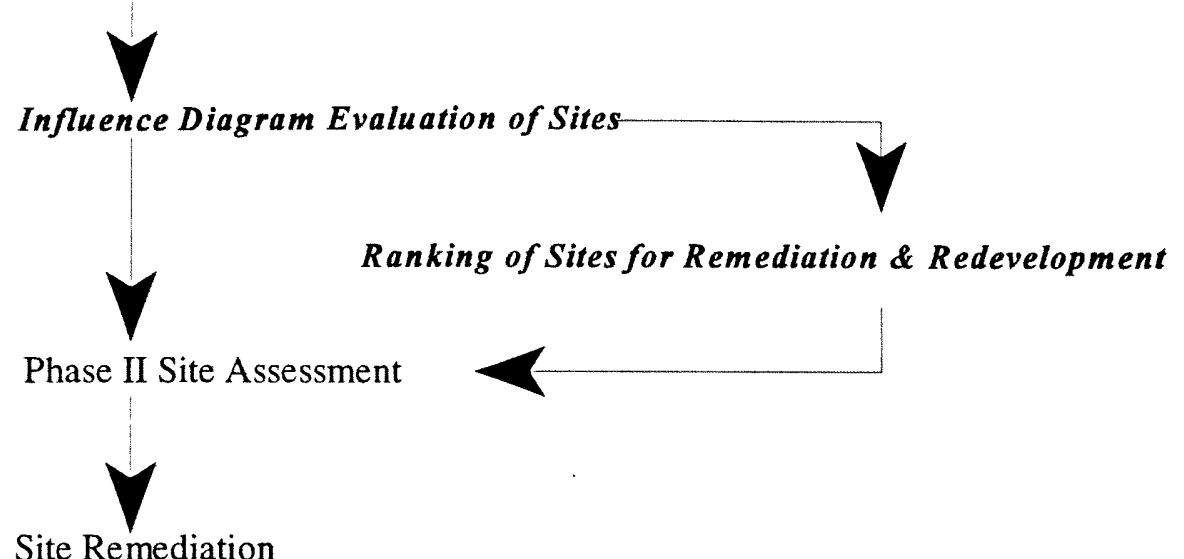

Site Remediation

Site Redevelopment

Figure 3.15: Improved Process for Brownfields Remediation and Redevelopment 


\subsection{Summary}

Brownfields decision-making typically involves the optimization of usually limited resources in the redevelopment of existing Brownfields. This objective, while straightforward, is typically complicated by several basic interrelated issues in Brownfields redevelopment, numerous stakeholders with sometimes conflicting objectives, and uncertainties arising out of the lack of adequate site-related information. Bayesian Influence Diagrams are a formal decision analytic tool that have been demonstrated as a powerful structure for modeling large and complex decision problems. They are especially useful in representing the decision problem from the decision-maker's point of view. Used in conjunction with sensitivity analyses tools, they provide a useful methodology for identifying critical variables for predetermined decision objectives and may eliminate the need for obtaining certain kinds of site-related information which are not deemed critical to a priori decision objectives. Influence Diagrams are also powerful for communicating significant relationships between important variables. In summary, they are a potentially useful tool for developing formalized Brownfields decision frameworks to depict and clarify the relationships between the significant issues in Brownfields redevelopment. They are also viable quantitative models, as is demonstrated in Chapter 5, for analyzing the redevelopment potential of different sites from a priori objectives, and ranking these sites to optimize the use of available resources for redevelopment. 
Chapter 4

Case Studies 


\subsection{Introduction to Dade County and its Brownfields Program}

Metropolitan Dade County is an urbanized area comprising 26 cities and approximately 2 million people on 2,000 square miles [1996]. It is located at the southwestern coast of Florida [Figure 4.1]. The County is situated on a sole source unconfined aquifer, (the Biscayne Aquifer), and between two national parks and in the remarkably sensitive environmental setting of the Everglades. Unique to Florida, the Everglades are an extensive sub-tropical swamp that once covered most of Florida's land mass. This feature extends from coast to coast like a broad "river of grass", and is the source of several of Florida's 30,000 and more lakes. While significant portions of the Everglades have been drained in Dade County, the feature still characterizes much of the County's landscape and is closely interwoven with the remaining ecosystem. Being such an enormous mass of water, the Everglades is in close cycle with the region's rain and ground water, and as such, any water contamination and air pollution are readily recycled throughout the ecosystem. The Biscayne Bay Aquifer, (the unconfined aquifer portion of this system), is the sole source of drinking water for the County.

Rapid urbanization began in many Floridian Cities in the 1920s. Florida seems to have stayed with this pace of growth, (if not overtaken it), up until the present time. Urbanization in Dade County came with the development of several commercial properties in an era when contamination was not strictly regulated [Irwin, 1996]. In the late 1960s the state began to experience problems with pollution. Around the same time, the state was exposed to the

burdensome effects or rapid population growth. In the decade between 1970 and 1980, 


\section{Map of Florida Showing Metropolitan Dade County}

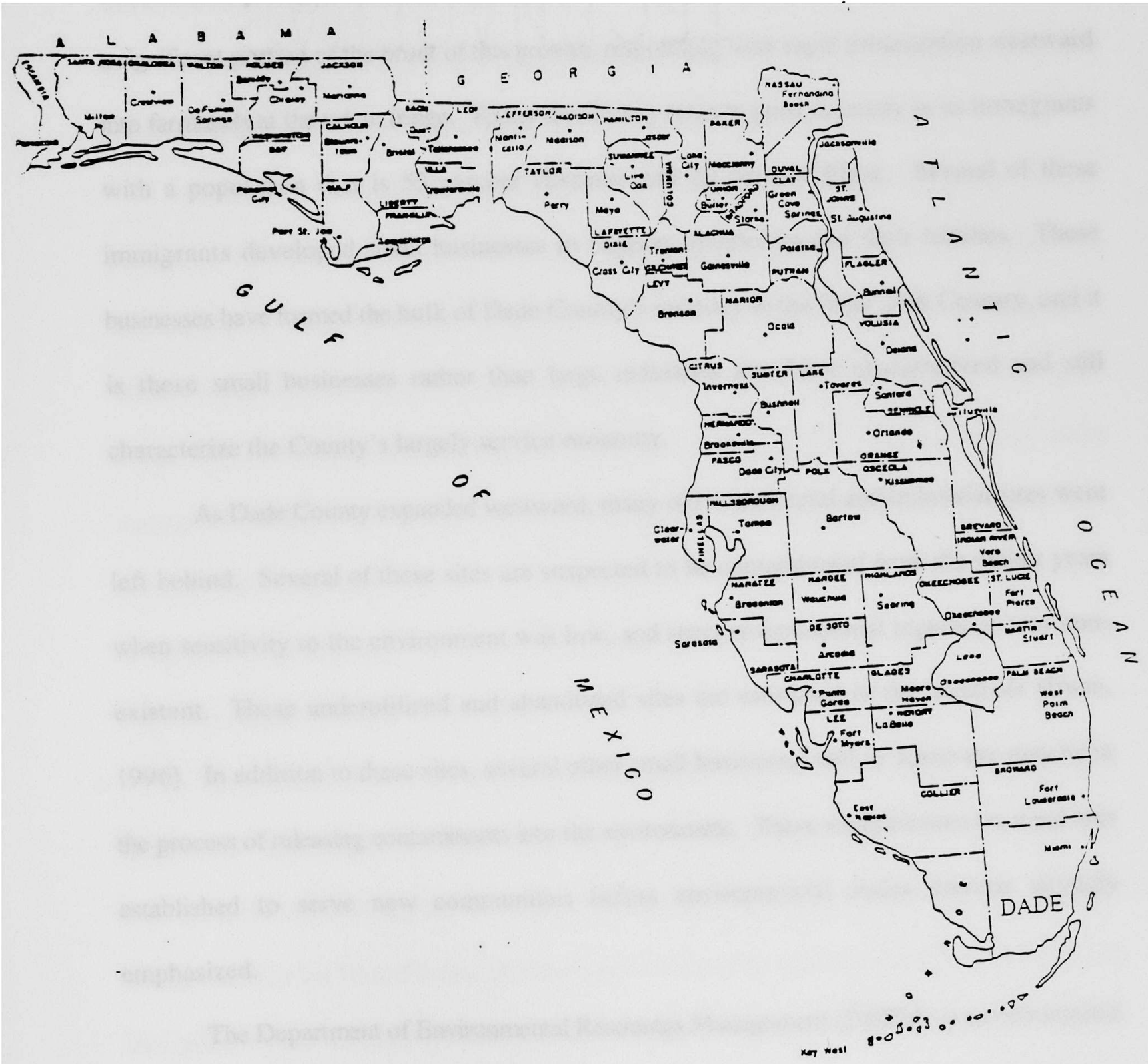

Figure 4.1 [Source: Morris. 1993-1994] 
Florida moved up from the 32nd most populous state to the nation's fourth, immigrants pouring into the state and creating great pressures on the natural and built environments. Indeed Florida's population increased by more than 900 persons a day at the peak of the 1980s boom [Longman, 1994]. In conjunction with the City of Miami, Dade County took a significant portion of the brunt of this growth, responding with rapid urbanization westward into farmlands at the urban fringe. Today the County reflects great diversity in its immigrants with a population that is 55 percent Hispanic and 20 percent Black. Several of these immigrants developed small businesses to support themselves and their families. These businesses have formed the bulk of Dade County's industry in the latter 20th Century, and it is these small businesses rather than large industries that have characterized and still characterize the County's largely service economy.

As Dade County expanded westward, many old commercial and industrial sites were left behind. Several of these sites are suspected to be contaminated from the earlier years when sensitivity to the environment was low, and strict environmental regulation was nonexistent. These underutilized and abandoned sites are estimated in the hundreds [Irwin, 1996]. In addition to these sites, several other small businesses still in active use may be in the process of releasing contaminants into the environment. These small businesses were also established to serve new communities before environmental audits became strongly emphasized.

The Department of Environmental Resources Management (DERM) is environmental regulatory agency in Dade County. DERM has disclosed that widespread groundwater 
contamination has resulted from numerous small contamination incidents and produced a significant impact on public drinking water. According to DERM, the 1985 EPA CERCLA study of the Biscayne Aquifer determined that many small industries in unsewered areas contributed to the chlorinated solvents found in the groundwater. More recently also, there have also been discoveries of chlorinated solvents in two residential communities, affecting over 600 private supply wells, and in at least one of these areas, several dry cleaning facilities were the culprits for this contamination [DERM, 1996].

In the past, DERM has used strict liability provisions to enforce cleanup orders on all properties. This active environmental restoration program has restored over 3,300 petroleum and hazardous waste contaminated cases, and over 1,500 cases have been closed to date. While this program has been successful in certain respects, like the federal Superfund Program it has also contributed to creating an inventory of orphan sites. The hazardous waste management climate in Dade County has largely been a Superfund one; as Irwin discloses [1996], even lenders are liable for site contamination. In recent years, DERM has come to recognize the inadequacy of its existing program, in the number of sites which have been left without a responsible and solvent party.

In search of a better solution to small site aquifer contamination, DERM has initiated a process to identify and redevelop Dade County's existing Brownfields. In conjunction with this initiative, DERM applied for a grant under the federal Brownfields Action Program administered by the United States Environmental Protection Agency (USEPA). If obtained, this grant would facilitate DERM's efforts in demonstrating a more successful process for 
responding to Brownfields sites. The County's Brownfields program would also serve as a model for other localities built largely on a service economy. The objectives of Dade County's proposed 2 year Brownfields Project are as follows [DERM, 1996]:

1. To establish a Brownfields Task Force for the purpose of identifying and reducing and removing impediments to Brownfields redevelopment in Dade County;

2. To build on current information in order to define a list of existing Brownfields;

3. To utilize techniques and approaches identified by the Task Force to facilitate the reuse of at least one Brownfield site during the 2 year project period with preference given to sites in or immediately influencing Dade County's designated Enterprise Communities.

4. To institutionalize the authorities, regulations, partnerships and community involvement techniques needed to maximize the redevelopment potential of Brownfields beyond the two year project period.

\subsection{Need for Brownfields Redevelopment in Dade County}

Metropolitan Dade has a limited development area primarily due to protected lands: the Everglades National Park and associated wetlands to the west, the Biscayne Bay National Park, and the Biscayne Bay to the East. Although the County contains 2,000 squared miles of area, only 900 square miles are available for development [Figure 4.2], and industrial and commercial parcels comprise only 5.5 percent of the parcels available for development [DERM, 1996]. This limited availability of land makes the redevelopment of Brownfields a 


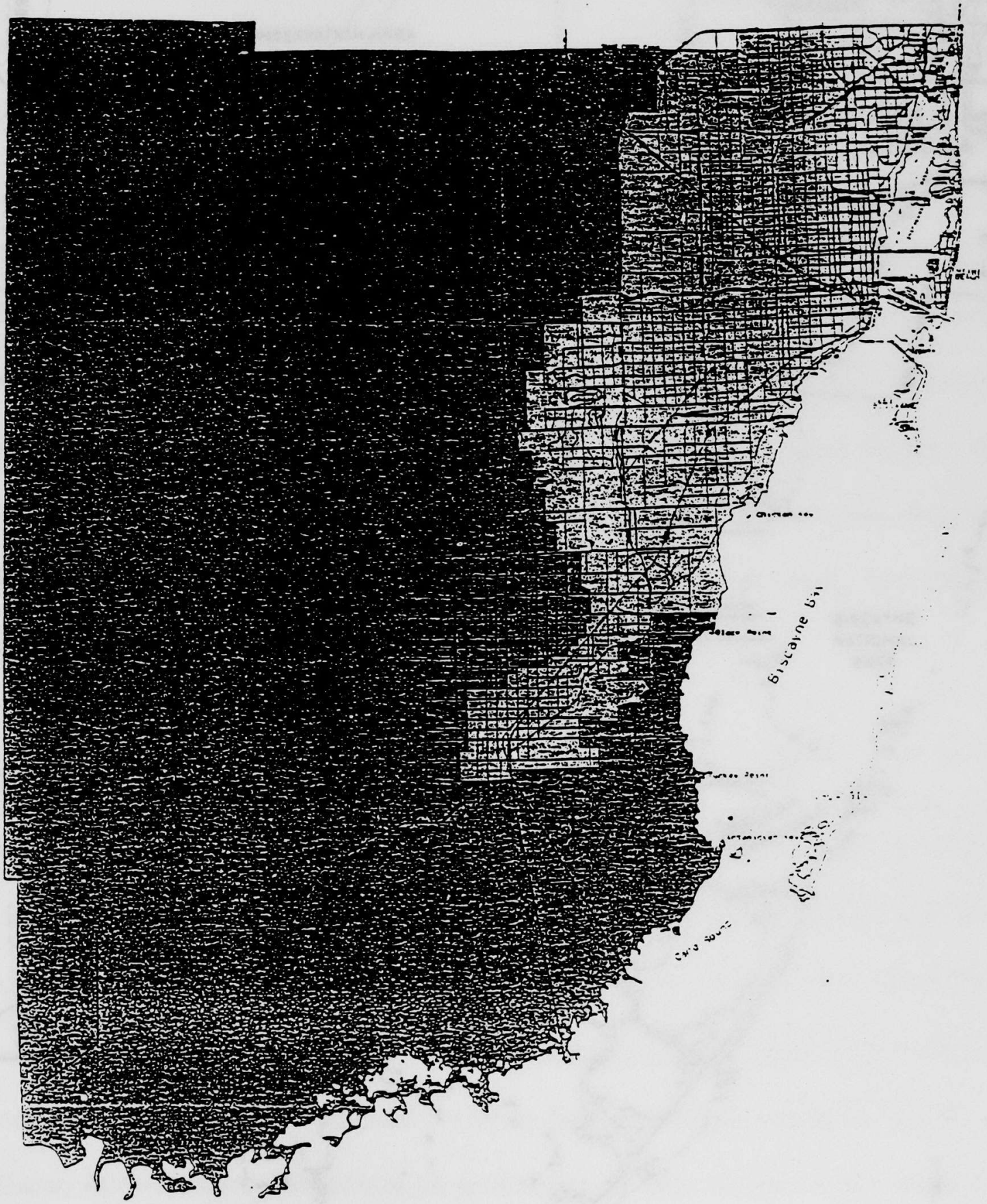




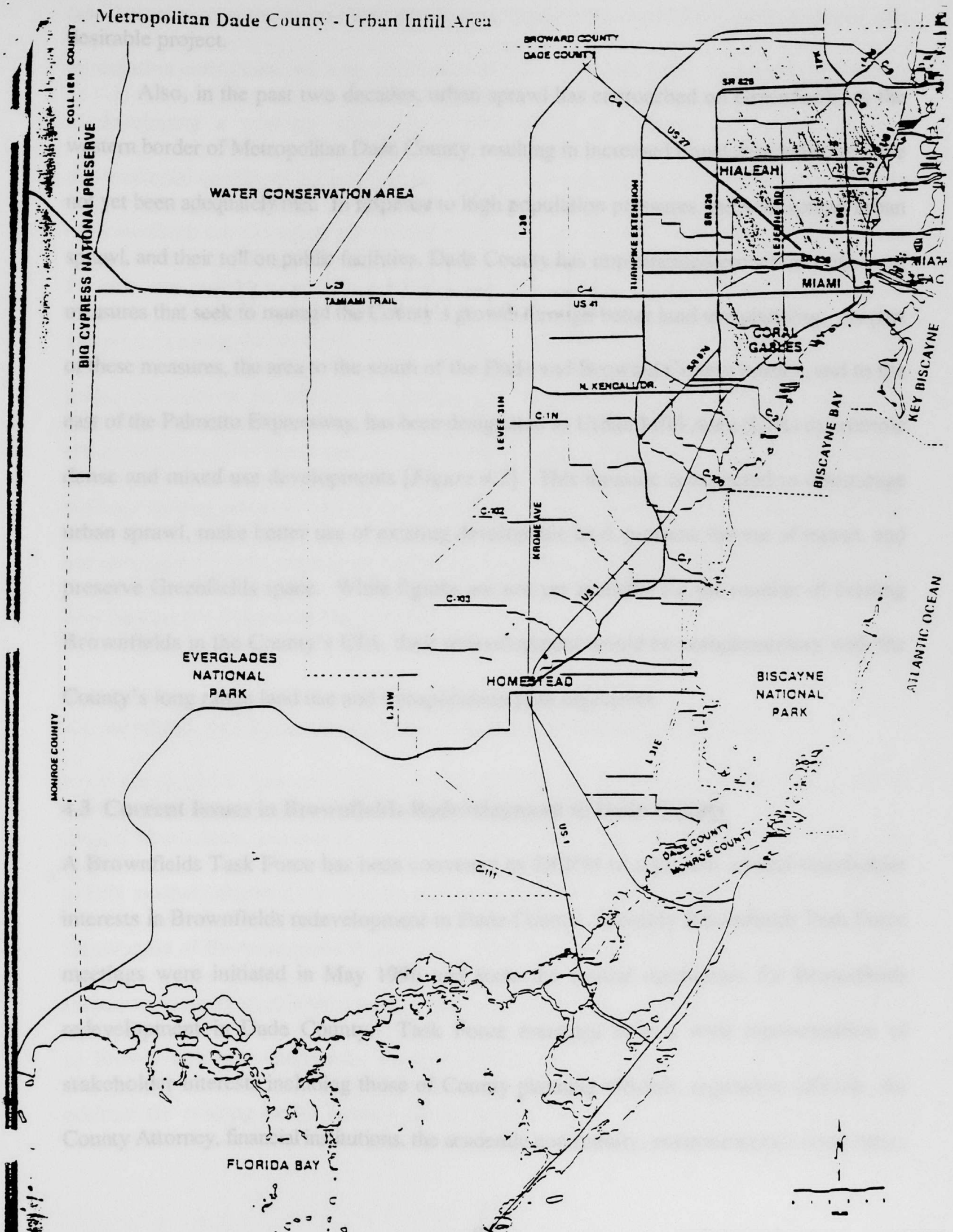


desirable project.

Also, in the past two decades, urban sprawl has encroached on Greenfields on the western border of Metropolitan Dade County, resulting in increased travel demands that have not yet been adequately met. In response to high population pressures and widespread urban sprawl, and their toll on public facilities, Dade County has implemented growth management measures that seek to manage the County's growth through better land use planning. As part of these measures, the area to the south of the Dade and Broward County border, and to the east of the Palmetto Expressway, has been designated as Urban Infill Area (UIA) to promote dense and mixed use developments [Figure 4.3]. This measure is expected to discourage urban sprawl, make better use of existing developable land, promote the use of transit, and preserve Greenfields space. While figures are not yet available for the number of existing Brownfields in the County's UIA, their redevelopment would be complementary with the County's long range land use and transportation plan objectives.

\subsection{Current Issues in Brownfields Redevelopment in Dade County}

A Brownfields Task Force has been convened by DERM to represent several stakeholder interests in Brownfields redevelopment in Dade County. Monthly Brownfields Task Force meetings were initiated in May 1996 and form the central mechanism for Brownfields redevelopment in Dade County. Task Force meetings have a wide representation of stakeholder interests including those of County planning officials, regulation officials, the County Attorney, financial institutions, the academic community, environmental conservation 
associations such as the Sierra Club, developers, engineering consultants, environmental and remediation consultants and City of Miami officials. The Task Force is primarily interested in developing a working definition of Brownfields in harmony with economic and environmental conditions in Dade County. DERM has expressed concerns that this definition of Brownfields not encourage solvent and responsible site owners to claim Brownfields status for their sites in order to avoid responsibility for site cleanup. DERM has also expressed an interest in restoring Brownfields in the County's lower income areas where such sites are an added disincentive for economic revitalization. Anticipated outputs from the Task Force efforts include a list of Brownfield areas in Dade County, a formal list of the priority sites (as well as a ranking process), interim and completed reports regarding assessment, remediation and development plans associated with at least one Brownfield site, and a description of the new process for addressing Brownfields.

\subsection{Available and Potential Resources for Brownfields Redevelopment}

From the point of view of technical issues, DERM has the in-house capacity required to oversee Brownfields assessment and remediation. The environmental regulation agency has a fully staffed laboratory to analyze ground and ground water samples following Florida Department of Environmental Protection's (FDEP's) standard operating procedures. With respect to stringent legal liability issues, there are plans to seek adjustments to legal obstacles to Brownfields redevelopment. As Irwin [1996] discloses, the Task Force has plans to address the existing lender liability rule in Dade County. In addition, there are plans to 
identify potential funding sources through public and private entities. Private funding sources may include property owners (previous, current and future), developers and lenders. Public funds may come from the County's various Enterprise Community programs.

Enterprise Communities and Empowerment Zones are examples of socio-economic and environmental justice movements sweeping the nation. In the past two decades, it has been realized that the nation's environmental laws, regulations and policies have not been applied fairly across all segments of the population. Over the years, certain individuals, groups and communities have received less protection than others because of their geographic location, race and economic status. It is generally noticeable that environmental problems in suburban areas pose far fewer health threats than do those in urban or rural areas. Specifically, low-income communities and communities of color bear a disproportionate burden of the nation's pollution problems. As a response to this bias, environmental activism has emerged in the last two decades, (largely as a grass roots movement in communities of color), to address these inequities. The purpose of this movement is to ensure that communities of color and low-income are not being exposed to relatively elevated health risks.

The situation in Dade County is no different from several others across the country. Low income communities tend to be communities of color, and have generally suffered higher exposures to environmental health risks over the years. In response to this situation, DERM has approved an Environmental Justice Plan, funded by the EPA, to address pollution prevention issues in the industrial community in Dade County. The plan is designed to 
interface with minority groups, local and industrial associations. The purpose is to provide training and workshops that will result in an awareness of environmental issues in depressed communities. The Brownfields Task Force plans to focus on enterprise communities (communities identified for their declining socio-economic conditions) and other low-income and disadvantaged communities with proximity to contaminated industrial sites. Examples of such communities may be found in the City of Opa-Locka, Homestead (Homestead Empowerment Zone), the Melrose Empowerment Zone, the Overtown Empowerment Zone, the Allapattah Empowerment Zone, and Liberty City (Empowerment Zone). As part of its long range planning objectives, Dade County has already began providing infrastructure improvements in such communities, including water and sewer lines as well as road and mass transit upgrading.

\subsection{Case Studies - Liberty City and the Poinciana Industrial Center Brownfields Sites}

Liberty City is located in the northern section of Dade County. It is an economically depressed City with a history of little economic development. Currently unincorporated, portions of Liberty City, including the City's Empowerment Zone, lie in Dade County's Model City Area. Dade County's Model City is a 7.3 square mile designated area near the center of urbanized Dade County. The Model City is part of the federal Model Cities Program, an effort to coordinate educational, social, economic and physical planning in concentrated areas. Florida's Model City Program is organized according to federal guidelines and involves the efforts of individuals, private organizations and the local 
County Map Showing Mode! Cities Area

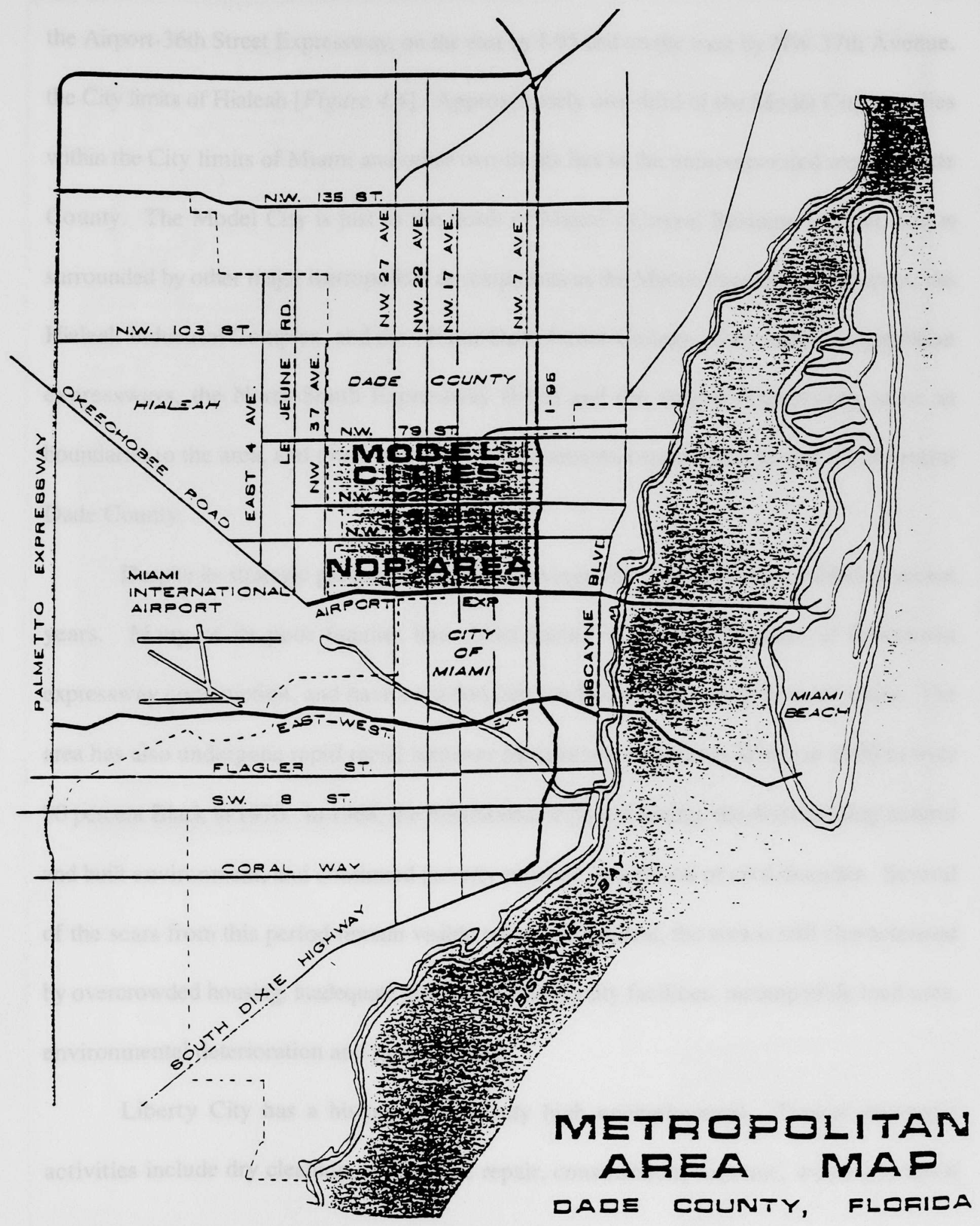

Figure 4.4 
government. The Model City is bounded on the north by NW 79th Street, on the south by the Airport-36th Street Expressway, on the east by I-95 and on the west by NW 37th Avenue, the City limits of Hialeah [Figure 4.4]. Approximately one-third of the Model City area lies within the City limits of Miami and other two-thirds lies in the unincorporated area of Dade County. The Model City is just to the north of Miami's Central Business District, and is surrounded by other major metropolitan developments as the Miami International Airport, the Hialeah Industrial Complex, and the Miami-Dade Junior College. Two major metropolitan expressways, the North-South Expressway (I-95) and the Airport Expressway serve as boundaries to the area, and numerous other traffic arteries connect this area to all of central Dade County.

Despite its strategic geographic location however, this area has been troubled in recent years. Many of its poor families have been forced to relocate because of downtown expressway construction, and have crowded into too few and too small housing units. The area has also undergone rapid racial turnover from nearly two-thirds White in 1950 to over 90 percent Black in 1970. In 1968, the frustrations of poor housing, the deteriorating natural and built environment, and continued poverty resulted in a period of civil disorder. Several of the scars from this period remain visible today. In general, the area is still characterized by overcrowded housing, inadequate public and community facilities, incompatible land uses, environmental deterioration and mass poverty.

Liberty City has a history of relatively high unemployment. Typical economic activities include dry cleaning, automobile repair, construction, concrete, wood and metal 

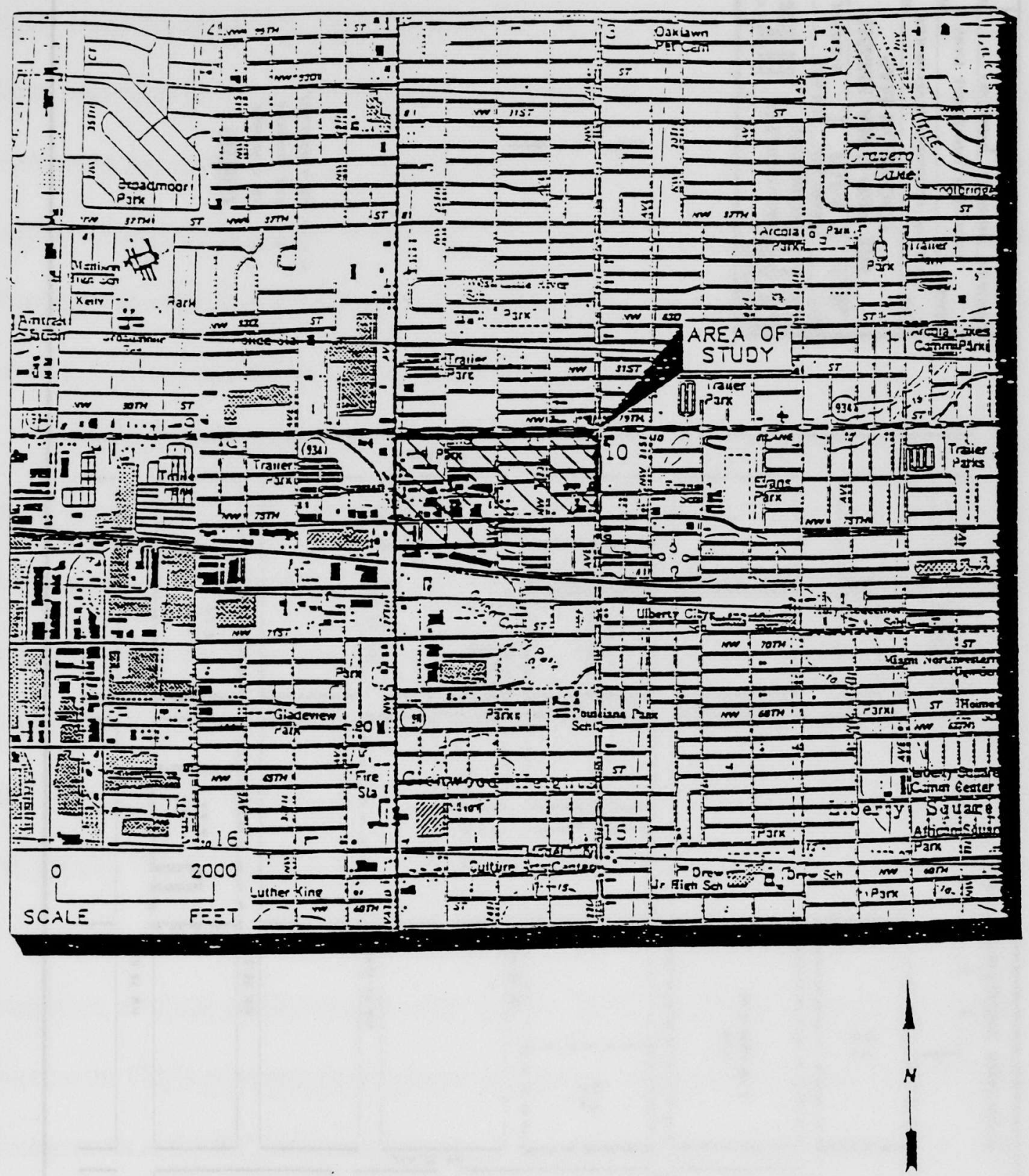

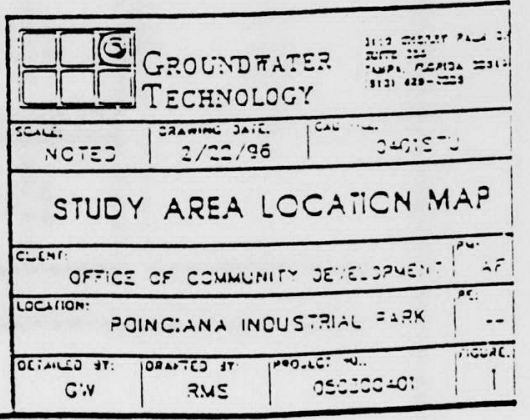

Figure 4.5 


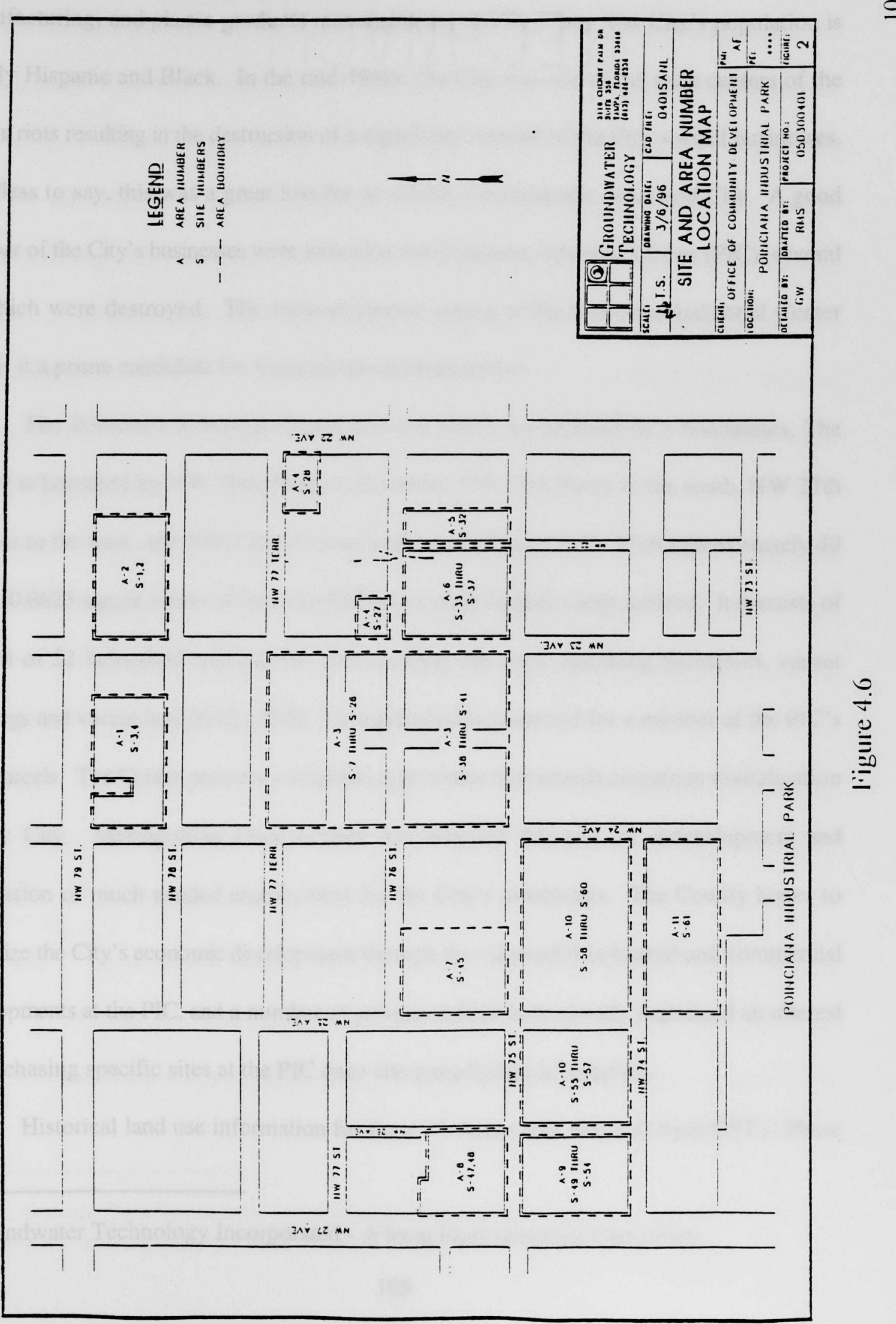


manufacturing, and plastic products manufacturing and recycling. The City's population is largely Hispanic and Black. In the mid-1980s, the City was one of the main centers of the Miami riots resulting in the destruction of a significant number of the City's small businesses. Needless to say, this was a great loss for an already economically depressed City. A good number of the City's businesses were located at the Poinciana Industrial Center (PIC), several of which were destroyed. The socio-economic setting of the Poinciana Industrial Center makes it a prime candidate for Brownfields redevelopment.

The Poinciana Industrial Center also lies within the Model City's boundaries. The Center is bordered by NW 79th Street to the north, NW 73rd Street in the south, NW 27th Avenue to the west, and NW 22nd Avenue in the east [Figure 4.5]. With approximately 40 acres ( 0.0625 square miles) of land, the PIC is currently largely under utilized. It consists of a total of 52 individual land parcels, and currently has some operating businesses, vacant buildings and vacant land [GTI, 1996]. Contamination is suspected for a number of the PIC's land parcels. The Center presents a blighted appearance that retards economic revitalization in any City. Metropolitan Dade County has acquired this site for redevelopment and generation of much needed employment for the City's inhabitants. The County hopes to revitalize the City's economic development through the successful industrial and commercial developments at the PIC, and a number of private entities have already expressed an interest in purchasing specific sites at the PIC once site remediation is complete.

Historical land use information for these 11 Areas was obtained from GTI's ${ }^{1}$ Phase

${ }^{1}$ Groundwater Technology Incorporated - A local Environmental Consultant. 
I Assessment Report for the Poinciana Industrial Center, through the Department of Environmental Resources Management (DERM). The Center's 52 land parcels have been grouped into 11 different Areas by the 1995 Industrial Park Land Inventory List as is shown in Figure 4.6. The GTI review was performed by conducting site investigations of these Areas including visual non-intrusive surveys of potential asbestos and PCB-containing materials, document reviews including topographic maps and aerial photographs, and reviews of the history of properties including the resources of a local environmental computer database firm (Environmental Data Resources, Inc. ${ }^{2}$ ), and the city directory. The GTI report was reviewed for the following purposes:

(1) To create a database from the land use information on the 11 designated Areas, a process which involved defining the decision objectives and associated variables that might be used in developing the decision analytic model for Brownfields ranking.

(2) To select a number of individual sites which collectively demonstrate the varying degrees of site contamination to be found within the PIC, and to develop relevant case histories for these sites; and finally,

(3) To develop a customized decision analytic model for analyzing and ranking these sites from the point of view of their respective redevelopment potentials.

As is shown in Table 4.1, a database was developed for all the 11 designated Areas in the

${ }^{2}$ Environmental Data Resources, Inc. furnishes computerized state and federal records regarding environmental conditions at specific sites. 


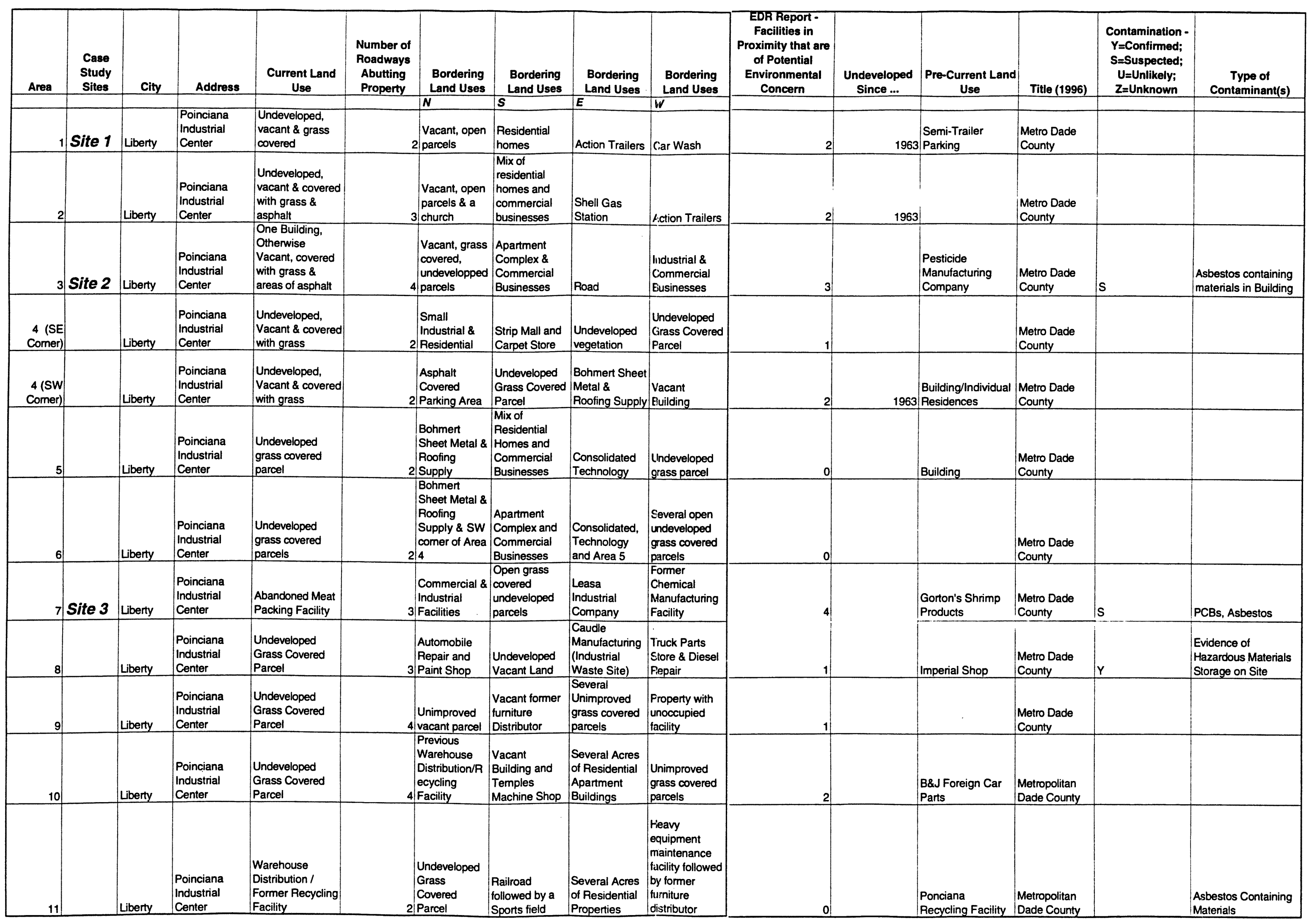


PIC, depicting the various site conditions to be found in the PIC. From this database, Areas 1, 3 and 7 were selected for ranking and renamed Sites 1,2 and 3 respectively. A customized decision analytic model will be developed to rank these sites in the order of their redevelopment potential. Land use case histories for the three selected sites are documented below [GTI, 1996]:

\subsubsection{Site 1 [Also Area 1]}

Current Site and Bordering Land Uses

Site 1 [Figure 4.7] is bordered by NW 79th Street followed by vacant open parcels to the north, NW 78th Street followed by residential homes to the south, Action Trailers, followed by NW 23rd Avenue to the east, and NW 24th Avenue followed by a car wash to the west. The current land use is undeveloped, vacant and grass covered. While there was no evidence of hazardous materials storage on the site, areas of dark stained soil were noted along the western border of this area. Small piles of miscellaneous debris, including concrete and cardboard, were noted along the eastern portion of the property. Also, areas of concrete flooring with steel I-beams embedded were noted at the south central area of the property. The Environmental

Database Review $(\mathrm{EDR})^{3}$ radius report notes two adjacent properties to be of potential environmental concern.

\footnotetext{
${ }^{3}$ The EDR City Directory Abstract is a screening tool designed to assist professionals in evaluating potential liability on a target property from past activities on a property or adjoining properties.
} 


\section{Historical Land Uses}

The property has not been developed since 1963 according to a review of aerial photographs. In 1963 the land appears to have been used for parking semi-trailers; in other years it was an open, grass covered area. From the review of the city directory, specific land usages were not indicated other than residential.

\subsubsection{Site 2 [Also Area 3]}

\section{Current Site and Bordering Land Uses}

Site 2 [Figure 4.8] is bordered by NW 77th Terrace followed by vacant, grass covered, undeveloped parcels to the north, NW 75th Street followed by a mix of residential homes (apartment complex) and commercial businesses to the south, NW 23rd Avenue to the east, and NW 24th Avenue followed by a mix of industrial and commercial businesses to the west.

The current land use is developed with one building located at the northeast corner area. Piles of miscellaneous debris of concrete and asphalt were noted on the south side. In addition, concrete footers with steel I-beams still embedded were noted at the southeast section of the property. According to the EDR radius report, two adjacent properties are noted to be of potential environmental concern. No subsurface remediation systems or groundwater monitoring wells were determined during a walk over of the property, other than the required (tank-pit) compliance wells associated with the gas station. A cement-block and painted building is located 
at the north east area, currently being used as an office. The building was already built in 1963, based on a review of aerial photographs, leading to a concern for asbestos containing materials.

According to the EDR radius report, three properties in the vicinity are of potential environmental concern, namely, the building described above, as well as another building are listed as RCRA small quantity generators. Previously located at the southwest corner of Area 3, the third building of concern was a pesticide manufacturing facility that no longer exists.

\section{Historical Land Uses}

From a review of aerial photographs, this site has been developed since 1963 with residential homes along the north, and industrial type facilities at the northeast and southwest corner areas. The city abstract review notes that the residential area was present until 1985. In the 1990 aerial photograph, it is observed that the residential area is no longer present: it has been developed into a four lane road. The currently existing building seems to have been in place since approximately 1985 . Prior to this time, the area was developed as a mix of residential and manufacturing land uses.

\subsubsection{Site 3 [Also Area 7]}

Current and Bordering Land Uses

Site 3 [Figure 4.9] is bordered to the north by NW 76th Street followed by 
commercial and industrial facilities, to the south by NW 75 th Street followed by open grass covered undeveloped parcels, to the east by Leasa Industrial Company followed by NW 24th Avenue, and to the west by NW 25th Avenue followed by a former chemical manufacturing facility. The current land use is developed with an abandoned meat packing facility: a building of approximately 300,000 square feet including former office, packaging and cold storage areas.

Several 55-gallon steel drums were located both inside and outside the facility. Sampling of the drums for waste stream determination and disposal characterization led to the identification of four separate waste streams: used oils, waste waters, possible asbestos fibers, and surfactants. Several rooms in the facility had lights with pre-1964 ballasts that could contain PCBs. In some of the rooms in the building, formerly used as office space, the ceiling tiles appear to have the characteristics of asbestos containing materials. Miscellaneous trash and debris were also observed, including empty automobile gas tanks along the east perimeter. According to the EDR radius report, four adjacent properties were noted to be of potential environmental concern, including one TSCA site and two LUST sites.

\section{Historical Land Uses}

Aerial photographs of the area indicate that since 1963, this area has been developed as it appears today. Maps show that the area was occupied by a food processing and cold storage facility during the mid $50 \mathrm{~s}$ and $60 \mathrm{~s}$. According to the city abstract 
review, a shrimp products company occupied the facilities from 1970. No documentation exists after 1985 . 


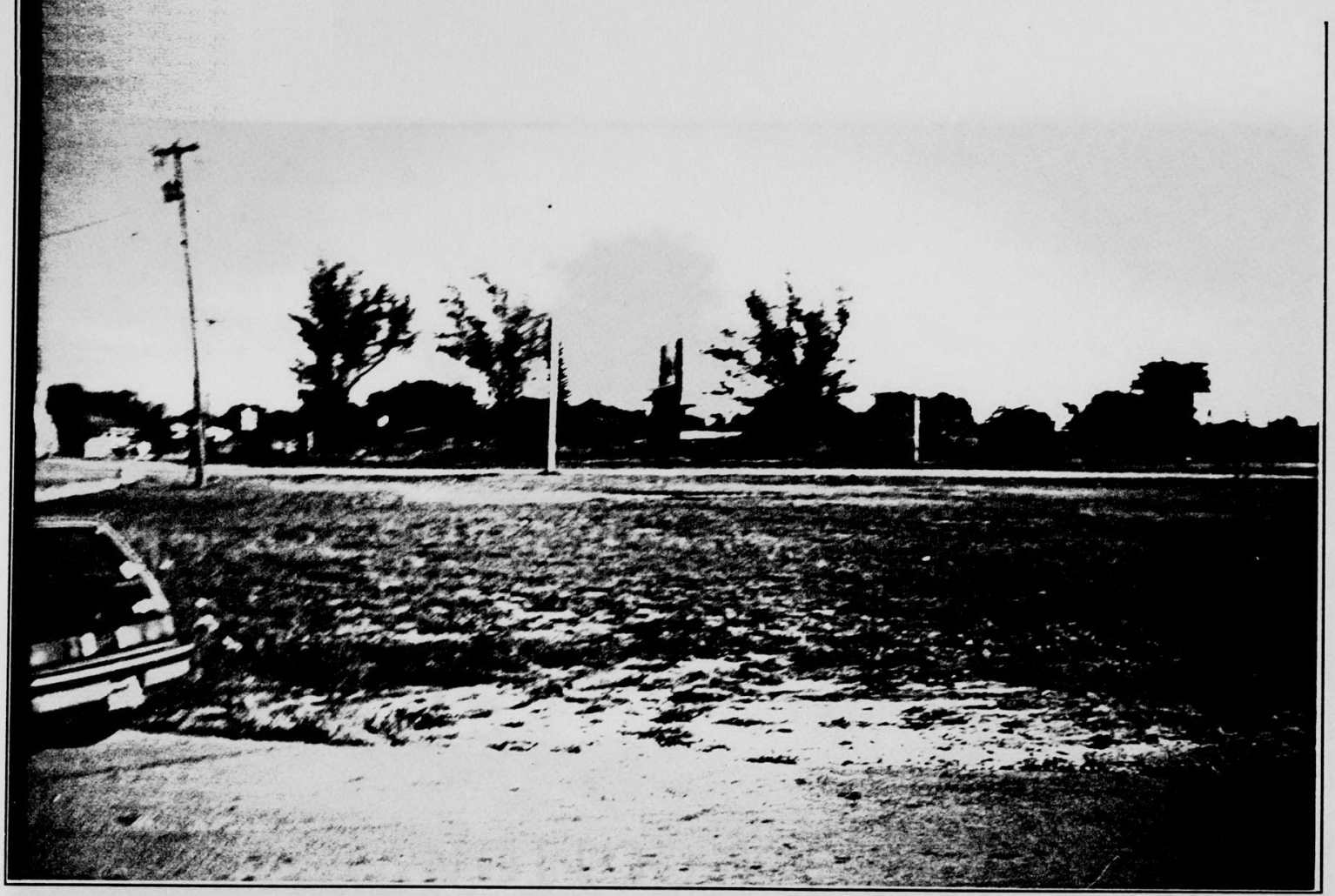

\section{Figure 4.7: Site 1}

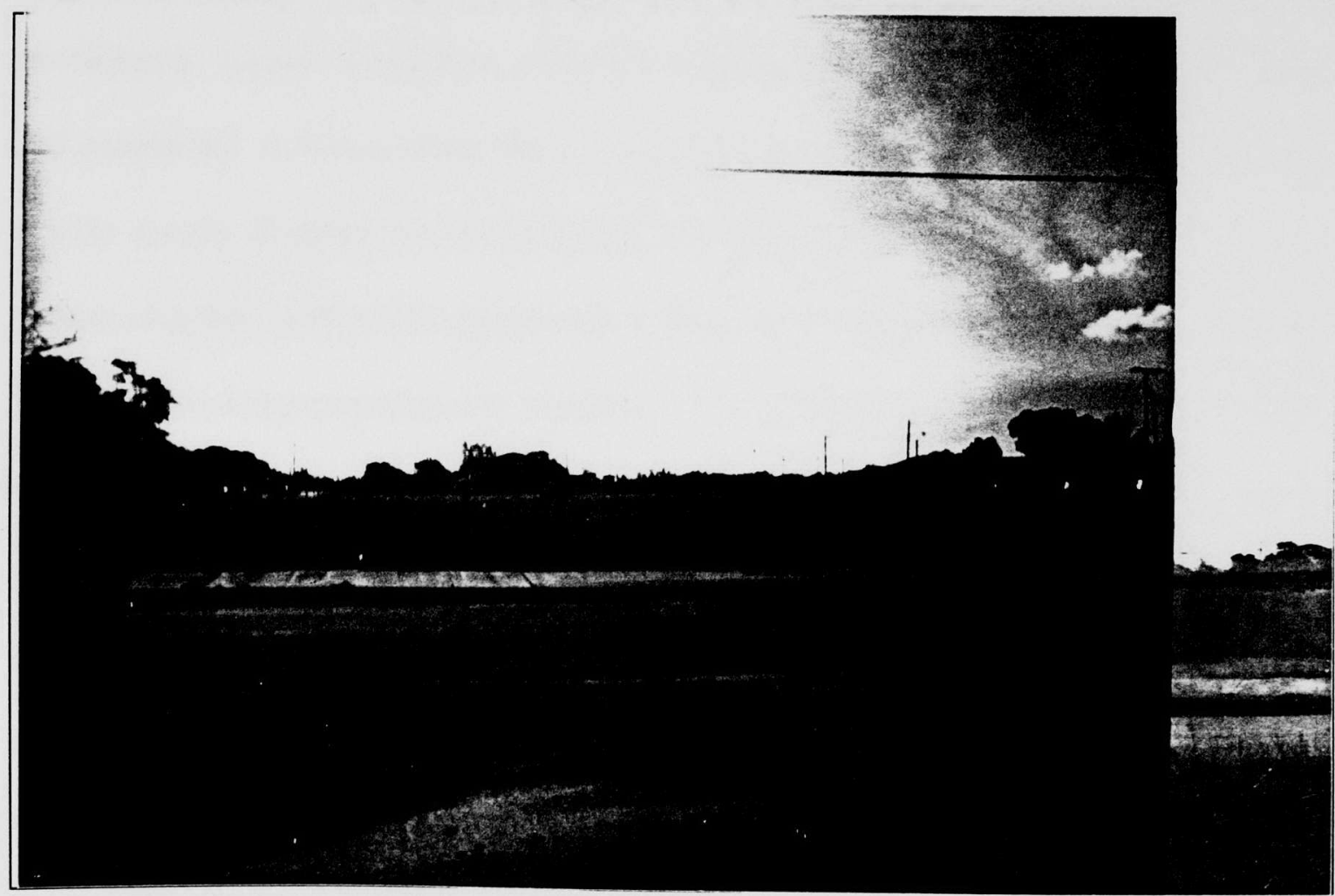

Figure 4.8: Site 2 


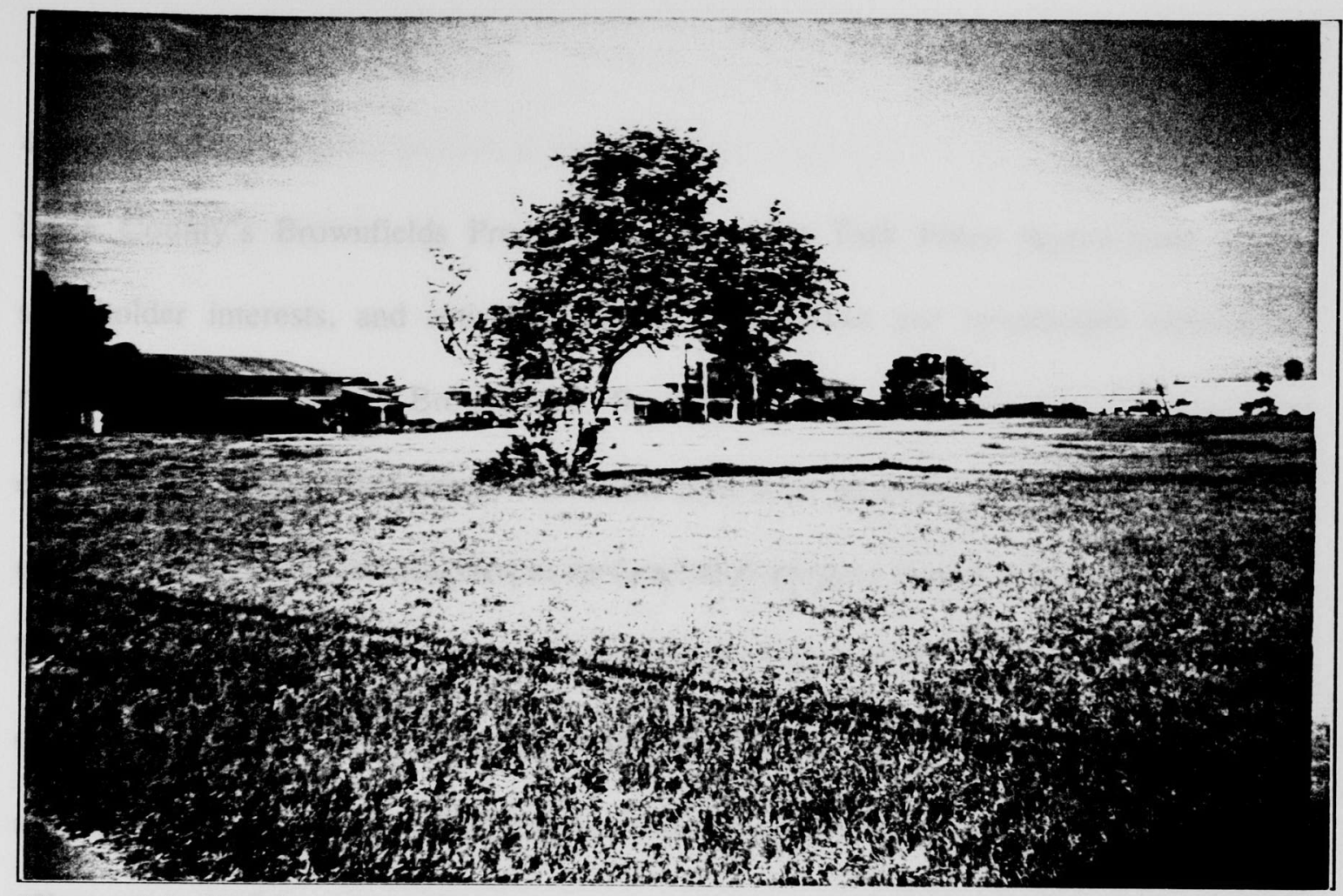

Figure 4.9: Site 3 


\subsection{Summary}

Dade County's Brownfields Program consists of a Task Force representing several stakeholder interests, and actively pursuing an effective and transferable method for redeveloping the County's Brownfields. Priority will be given to sites in economically and environmentally depressed areas. One such area is to be found in Liberty City, a highunemployment City of color located in the heart of Urbanized Dade County. The Poinciana Industrial Center is a 40 acre complex, located in the City, which has suffered from the riots of the 1980s and currently poses socio-economic and environmental health threats to the surrounding neighborhoods. Metropolitan Dade County has recently acquired the PIC in an effort to remediate and redevelop its sites for the provision of jobs and economic revitalization. As part of this effort, a Phase I Assessment of the PIC's sites has been funded and completed. A review of the Phase I Assessment report indicates that the PIC contains a wide variety of sites from the perspective of environmental contamination. Already, a number of private entities have expressed an interest in purchasing specific tracts of land once their environmental remediation is completed. The question as to who pays for the usually expensive remediation processes still lingers. In the likelihood that no solvent and responsible parties are found for the sites, creative methods will have to be developed to extend limited resources in financing the remediation of these sites. A revolving fund or similar funding mechanism could maximize the use of limited resources if site remediation could be performed in an order that prioritized those sites with the highest potential to return the costs of remediation, as well as anticipated socio-economic gains for the City. The next Chapter 
develops and customizes a decision analytic model for ranking these sites in the order of their redevelopment potential. 
Chapter 5

Model Development ANd RANKING OF SiteS 


\subsection{Decision Model Development for the PIC Sites}

Decision modeling begins with defining the problem to be solved and developing a decision structure that best represents the decision-maker's perception of the problem and potential solution alternatives. The proposed methodology involves the combination of four major components in developing a Brownfields Ranking Models with the capability of ranking given inventories of Brownfields sites:

(I) Influence Diagrams;

(II) Sensitivity Analysis;

(III) Decision Objectives and Associated Variables, and

(IV) Decision Variable Relationships

As illustrated in Figure 5.0-A these four components comprise the major elements of a Brownfields Ranking Model. Chapter 2 provides an overview of Influence Diagrams and Sensitivity Analysis as Decision Analytic Tools. Influence Diagram are the major building blocks of the Ranking Model and Sensitivity Analysis tools are useful in refining the model. The following sections explain the significance of the third and fourth components of the model.

\subsubsection{Identifying Decision Goals, Supporting Objectives and Decision Variables}

A Decision Analytic Model depicts, analyzes and helps to refine the way in which a decision-maker thinks about a problem. Fundamentally, it models the goals, objectives and important variables in a decision, and the relationships between these 


\section{Decision Analytic Models}

\section{Model Refinement Tools}

*Influence Diagranis

*Decision Trees

\section{Brownfields Ranking}
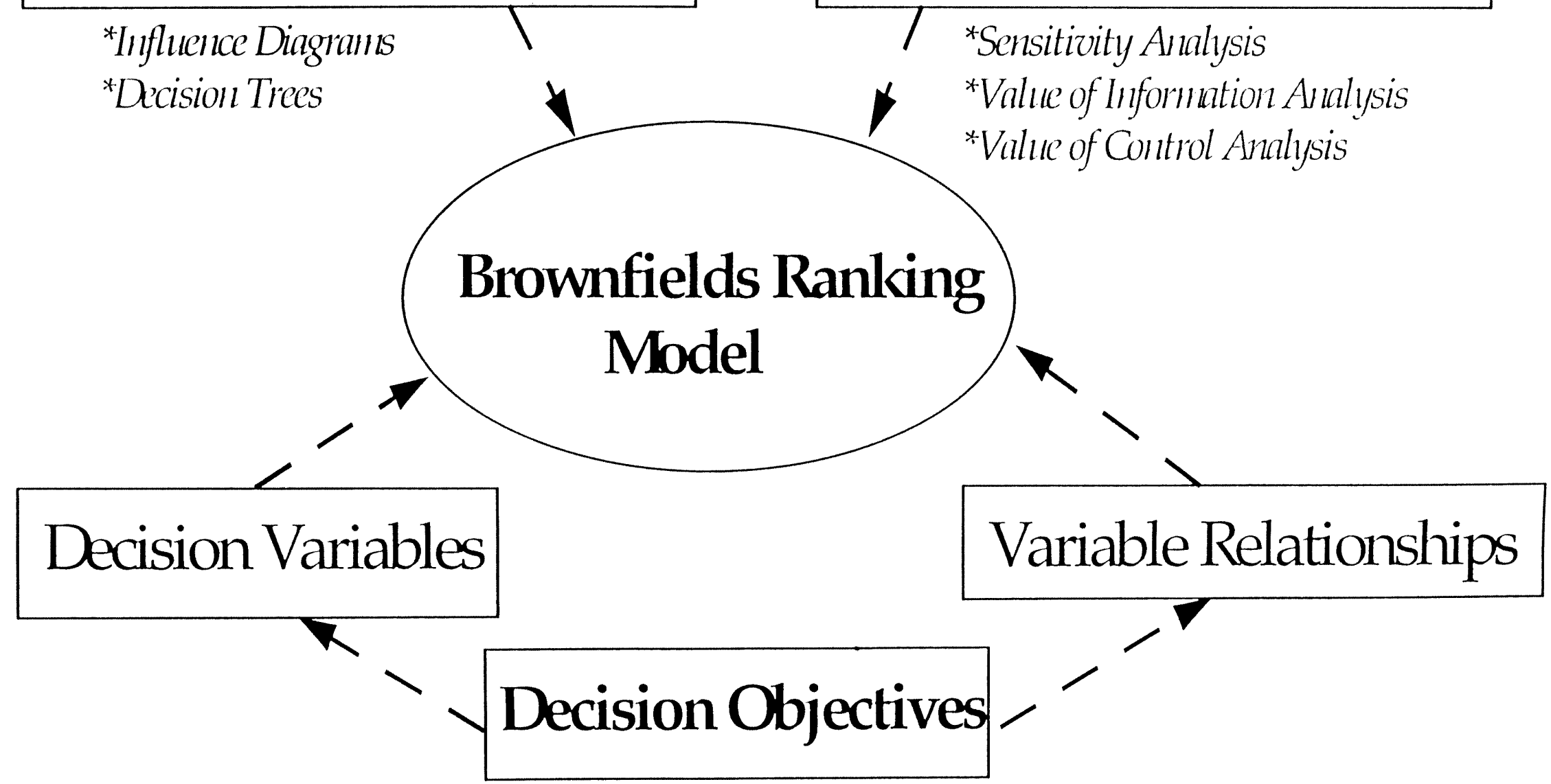
variables, as perceived by the decision-maker. The goal of decision-making for the Poinciana Industrial Center sites is to be able to rank the sites in the order of their attractiveness from the perspective of redevelopment potential. Thus the first question to be asked is how we measure this "redevelopment potential". We may do so by considering the important development factors identified from the socioeconomic case study on Liberty City and the PIC (see Chapter 4). It is clear that providing jobs and revitalizing the economy are two major objectives for the City in redeveloping its vacant and underused sites. Hence these criteria may be used as desired objectives (or decision objectives) in ranking the PIC sites. Correspondingly, we define two variables: Jobs_Factor and Economic_Link_Potential_Factor, to be used as measures for rating the PIC sites. The former factor is related to the potential for a site to provide some of the much needed jobs in the community. This factor will be related to the future use of the site as well as the site's accessibility to potential labor. The latter factor is related to the land use compatibility of the future use of the site with existing land uses in the area. For instance, since automobile mechanics and metal manufacturing facilities are historically characteristic of the Liberty City area, a metal recycling facility would be rated higher on this factor than say a storage warehouse because the former has more potential links to the City's economic activities, and hence a stronger potential to revitalize the City's economy. It is also clear from the study on Dade County (see Chapter 4) that sites within Environmental Justice areas will be given a preference over other sites, with respect to funding and 
other resources that aid in site redevelopment. Hence we may define another variable: the Environmental_Justice_Zoning_Factor, so to speak, as one of the criteria to be used in ranking the PIC sites. Likewise, it clear that some sites may be contaminated and require remedial action before redevelopment could proceed. Site remediation costs are usually very high and a huge obstacle to site redevelopment. Thus we define yet another variable, the Remediation_Cost_Factor, to be used in rating the sites on the basis of their contamination status. We could refer to these factors collectively as "redevelopment potential measures", and observe that they fall into the two broader categories of environmentally-related, and economically-related measures. The environmentally-related measures are connected to the contamination status of the sites and translate into resources to be expended in remediating these sites. The economically-related measures, on the other hand, are linked to the future gains expected from redeveloping these sites. The difference between these two sets of measures could provide some idea of how redevelopable each site is.

Identified variables may also be classified as independent (explanatory) and dependent (derived) variables. Independent variables are those variables which do not depend on any other variables for their values. Dependent variables on the other hand will be estimated from one or more independent variables as shown in Figure 5.0-B. For example, the Site_Contamination_Potential_Factor is estimated from the site's current, former and bordering land uses. Using these primary or independent variables, we develop linkages to derive secondary variables and other higher level 
variables so that we ultimately estimate the value of the Redevelopment_Potential_Factor. Figure 5.0-B depicts the linkages between model variables and differentiates between independent and dependent variables. Table 5.I lists and explains our inventory of identified independent redevelopment potential measures for the Ranking Model for the PIC, both environmental and economic. These measures are modeled as variables in the Influence Diagram, because they have varying states or conditions for the different sites.

Decision variables must represent points of difference rather than points of similarity between the sites to be ranked. Thus, if the sites to be ranked are subject to the same set of legal liabilities for example; then they cannot be differentiated based on this measure. The variables that compose the model must measure differences rather than similarities between the sites to be ranked, because the sites will be ranked on the basis of their relative differences in selected attributes.

A relative point system is developed to assign numeric values to variable states using an incremental point per state. Thus the points assigned to each variable state increase collaterally with the benefits of each different variable state to our decision objectives. This implies that the optimal state value for each variable is the total number of significant states held by the variable (i.e., the optimal value that a variable may assume is the total number of valued states held by that variable). Table 5.2 provides detailed information on the possible states that may be assumed by the independent variables defined in Table 5.1, and the corresponding values assigned to 


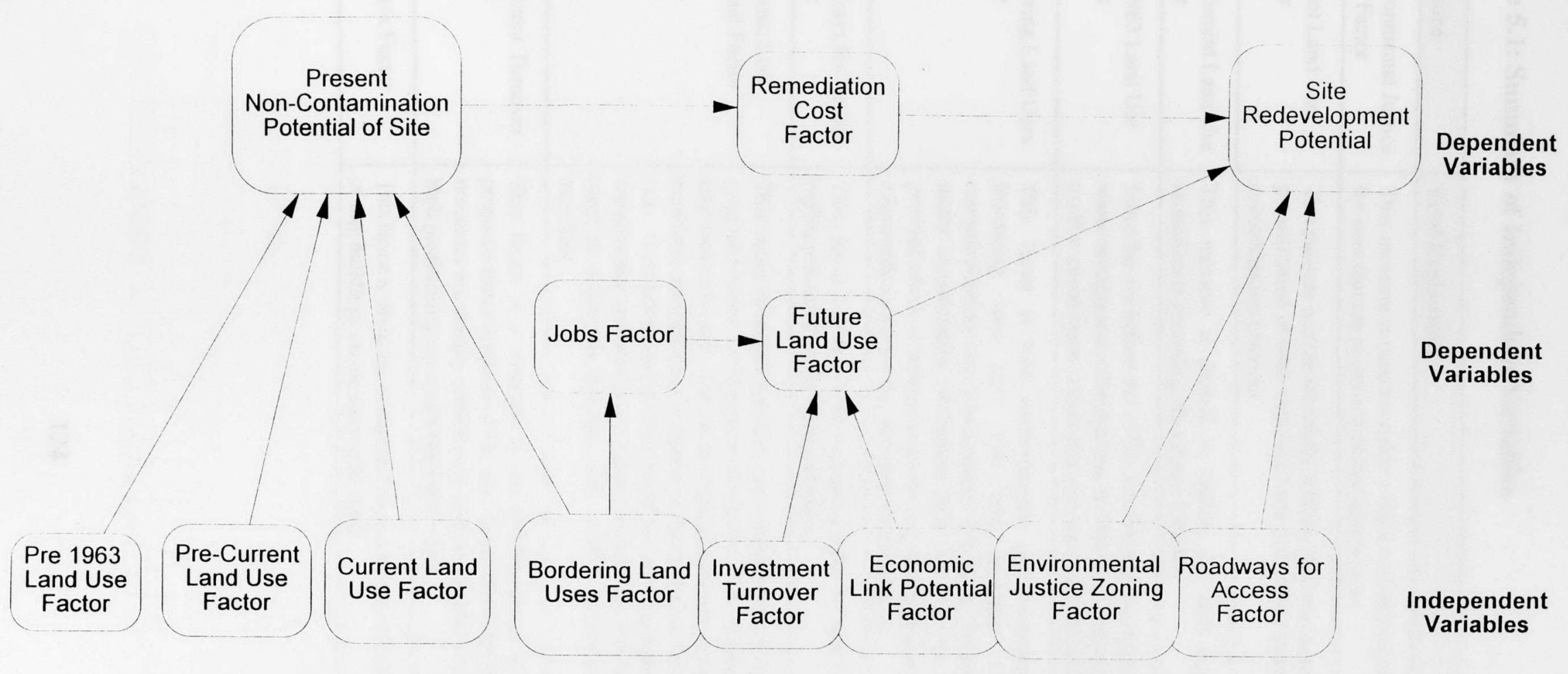

Figure 5.0-B: Dependent and Independent Variables 
Table 5.1: Summary of Independent Variables

\begin{tabular}{|c|c|c|c|}
\hline Measure & Brief Explanation & Environmental & Economic \\
\hline $\begin{array}{l}\text { Environmental Justice } \\
\text { Zone Factor }\end{array}$ & $\begin{array}{l}\text { This measure is used to enable a higher priority rating } \\
\text { for sites that are in environmental justice areas }\end{array}$ & $\mathrm{Y}$ & $\mathrm{N}$ \\
\hline $\begin{array}{l}\text { Current Land Use } \\
\text { Factor }\end{array}$ & $\begin{array}{l}\text { This measure is environmentally related, enabling higher } \\
\text { prioritization of sites with land uses that have a lower } \\
\text { contamination potential. }\end{array}$ & Y & $\mathrm{N}$ \\
\hline $\begin{array}{l}\text { Pre-Current Land Use } \\
\text { Factor }\end{array}$ & $\begin{array}{l}\text { This measure is defined to capture site land uses } \\
\text { immediately preceding the current land use. }\end{array}$ & $\mathrm{Y}$ & $\mathrm{N}$ \\
\hline $\begin{array}{l}\text { Pre-1963 Land Use } \\
\text { Factor }\end{array}$ & $\begin{array}{l}\text { Since the era before the } 1970 \mathrm{~s} \text { was without hazardous } \\
\text { waste management and regulation, this factor is designed } \\
\text { to allow penalization of industrial site uses prior to } 1963 \text {. }\end{array}$ & Y & $\mathrm{N}$ \\
\hline $\begin{array}{l}\text { Bordering Land Uses } \\
\text { Factor }\end{array}$ & $\begin{array}{l}\text { This factor is both environmental and economic. } \\
\text { Bordering land uses with high potential for } \\
\text { contamination are also contamination threats for the site } \\
\text { under consideration. Bordering land uses that are a } \\
\text { potential source of human resources (e.g. residential) are } \\
\text { a favorable factor for the site under consideration. }\end{array}$ & $\mathrm{Y}$ & $\mathrm{Y}$ \\
\hline $\begin{array}{l}\text { Roadways for Access } \\
\text { Factor }\end{array}$ & $\begin{array}{l}\text { This factor enables more accessible sites to receive } \\
\text { higher prioritization for redevelopment. }\end{array}$ & $\mathrm{N}$ & $\mathrm{Y}$ \\
\hline $\begin{array}{l}\text { Economic Link } \\
\text { Potential Factor }\end{array}$ & $\begin{array}{l}\text { This factor measures the land use compatibility of the } \\
\text { proposed future development of the site with existing } \\
\text { land uses in the area. The factor is thus a measure of the } \\
\text { economic revitalization potential of the proposed land } \\
\text { use. A recycling facility that would use existing metal } \\
\text { manufacture facilities as a resource for example will be } \\
\text { rated to reflect its linkages with existing economic } \\
\text { activities. }\end{array}$ & $\mathrm{N}$ & $\mathrm{Y}$ \\
\hline $\begin{array}{l}\text { Investment Turnover } \\
\text { Factor }\end{array}$ & $\begin{array}{l}\text { This factor is a measure of the profitability of the } \\
\text { proposed future land use of the site. Since Brownfields } \\
\text { resources are usually limited, site redevelopments with } \\
\text { high profitability are commensurately rated. }\end{array}$ & $\mathrm{N}$ & $\mathrm{Y}$ \\
\hline Asbestos Factor & $\begin{array}{l}\text { This factor is designed to capture the asbestos condition } \\
\text { of any buildings on the sites to be rated. }\end{array}$ & $\mathrm{Y}$ & $\mathrm{Y}$ \\
\hline
\end{tabular}


Table 5.2: Independent Variables, States and Values

\begin{tabular}{|c|c|}
\hline \multicolumn{2}{|l|}{ 1. Environmental Justice Zone Factor } \\
\hline States & Values \\
\hline Environmental Justice Zone & \\
\hline Non-Environmental Justice Zone & 1 \\
\hline \multicolumn{2}{|l|}{ 2. Current Land Use Factor } \\
\hline States & Values \\
\hline \multicolumn{2}{|l|}{ Residential } \\
\hline \multicolumn{2}{|l|}{ Vacant/Underused Industrial with no Suspected Contamination } \\
\hline \multicolumn{2}{|l|}{ Vacant/Underused Industrial with Suspected Contamination } \\
\hline \multicolumn{2}{|l|}{ Vacant/Underused Industrial with Confirmed Contamination } \\
\hline \multicolumn{2}{|l|}{ 3. Pre-Current Land Use Factor } \\
\hline States & Values \\
\hline Residential & 4 \\
\hline Vacant/Underused Industrial with no Suspected Contamination & 3 \\
\hline Vacant/Underused Industrial with Suspected Contamination & 2 \\
\hline Vacant/Underused Industrial with Confirmed Contamination & 1 \\
\hline \multicolumn{2}{|l|}{ 4. Pre 1963 Land Use Factor } \\
\hline States & Values \\
\hline \multicolumn{2}{|l|}{ Residential or Vacant } \\
\hline & 3 \\
\hline Industrial & 1 \\
\hline \multicolumn{2}{|l|}{ 5. Bordering Land Uses Factor } \\
\hline States & Values \\
\hline Residential & 5 \\
\hline \multicolumn{2}{|l|}{ Actively Industrial/Commercial } \\
\hline \multicolumn{2}{|l|}{ Vacant/Underused Parcel with no Suspected Contamination } \\
\hline \multicolumn{2}{|l|}{ Vacant/Underused Parcel with Suspected Contamination } \\
\hline \multicolumn{2}{|l|}{ Vacant/Underused Parcel with Confirmed Contamination } \\
\hline \multicolumn{2}{|l|}{ 6. Roadways for Access Factor } \\
\hline States & Values \\
\hline \multicolumn{2}{|l|}{4 or More Roadways } \\
\hline 3 Roadways & 3 \\
\hline 2 Roadways & 2 \\
\hline 1 Roadway & \\
\hline
\end{tabular}

\begin{tabular}{|l|r|}
\hline 7. Economic Link Potential Factor & Values \\
\hline States & 3 \\
\hline High & 2 \\
\hline Moderate & 1 \\
\hline Low & 0 \\
\hline Negligible & \\
\hline
\end{tabular}

\begin{tabular}{|l|r|}
\hline 8. Investment Turnover Factor & \\
\hline States & Values \\
\hline High & \\
\hline Moderate & 2 \\
\hline Low & 1 \\
\hline Negligible & 0 \\
\hline
\end{tabular}

\begin{tabular}{|l|r|}
\hline Negligible & 0 \\
\hline & \\
\hline 9. Asbestos Factor & Values \\
\hline States & 5 \\
\hline No Asbestos Suspected & 4 \\
\hline & 3 \\
\hline & 2 \\
\hline Asbestos Suspected & 1 \\
\hline
\end{tabular}


each states. Ultimately, each independent variable has a number of internal states with associated internal values reflecting all the different possible conditions that may be assumed by that particular variable.

\subsubsection{Defining Relationships between Model Variables}

Defining decision-making objectives and associated variables is only the first step in developing the decision model. Once the decision variables have been identified and linkages between independent and dependent variables developed, we must define the actual relationships that exist between these variables. The Ranking Model's utility function is developed to maximize the expected value or utility of each site. Together with the values associated with the variables, relationships between the variables will produce a final value (the expected value of the site) which is indicates a more redevelopable site for higher values.

Variable relationships may be defined through numeric assignments to the internal states of variables or through functional relationships, resulting in implicit and explicit inter-variable relationships respectively. The internal values assigned to the variables (see Table 5.2) produce implicit inter-variable relationships. As we move from variable to variable, the values held by each variable's states become relative measures for determining the relative importance of different variables in making our final decision. For example, if it is the case that one variable $\mathrm{X}$ has $\mathrm{N}$ valued states and another variable $\mathrm{Y}$ has say $3 \mathrm{~N}$ valued states, then implicitly, the optimal state of 
variable $\mathrm{Y}$ is three times as high as that of variable $\mathrm{X}$. Explicit inter-variable relationships may also be defined using functional relationships. For example, to adjust the relationship between the variables $\mathrm{X}$ and $\mathrm{Y}$ in the example given above, functional relationships may be defined between these two variables through a third dependent variable. Let's say for example that both variables $\mathrm{X}$ and $\mathrm{Y}$ have influence arcs into another variable say $\mathrm{Z}$, i.e., $\mathrm{Z}$ is determined by some combination of $\mathrm{X}$ and $\mathrm{Y}$. Then we would define $\mathrm{Z}$ as $3 \mathrm{X}+\mathrm{Y}$ if we ultimately wanted to assign the same weight to the optimal value of $\mathrm{X}$ as that of $\mathrm{Y}$. If on the other hand we wanted to assign twice the weight of the optimal value of $\mathrm{Y}$ to that of $\mathrm{X}$ in our final decision, then we would define $\mathrm{Z}$ as $6 \mathrm{X}+\mathrm{Y}$ and so on. Figure 5.0-C demonstrates these implicit and explicit inter-variable relationships. To further illustrate these relationships we use an example from the preliminary Ranking Model shown in Figure 5.0-B. In Figure 5.0-B, we notice that Investment_Turnover_Factor and Economic_Link_Potential_Factor both have influence arcs into the Future_Land_Use_Factor. From Table 5.2 we observe that the optimal value assigned for each of these two variables is 3 . We define a functional relationship in Figure 5.0-D, such that the Investment_Turnover_Factor is weighted twice as much as Economic_Link_Potential_Factor in calculating the value of the dependent variable Future_Land_Use_Factor. This reflects the fact that the decision-maker values the investment turnover of any site development twice as much as he or she values the economic link potential (or land use compatibility) of the development on 


$$
\begin{aligned}
& Z=\mathrm{A} X+\mathrm{B} Y \\
& \text { State Value } \\
& 1 \quad \mathrm{~N} \\
& 2 \quad \mathrm{~N}-1 \\
& 3 \quad \mathrm{~N}-2 \\
& 4 \quad \mathrm{~N}-3 \\
& N \quad \mathrm{~N}-(\mathrm{N}-1) O R
\end{aligned}
$$

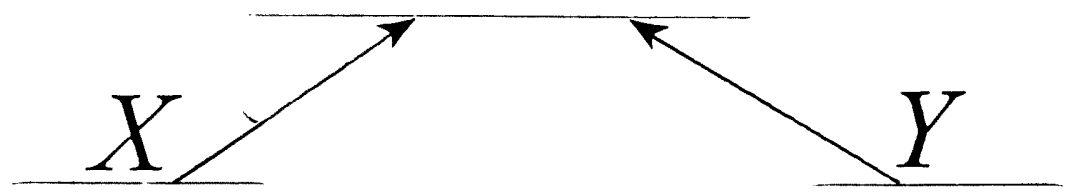

$\begin{array}{ll}\text { State } & \text { Value } \\ 1 & \mathrm{~N} \\ 2 & \mathrm{~N}-1 \\ 3 & \mathrm{~N}-2 \\ 4 & \mathrm{~N}-3 \\ \cdot & \cdot \\ \cdot & \cdot \\ . & . \\ \mathrm{N} & \mathrm{N}-(\mathrm{N}-1) \text { OR } \\ \mathrm{N} & \mathrm{N}-\mathrm{N}\end{array}$

$\mathrm{X}, \mathrm{Y}$ - Independent Variables

Z- $\quad$ Dependent Variable

N - Total Number of States of Variable (Integer)

A, B - Positive Real Constants

Figure 5.0-C: Implicit \& Explicit Inter-Variable Relationships 


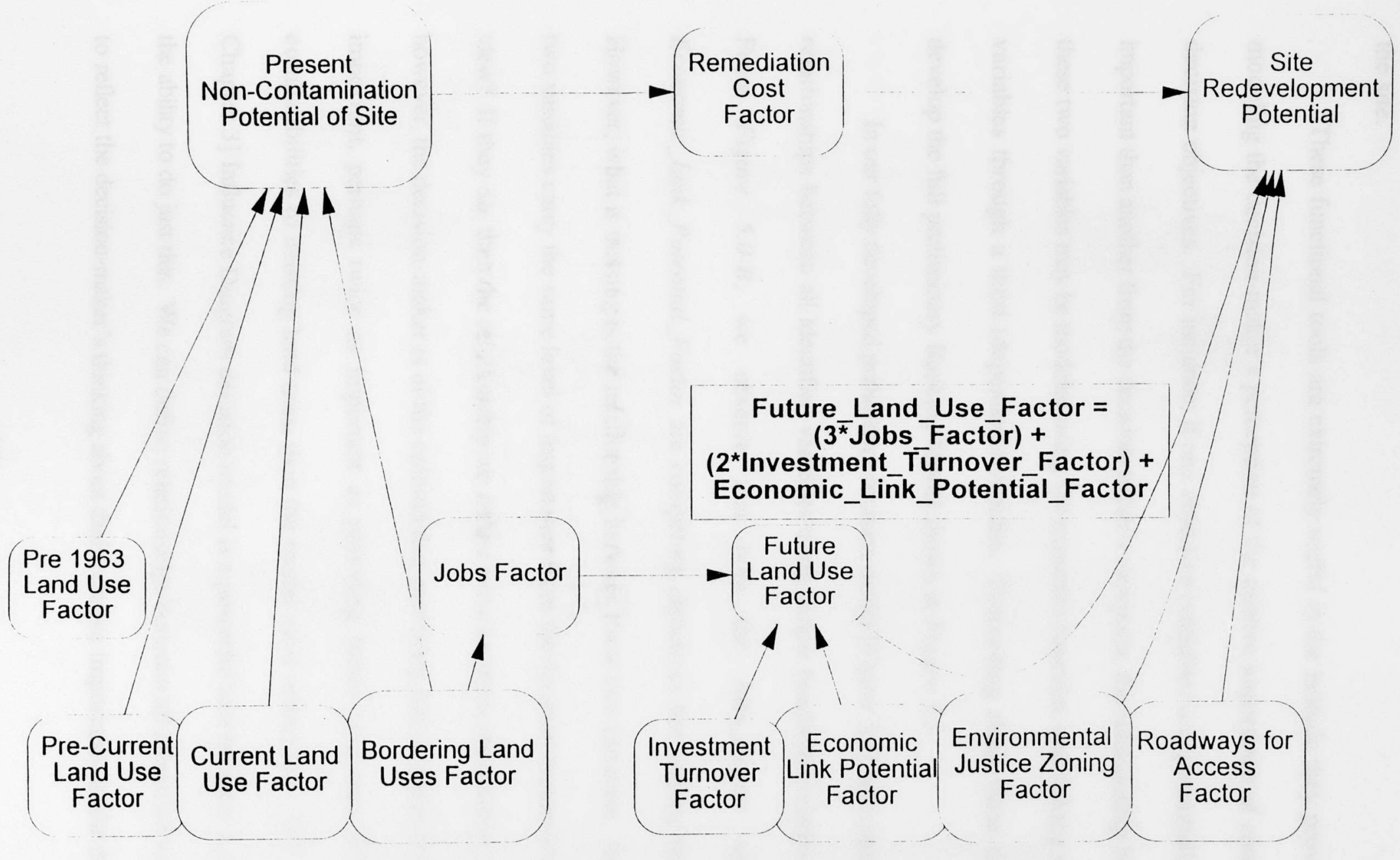

Figure 5.0-D: Defining Functional Relationships Between Model Variables 
the site.

These functional tools are extremely useful in the latitude they provide for modeling the decision-maker's perception of the relative importance of competing decision objectives. For instance, if one objective (variable) is exponentially more important than another from the decision-maker's viewpoint, the relationship between these two variables may be modeled using the exponent function, and linking the two variables through a third (dependent) variable. Proceeding along these lines we develop the full preliminary Ranking Model shown in Figure 5.1.

In our fully developed preliminary decision model [Figure 5.1], we capture the relationships between all identified variables using simple functional relationships . From Figure 5.0-B, we observe that both the Jobs_Factor and the Economic_Link_Potential_Factor are competing objectives for ranking the sites. However, what is missing is the relationship between these two variables. Do these two variables carry the same level of importance from the decision-maker's point of view? If they do, then the relationship we define between them must reflect this. If however, the decision-maker is of the opinion that providing jobs is somewhat more important, perhaps twice as important as providing future land uses with high compatibilities to existing land uses, then the model must reflect this. DPL's [see Chapter 3] Influence Diagram decision model is a powerful tool because it gives us the ability to do just this. We can define relationships between all identified variables to reflect the decision-maker's thinking about their relative importance in the decision 


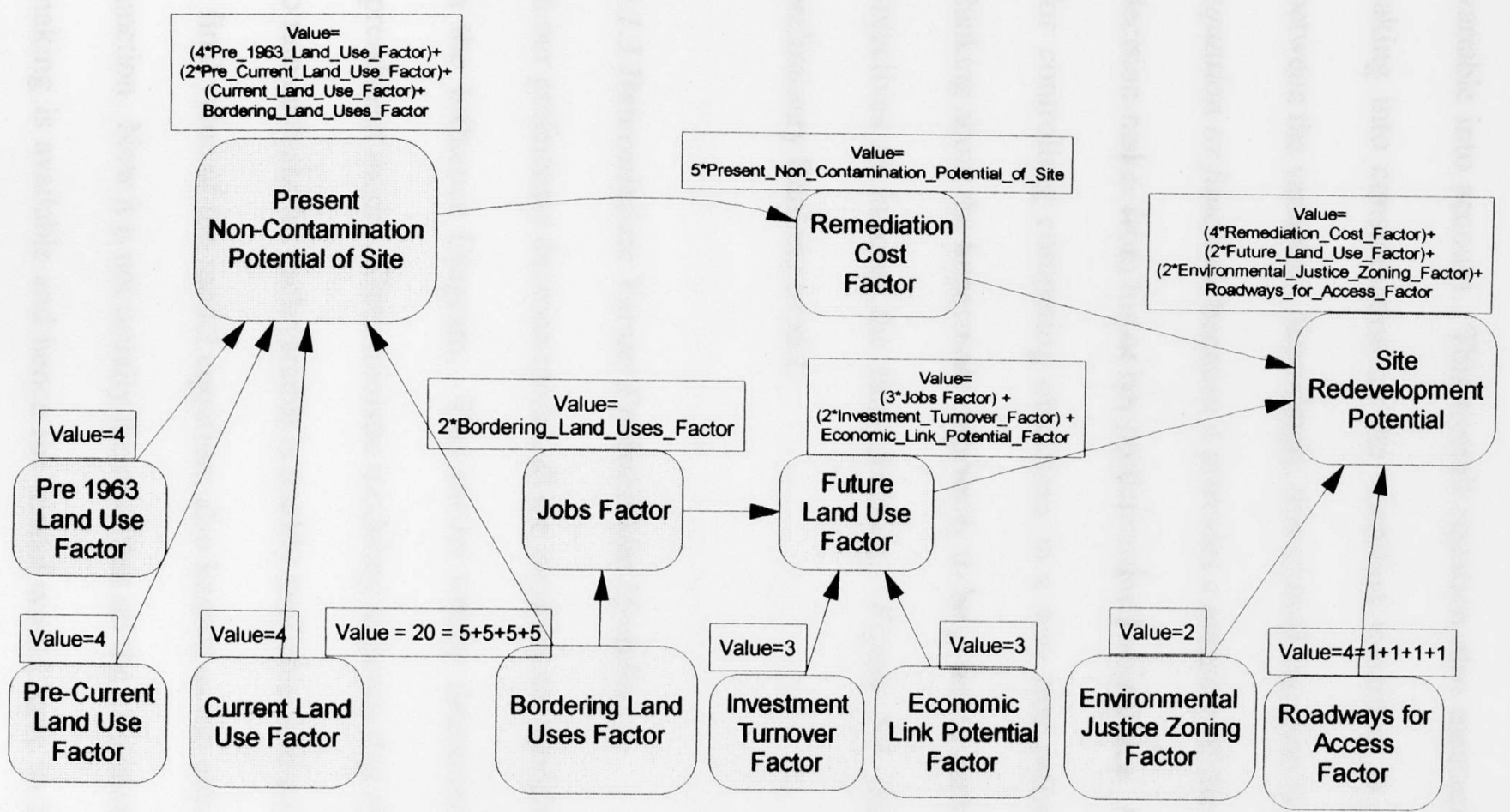

Figure 5.1: Preliminary Model - Poinciana Industrial Center 
to be made. These relationships will then be used in calculating the final redevelopment potential of the site in an overall equation which takes each single variable into account. This overall equation also measures the utility of each site taking into consideration all the identified variables, as well as the relationships between the variables. Accordingly, this overall equation is also known as our utility equation or function, because it provides a measure of the utility of each site to the decision-maker from his or her predetermined objectives. It also provides a method for controlling competing objectives in a way that reflects the decision-maker's thinking about the importance or priority to be given to each of the different decision objectives in making the final decision. Figure 5.1 shows our fully-developed preliminary Ranking model.

\subsubsection{Deterministic Versus Probabilistic Modeling}

In our preliminary decision model, all the variables are modeled as deterministic nodes in the Influence Diagram. This model totally deterministic, i.e., it is akin to a spreadsheet model. Deterministic modeling assumes that all the information needed to rate each site for each variable is readily available, and can be inputted to calculate a final value of the model equation, also known as the expected value of our utility function. Now it is not usually the case that all the information required for decision making is available and hence the model would have to be refined to reflect this, which is done in the following sections. Assuming that a set of variables present in 
our preliminary model, say $\left(X_{1} \ldots X_{n}\right)$, have no readily available information, the benefit of using Influence Diagram modeling is once again evident here. With Influence Diagrams, we can test the sensitivity of the expected value of our utility function to each variable $\left(X_{1} \ldots X_{n}\right)$. For variables which produce a significant effect on the expected value of the utility function, i.e., variables to which the utility function is highly sensitive, it is necessary to consider one of the following two alternatives:

(1) Either obtaining complete information for each site with respect to this particular variable, and retaining the variable as deterministic (since its effect on the utility function is significant); or,

(2) Modeling the variable probabilistically and obtaining some information for each site with respect to this variable; information which is incomplete but nonetheless better represents the status of each site from the perspective of this variable. Of course, the first alternative is the more accurate approach but also one that typically requires the expenditure of more time, financial and other valuable resources.

The strong benefit of Influence Diagrams is in determining which of variables the ( $X_{1}$ $\left.\ldots X_{n}\right)$ do not have a significant effect on the final value of the utility function $\mathrm{U}(X)=$ $\mathrm{F}\left(X_{1} \ldots X_{n}\right)$. Rather than expending limited resources to collect information for these variables, they may be entirely dropped from the model since their effect is insignificant. So say, for example, that the decision-maker's initial thinking is that the 
Asbestos_Factor is a potentially significant variable in ranking the sites. Assuming that there is no readily available information for any of the sites that allows for the determination of the condition of each site relative to this variable, and that sensitivity analysis showed that this variable did not significantly affect the expected value of the utility function, then this variable could be simply dropped from the model without significant harm to the final decision outcome and a lot of savings in time and other limited resources on the part of the decision-maker.

\subsubsection{Preliminary Model Run}

All Influence Diagram models were developed using the Decision Analytic software package Decision Programming Language or simply, DPL. DPL is a windows-based IBM PC program with both Influence Diagram and Decision Tree modeling capabilities. The nodes (variables) for the preliminary Influence Diagram model were first defined and then arithmetic equations were inputted to reflect the relationships between these nodes (just in a similar way as one would input equations into a generic spreadsheet model to reflect relationships between independent variables). For those explanatory variables in the model, (i.e. variables which are independent of all other variables for their values), numeric values were inputted into the model. In our preliminary model run, we input values for a hypothetical 'optimal site' whose values reflect the best state achievable by any site using this model [see Table 5.2]. For example, a value of 20 is inputted for "Bordering Land Uses" indicating that all four 
bordering land uses on this preliminary model site are residential (residential land use has an optimal value of 5). Using DPL, the Influence Diagram is solved automatically to give an expected value of 1226 [Figure 5.1.1], a value which at this point in time is of little use to us, except for the fact that it represents the upper boundary value obtainable by any of the sites to be ranked using this preliminary model. We must now analyze and refine our model.

\subsubsection{Refining the Model I}

Sensitivity Analysis is performed on the explanatory variables of the preliminary model to determine the sensitivity of the utility function to each explanatory variable. In Figure 5.1.2, we can observe the relationship of our explanatory variables to the expected value of the utility function in a Tornado Diagram. The Bordering_Land_Uses_Factor most significantly impacts the expected value of our utility function, producing a significant range of 608 redevelopment potential points on the expected value of our utility function, i.e., when this variable is at its lowest possible value of 1 , the expected value is 618 points and at its highest possible value of 20 , the expected value is 1226 , all other variables remaining equal. On the other hand the Environmental_Justice_Zoning_Factor produces a negligible range of 2 redevelopment potential points on the expected value of our utility function, (i.e., this variable produces a total range of 2 points in the expected value of our utility function). Now, if we had no information on the bordering land uses of the sites, we 


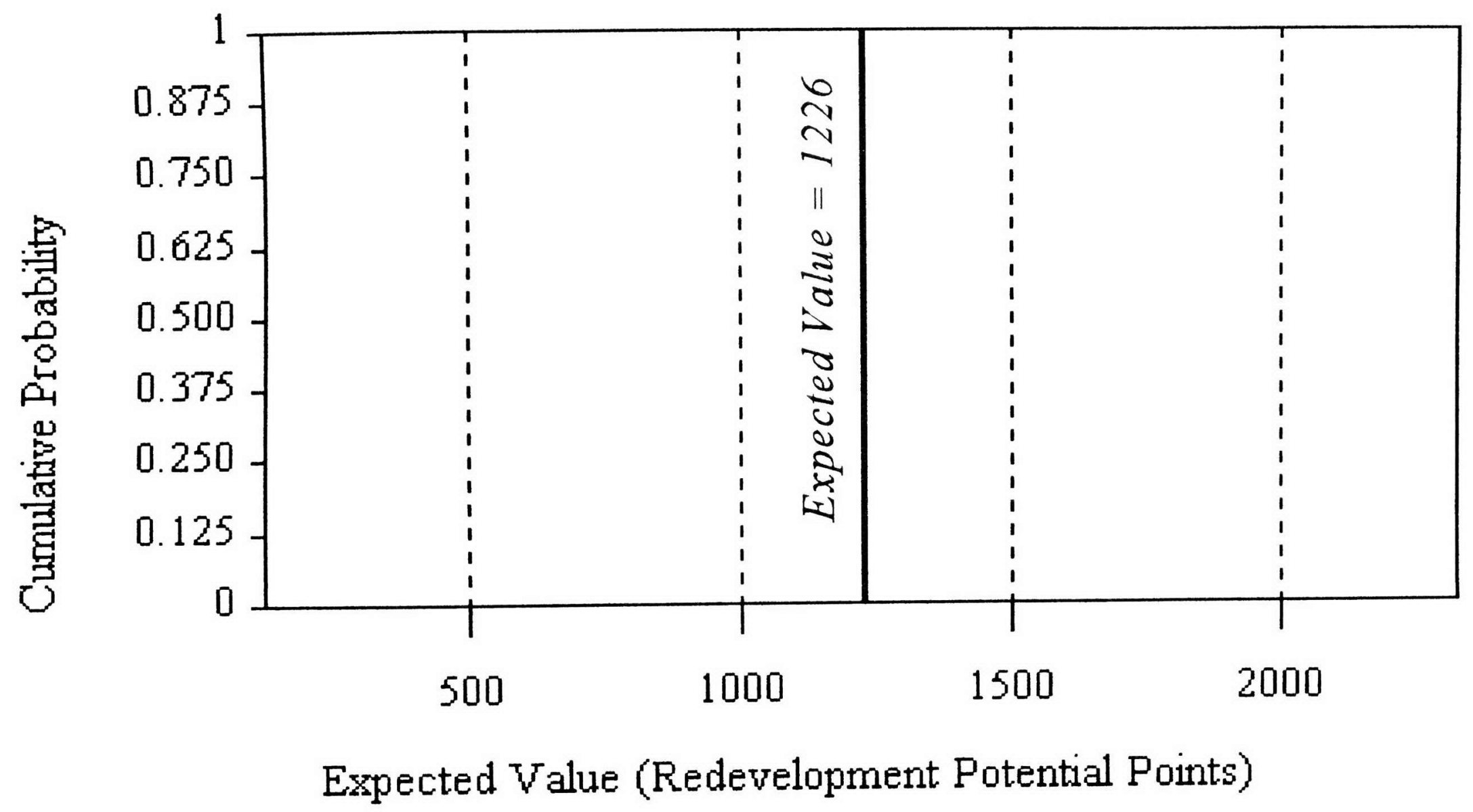

Figure 5.1.1: Expected Value for Preliminary Model Run 
Bordering Land_Uses_Factor

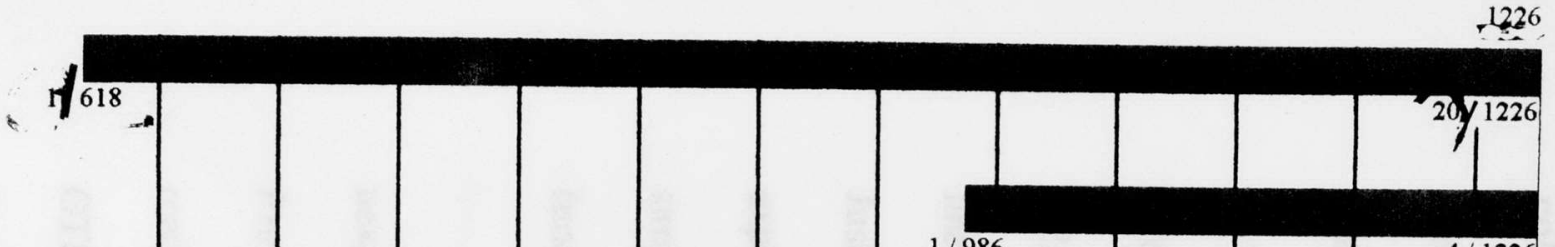

Pre_1963_Land Use_Factor

Pre_Current_Land_Use_Factor

Current_Land Use Factor

Investment_Tumover_Factor

Economic Link Potential Factor

Roadways for_Access Factor

Environmental_Justice_Zoning_Factor

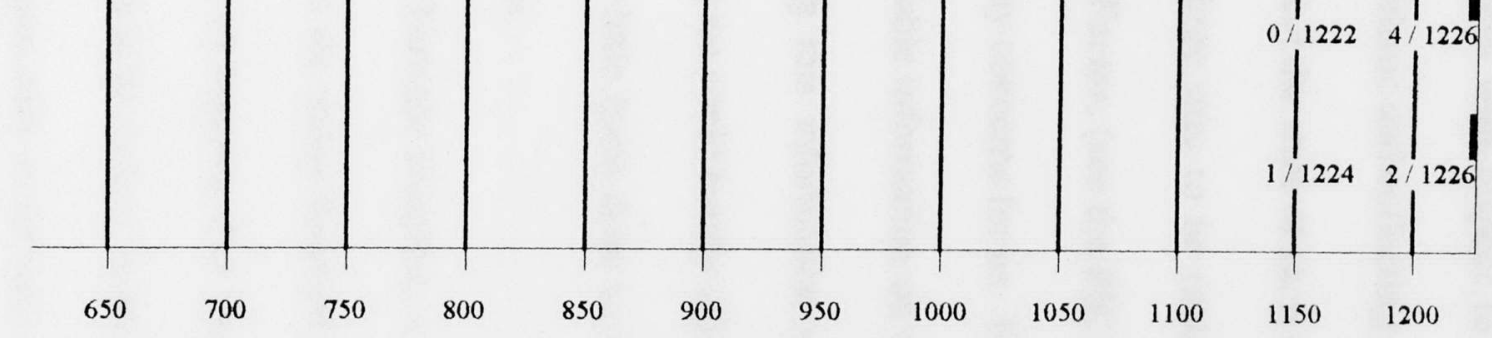

Figure 5.1.2: Sensitivity Analysis for Preliminary Model 
would have to resort to one of the two options mentioned in section 5.1.3, namely, collecting perfect information for all the sites with respect to this deterministic variable, or remodeling the variable as probabilistic and collecting some information, which although not perfect, would better reflect the state of each site from the point of view of this variable. Now since the three sites to be ranked have adequate information for the Bordering_Land_Uses_Factor, (see the PIC Database in Table 4.2, Chapter 4), this variable does not raise any concerns for us. Following a similar line of reasoning, if we had no readily available information on the Environmental Justice Zoning for the sites, and obtaining this information would require the expenditure of large amounts of resources that we could hardly afford, then we could simply drop this node from the model with little harm done to the model's utility function's outcome and our limited resources.

Going down the list of variables in the Tornado Diagram, we observe that the next most important variable with respect to the utility function's sensitivity is the Pre_1963_Land_Use_Factor. Now it just so happens that there is currently no readily available information for any of our sites to be ranked, relating to this variable. GTI's land use history provided for the sites goes only as far back as 1963 for all the PIC sites. The variable was included in the model however because it is an important measure in ranking any potentially contaminated sites. The reason for this is that the pre-1960s preceded the modern era of environmental regulation and hazardous waste management. In this lax environment, industrial activities polluted many sites. As 
such, this variable is a significant one for sites with suspected contamination. Since this variable produces a significant impact on our expected value, and we presently have no information for any site in relation to variable, we have one of the two options mentioned above. Collecting perfect information for this variable may be possible; however it will likely require the expenditure of a relatively high quantity of valuable resources (time and money); on the other hand, some information could be gathered that gives us an idea about the pre-1963 land uses on each site without specifically telling us what land uses they were, the more economical alternative. Since we are only interested in knowing whether a site had industrial uses prior to 1963, we could devise a simple method for estimating the likelihood for the different sites having industrial land uses prior to 1963. For instance we could develop a survey to elicit information from relevant entities and individuals (such as the County's Planning Department, and individuals who have lived in this area since the late 1950s), and use this information to estimate the probabilities of each site having industrial land uses prior to 1963 . For example if 8 out of 10 of the returned surveys indicated an industrial use for a particular site, then we could assign a probability of 80 percent to the "Industrial Use" state for this particular site's Pre_1963_Land_Use variable, and 20 percent for "Non Industrial Use." This probabilistic modeling is exactly the step we take in refining our preliminary model.

As shown in Refined Model I [Figure 5.2], we model the Pre_1963_Land_Use_Factor variable as a chance or probabilistic node. As 


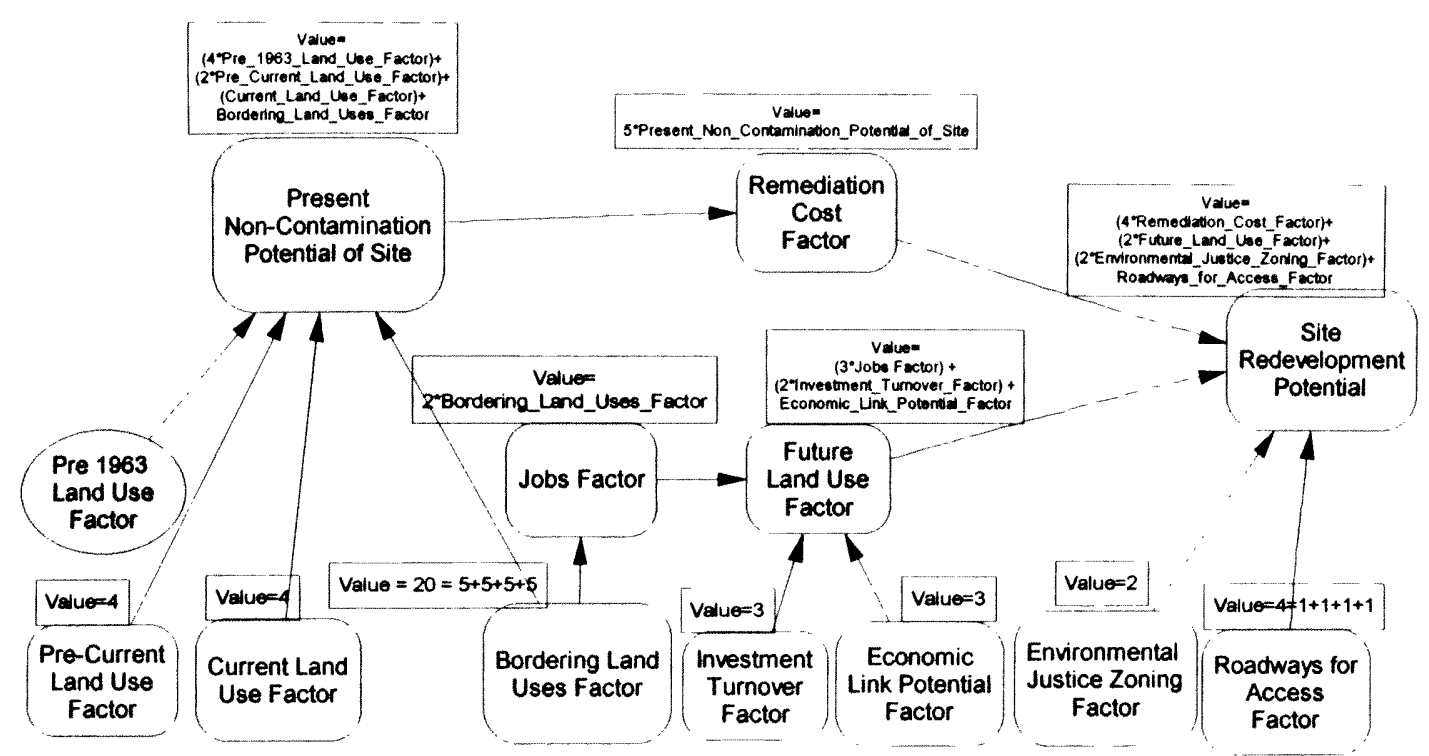

Pre_1963_Land_Use_Factor

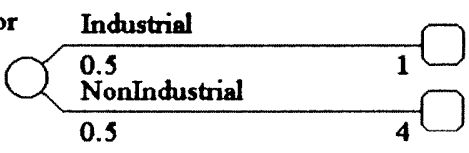

Figure 5.2: Refined Model I - Poinciana Industrial Center 
documented in Table 5.2, the original values assigned to this variable's different states still remain. "Industrial" land use has been assigned a value of 1 since such a state has a high potential of site contamination; the "NonIndustrial" state, on the other hand, is assigned a value of 4 because it reflects no site contamination prior to 1963 . What changes is the fact that we can no longer assign a single value to our Pre_1963_Land_Use_Factor node because of our uncertainty with regard to the land use condition of the sites before 1963. In this second model run, we assign probabilities of 50 percent to each of the two states, reflecting that we have no idea about the pre-1963 land use status of our hypothetical site: as far as we are concerned, there is a fifty percent chance that the site could have been used industrially. (Note that these states are assumed prior to collecting any information for this variable). With this refined structure, the Influence Diagram (Refined Model $I$ ) is solved, giving an expected value of 1106 redevelopment potential points [Figures 5.2.1], a smaller value than the expected value of 1226 points obtained for the preliminary model run [Figures 5.1.1]. This value reflects our uncertainty about the land use status of the site prior to 1963, commensurately, it has a lower value than that of our preliminary model. This refined model better caters for the utility function's high sensitivity to the "Pre 1963 Land Use" variable and is a therefore a better model than the preliminary model given as there is currently no available information on the sites' land uses prior to 1963. Figures 5.2.1 show the possible outcomes of our model for our hypothetical site (i.e., a site with optimal values on all 

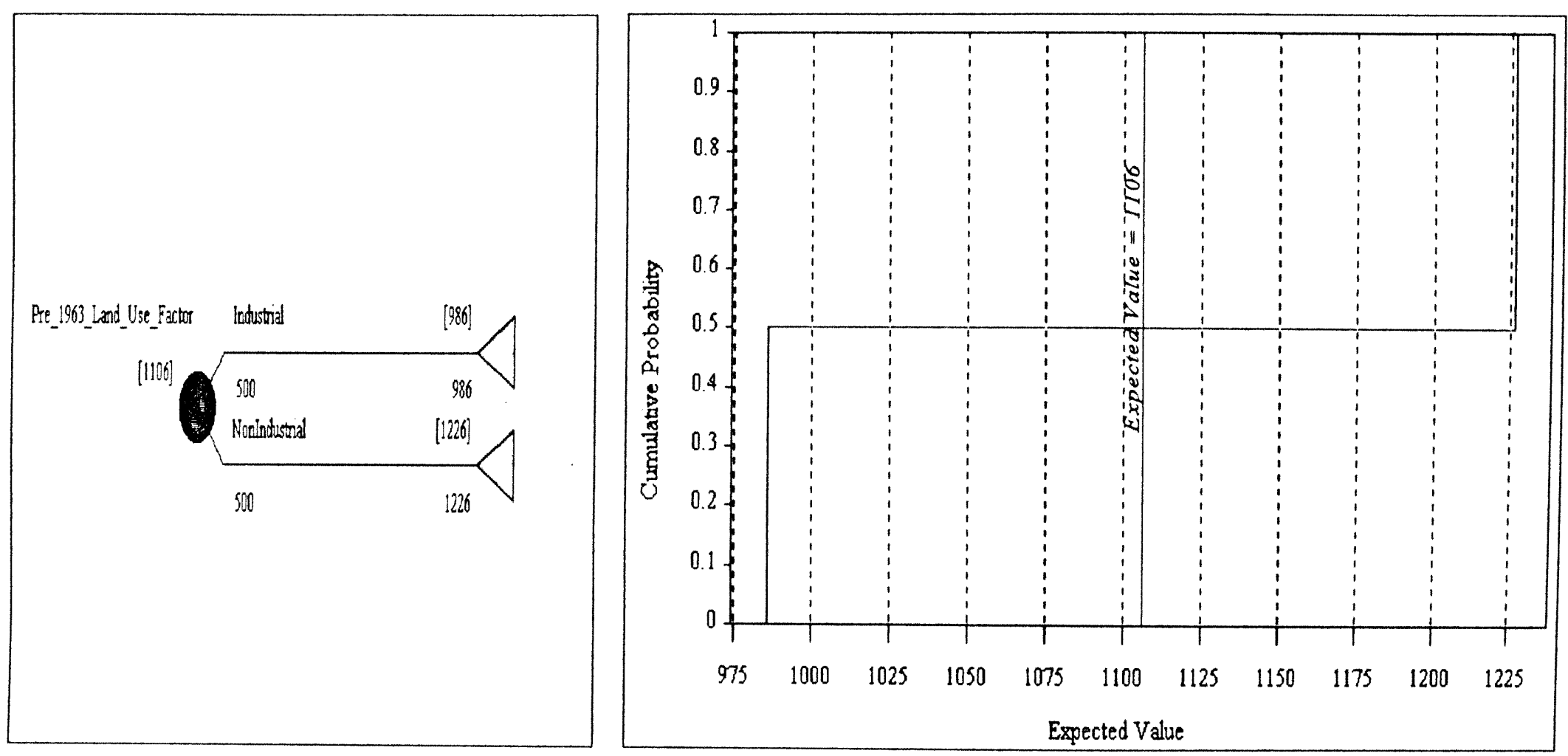

Figures 5.2.1: Expected Value \& Risk Profile for Refined Model I Run 
the independent variables with the exception of the Pre_1963_Land_Use_Factor variable which has a 50 percent chance of contamination). The risk profile in Figures 5.2.1 shows that the site has a 50 percent chance of having an expected value of 986 (if it has been used industrially) and a 50 percent chance of having an expected value of 1226 (if it has not been used industrially prior to 1963). The expected value of these two states $[0.5 *(986+1226)]$ is the model's final output. From the probabilistic node introduced into the preliminary model therefore, the sensitivity of the utility function's expected value to the Pre_1963_Land_Uses_Factor decreases [see Figure 5.2.2] relative to that of our preliminary model run, making our current model slightly more dependable than the preliminary model: i.e., we want to lower the sensitivity of the utility function to variables for which there is uncertainty with regard to site information.

\subsubsection{Refining the Model II}

Since we have information on the potential for asbestos contamination on all sites to be evaluated, we introduce an new node known as Asbestos_Factor into our Refined Model I to obtain Refined Model II shown in Figure 5.3. While we could have introduced this node in the preliminary model, we take this approach to demonstrate the ease with which the Influence Diagram model may be updated as information becomes available. The Asbestos_Factor variable is modeled deterministically. An optimal value of 5 is inputted for this variable in the updated model (reflecting the 
Redevelopment

Potential

Variables

Bordering_Land_Uses_Factor

Pre_1963_Land_Use_Factor|Pre_1963_Land_Use_Factor.NonIndustrial

Pre_Current_Land_Use_Factor

Current_Land_Use_Factor

Investment_Turnover_Factor

Economic Link Potential Factor

Roedways for Access Factor

Environmental_Justice_Zoning_Factor

Pre_1963_Land_Use_Factor|Pre_1963_Land_Use_Factor.Industrial

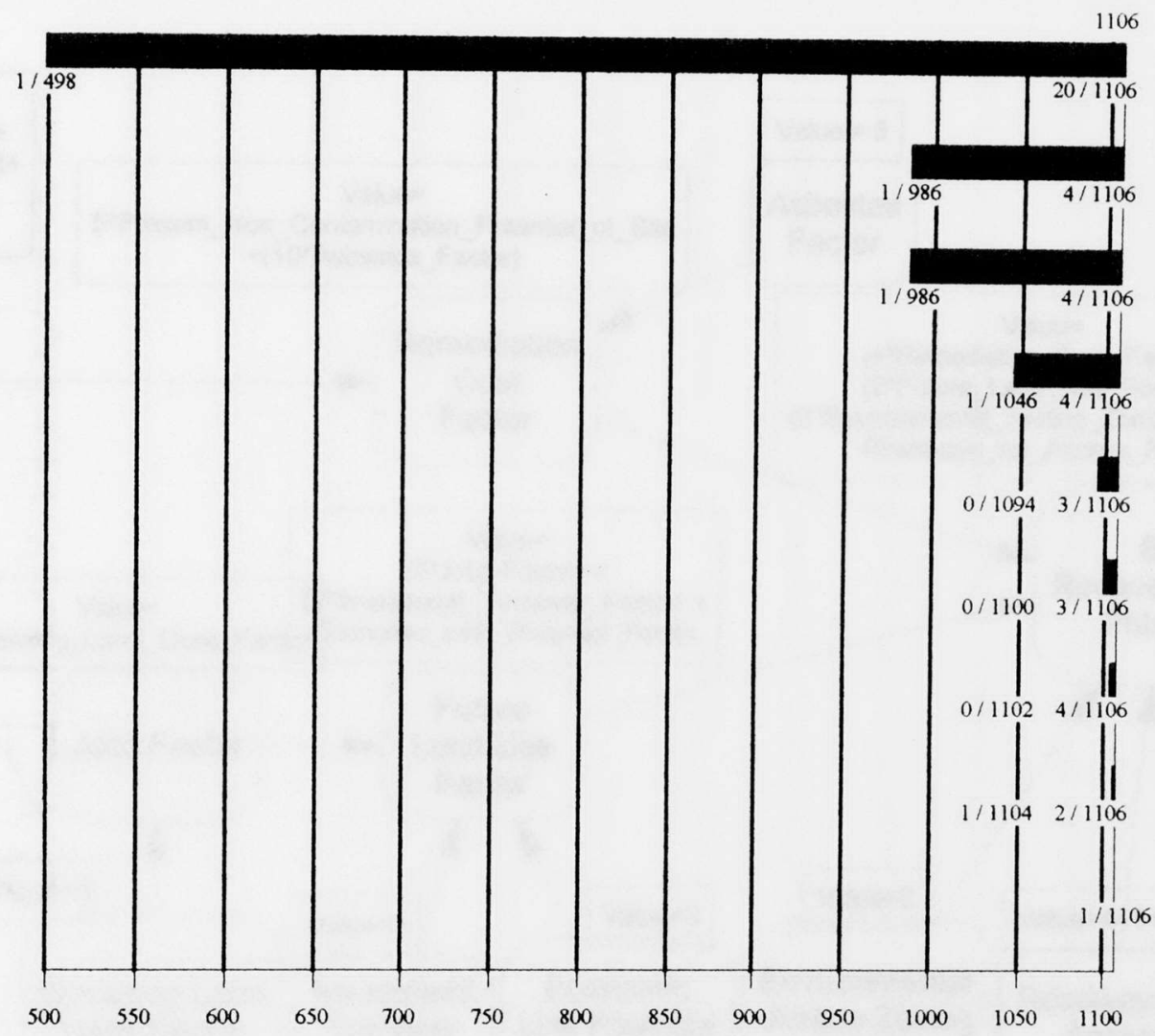

Expected Vahue

Figure 5.2.2: Sensitivity Analysis for Refined Model I 


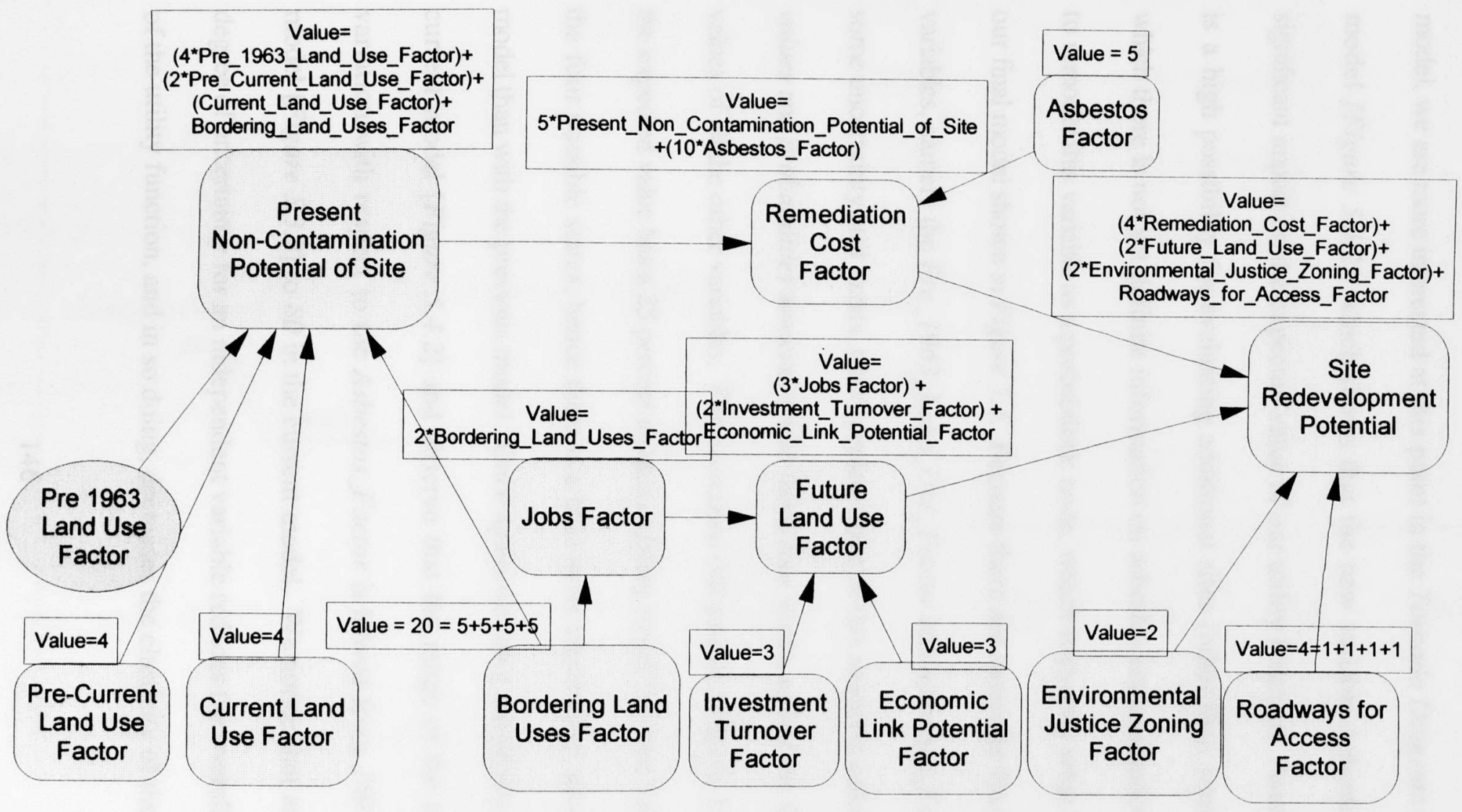

Figures 5.3: Refined Model II - Poinciana Industrial Center 
optimal hypothetical site being used to refine our model), and the model is solved with an expected value of 1306 as shown in Figures 5.3.1. Since we are still refining our model, we are more interested at this point in the Tornado Diagram for out updated model [Figure 5.3.2], which shows that the new variable Asbestos_Factor has a significant impact on the expected value of our utility function. Assuming that there is a high possibility for evaluating additional sites (other than sites 1,2 and 3 ) for which there is not yet definite information on asbestos contamination, we may want to remodel this variable as a probabilistic node, which is exactly what we do to obtain our final model shown in Figure 5.4. Because there are currently four states (for two variables, namely the Pre_1963_Land_Use_Factor and Asbestos_Factor) for which some uncertainty still exists, the expected value of this model is calculated using the values and probabilities associated with these four states, as well as the deterministic values of all the other variables. The associated risk profile [Figure 5.4.1] shows that the expected value has a 25 percent chance or being any of the four values linked with the four possible states, hence there is a little more uncertainty associated with this model than with the previous model. Once again we run a sensitivity analysis for the current model [Figure 5.4.2] and observe that the range of the utility function's variation with respect to the Asbestos_Factor is halved from 160 in the previous model [Figure 5.3.2] to 80 in the current model. We notice that an increase in the degree of uncertainty for an independent variable reduces the overall expected value of the utility function, and in so doing, decreases the elasticity of the utility function 

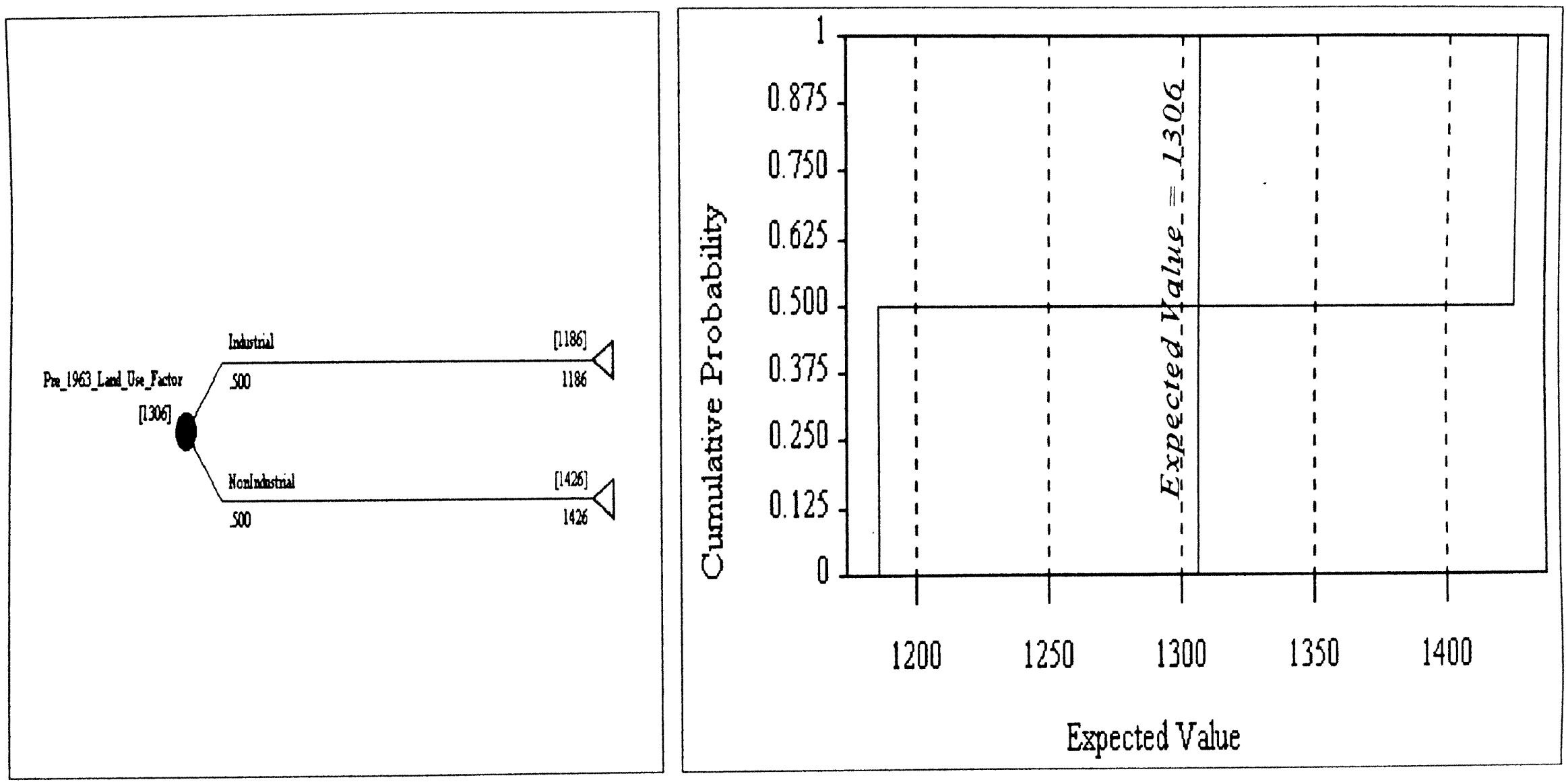

Figure 5.3.1: Expected Value and Risk Profile for Refined Model II Run 
Asbestos_Factor

Pre_1963_Land Use_Factor|Pre_1963_Land Use_Factor.NonIndustria

Pre_Current_Land_Use_Factor

Current Land Use Factor

Investment_Tumover_Factor

Economic_Link_Potential Factor

Roadways_for_Access_Factor

Environmental Justice_Zoning_Factor

Pre_1963_Land_Use_Factor|Pre_1963_Land_Use_Factor.Industrial

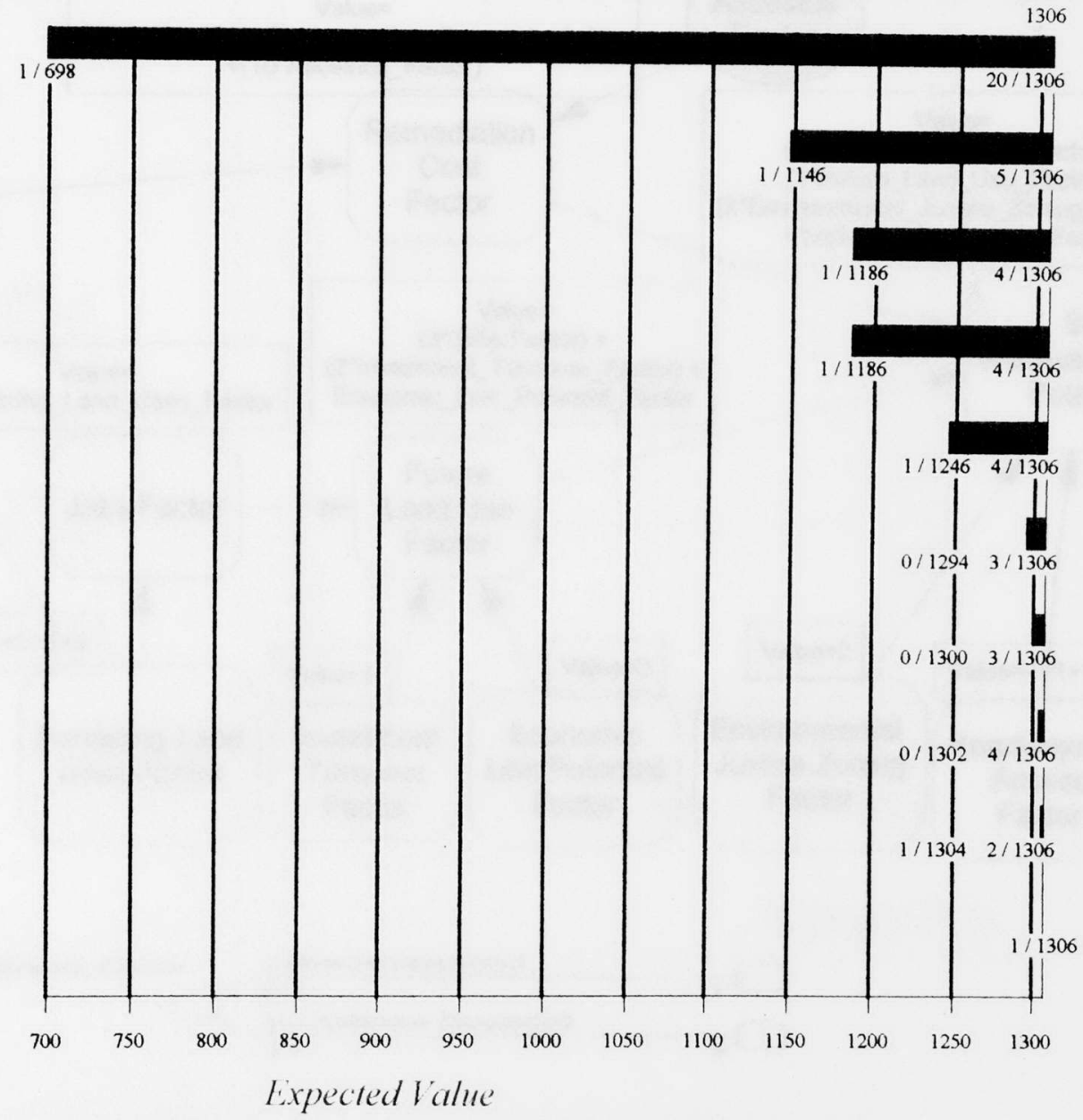

Figure 5.3.2: Sensitivity Analysis for Refined Model II 


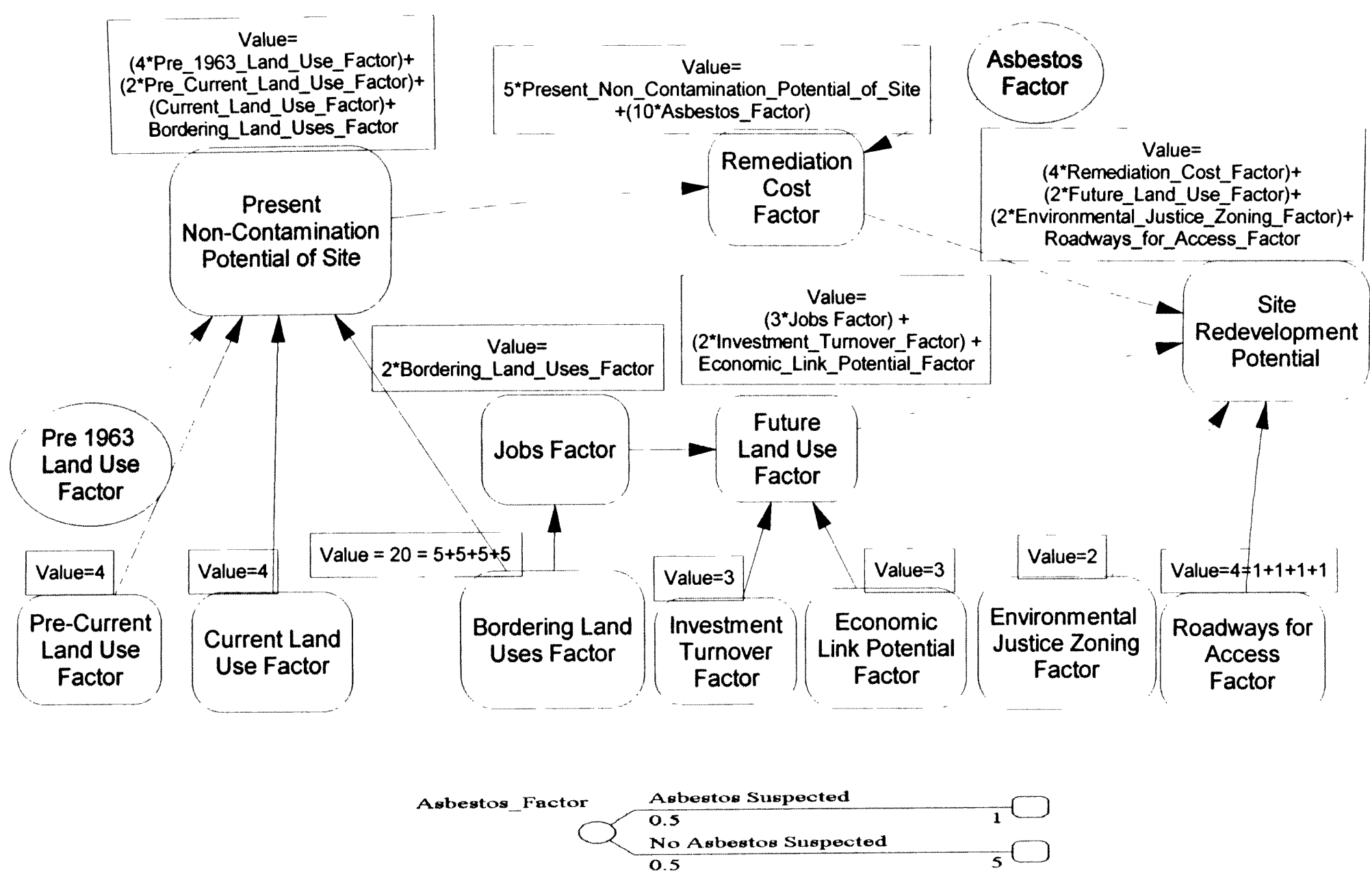

Figure 5.4: Final Model - Poinciana Industrial Center 

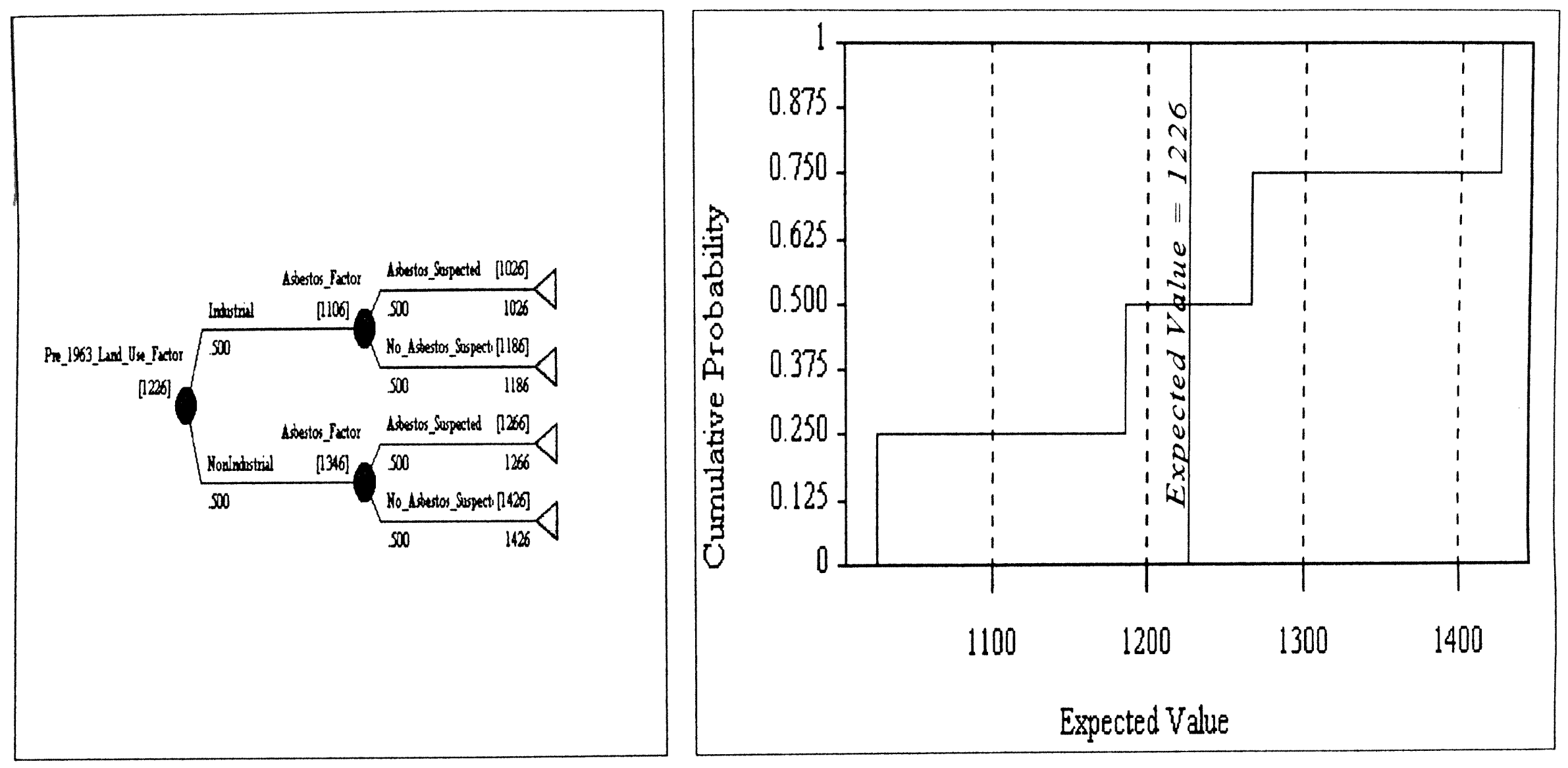

Figure 5.4.1: Expected Value and Risk Profile for Final Model Run 
Pre_1963_Land_Use_Factor|Pre_1963_Land_Use_Factor.Nonlndustrial Pre_Current_Land_Use_Factor

Asbestos_Factor|Asbestos_Factor.No_Asbestos_Suspected

Current_Land_Use_Factor

Investment_Turnover_Factor

Economic_Link_Potential_Factor

Roadways_for_Access_Factor

Environmental_Justice_Zoning_Factor

Asbestos_Factor|Asbestos_Factor.Asbestos_Suspected

Pre_1963_Land_Use_Factor|Pre_1963_Land_Use_Factor.Industrial

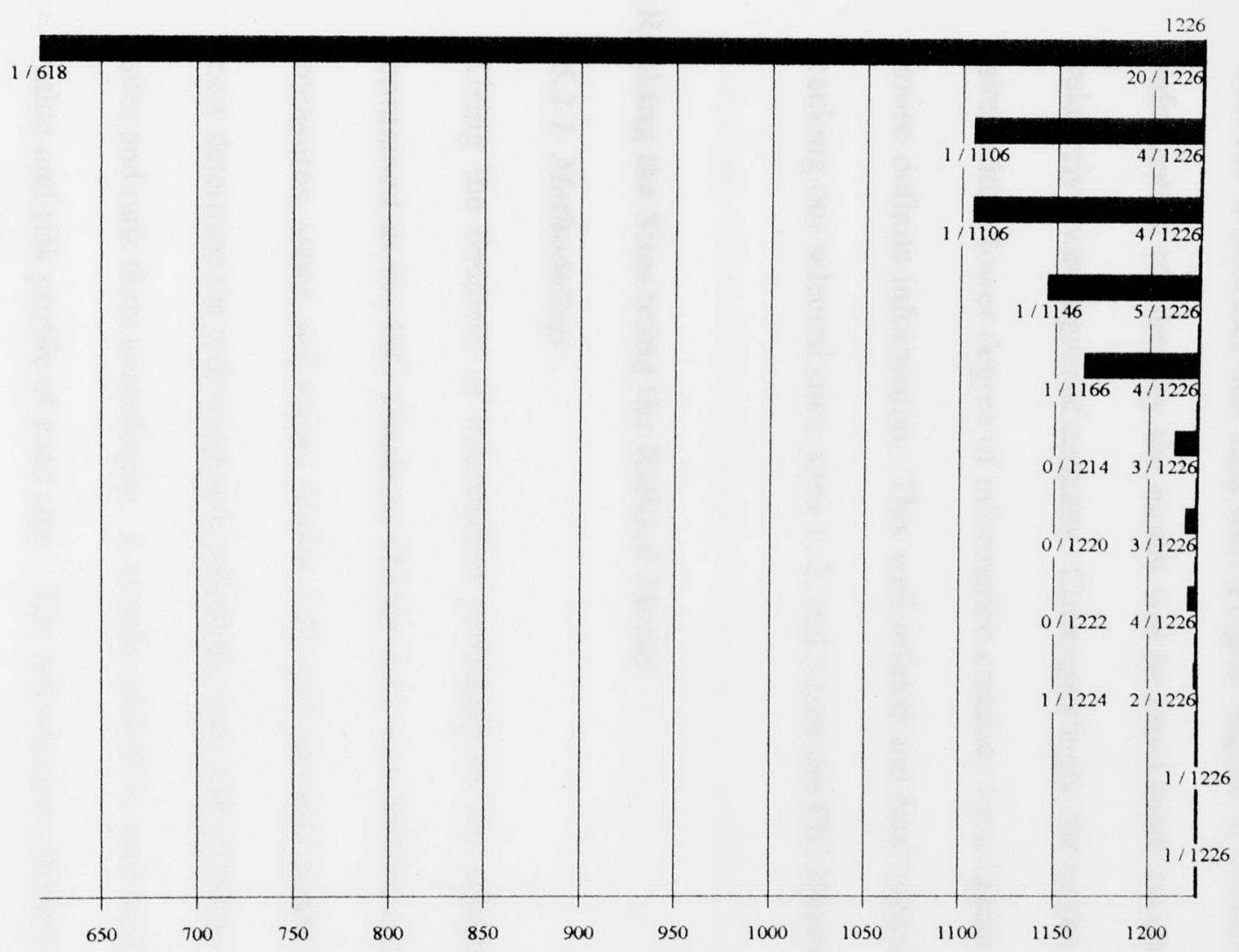

Expected Value

Figure 5.4.2: Sensitvity Analysis for Final Model 
with respect to the independent variable. This is a useful feature for our purpose because it indicates that sites with a higher degree of certainty with respect to the information required by the model will be rated more favorably than sites with a relatively lower degree of certainty. Correspondingly, the model captures the fact that sites with a lower degree of information certainty have higher risks than those with more definite information. This well-refined and final model will now be used in ranking our selected sites: sites 1, 2, and 3 (see the PIC Database in Table 4.l).

\subsection{Ranking the Sites using the Refined Model}

\subsubsection{Methodology}

Using the database of information pertaining to our selected sites: 1, 2, and 3 contained in the PIC Database [Table 4.1], our defined redevelopment potential measures, states and values [Table 5.2], and our final model [Figure 5.4], we will now determine the redevelopment potentials (and risk profiles) for our three selected sites and rank them accordingly. A simple method is used to determine the expected value and risk profile of each site. The information contained in the PIC Database [Table 4.1] is reduced to the relative numeric system contained in Table 5.2. Table 4.1 and Table 5.2 are simultaneously consulted to determine the states and associated values for each independent variable for each of the three sites. For example, for site 1, the value of the Bordering_Land_Uses_Factor is determined by consulting Table 4.1 for the site's bordering land uses: this site has "Vacant, Open Parcels" on the 
northern border and receives a corresponding value of 3 [see Table 5.2 where a value of 3 is assigned to all "Vacant Industrial with no Suspected Contamination."], "Residential Homes" to the south receives a value of 5, "Action Trailers" (also residential) to the east receives a value of 5, and "Car Wash" to the west receives a value of 2, giving a total value of $3+5+5+2=15$ for the Bordering_Land_Uses_Factor for site 1. Using the same process, site 2 receives a value of $13+5+3+4=15$, and site 3 receives a value of $4+3+4+2=13$ for this variable. Similarly, all the other explanatory variables are rated for all the sites using the PIC Database [Table 4.1] and Table 5.2 to determine the values associated with the respective site values.

\subsubsection{Ranking the Sites (Case I Scenario)}

Using the method described above, we develop a summary of state values for the three sites as shown in Table 5.3 using existing information in the PIC database.

Table 5.3: Summary of Site Ranking Information for Case 1 Scenario

\begin{tabular}{|c|c|c|c|c|c|c|c|c|c|}
\hline Site & $\begin{array}{l}\text { Env. } \\
\text { Justice } \\
\text { Zone } \\
\text { Factor }\end{array}$ & $\begin{array}{l}\text { Current } \\
\text { Land Use } \\
\text { Factor }\end{array}$ & $\begin{array}{l}\text { Pre- } \\
\text { Current } \\
\text { Land Use } \\
\text { Factor }\end{array}$ & $\begin{array}{l}\text { Pre- } 1963 \\
\text { Land Use } \\
\text { Factor }\end{array}$ & $\begin{array}{l}\text { Bordering } \\
\text { Land Uses } \\
\text { Factor }\end{array}$ & $\begin{array}{l}\text { Roadways } \\
\text { for Access } \\
\text { Factor } \\
\end{array}$ & $\begin{array}{l}\text { Economic } \\
\text { Link } \\
\text { Potential } \\
\text { Factor }\end{array}$ & $\begin{array}{l}\text { Investment } \\
\text { Turnover } \\
\text { Factor }\end{array}$ & $\begin{array}{l}\text { Asbestos } \\
\text { Factor }\end{array}$ \\
\hline 1 & 2 & 3 & 4 & N/A & 15 & 2 & N/A & N/A & 5 \\
\hline 2 & 2 & 2 & 2 & N/A & 15 & 4 & $\mathrm{~N} / \mathrm{A}$ & N/A & 1 \\
\hline 3 & 2 & 2 & 3 & N/A & 13 & 3 & N/A & N/A & 1 \\
\hline
\end{tabular}


We call this first series of runs our Case I Scenario, the scenario in which all of our information comes directly from the PIC Database. The Case 1 Scenario assumes that there is no pre-1963- as well as future land use information readily available for the three sites to be ranked. Hence the two variables Investment_Turnover_Factor and Economic_Link_Potential_Factor are both assigned values of zero [see Table 5.2], and the Pre_1963_Land_Use_Factor is assigned a 50\% probability for Industrial Uses for all of the three sites. All other model variables for which information is contained in the PIC Database are rated accordingly. The resulting Influence Diagram models for the respective sites are shown in Figures 5.5.1, 5.5.2 and 5.5.3. The models are then solved to provide both the expected value and risk profiles for each site shown in Figures 5.5.1A, 5.5.2A and 5.5.3A. As summarized in Table 5.4, site 1 has the highest expected value of 1106 redevelopment potential points, site 2 comes in second with 848 points, and site 3 follows close behind with 823 points. A look at the risk profiles for the separate sites is necessary for determining the final ranking of the sites. The shapes of the risk profiles and the expected value differences between low and high probabilities in this case 1 scenario are similar for all the three sites, and hence will not have any significant impact on the final ranking.

Table 5.4: Site Expected Values for Case 1 Scenario

\begin{tabular}{|c|c|}
\hline Site & Expected Value \\
\hline 1 & 1106 \\
\hline 2 & 848 \\
\hline 3 & 823 \\
\hline
\end{tabular}



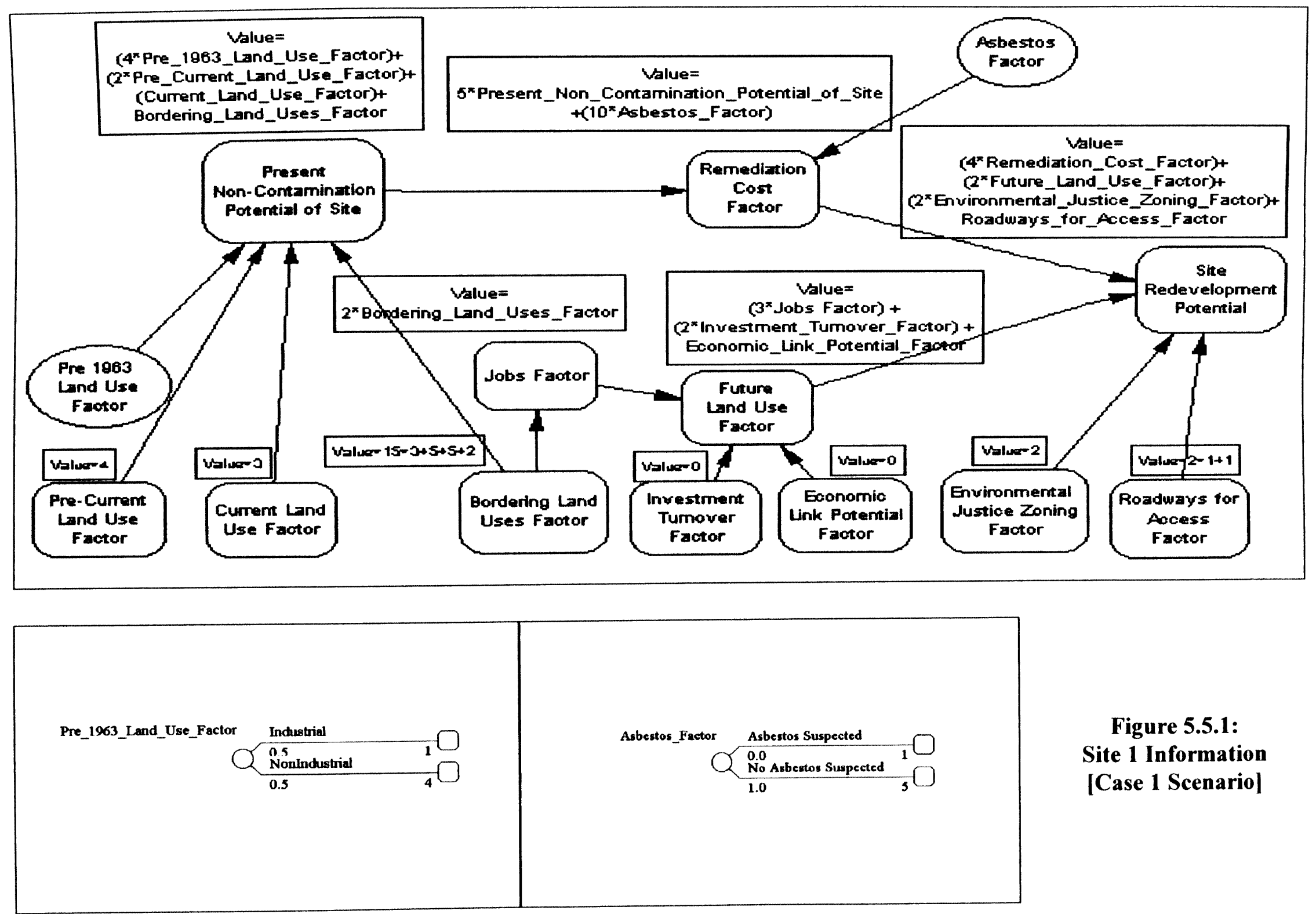

Figure 5.5.1:

Site 1 Information

[Case 1 Scenario] 

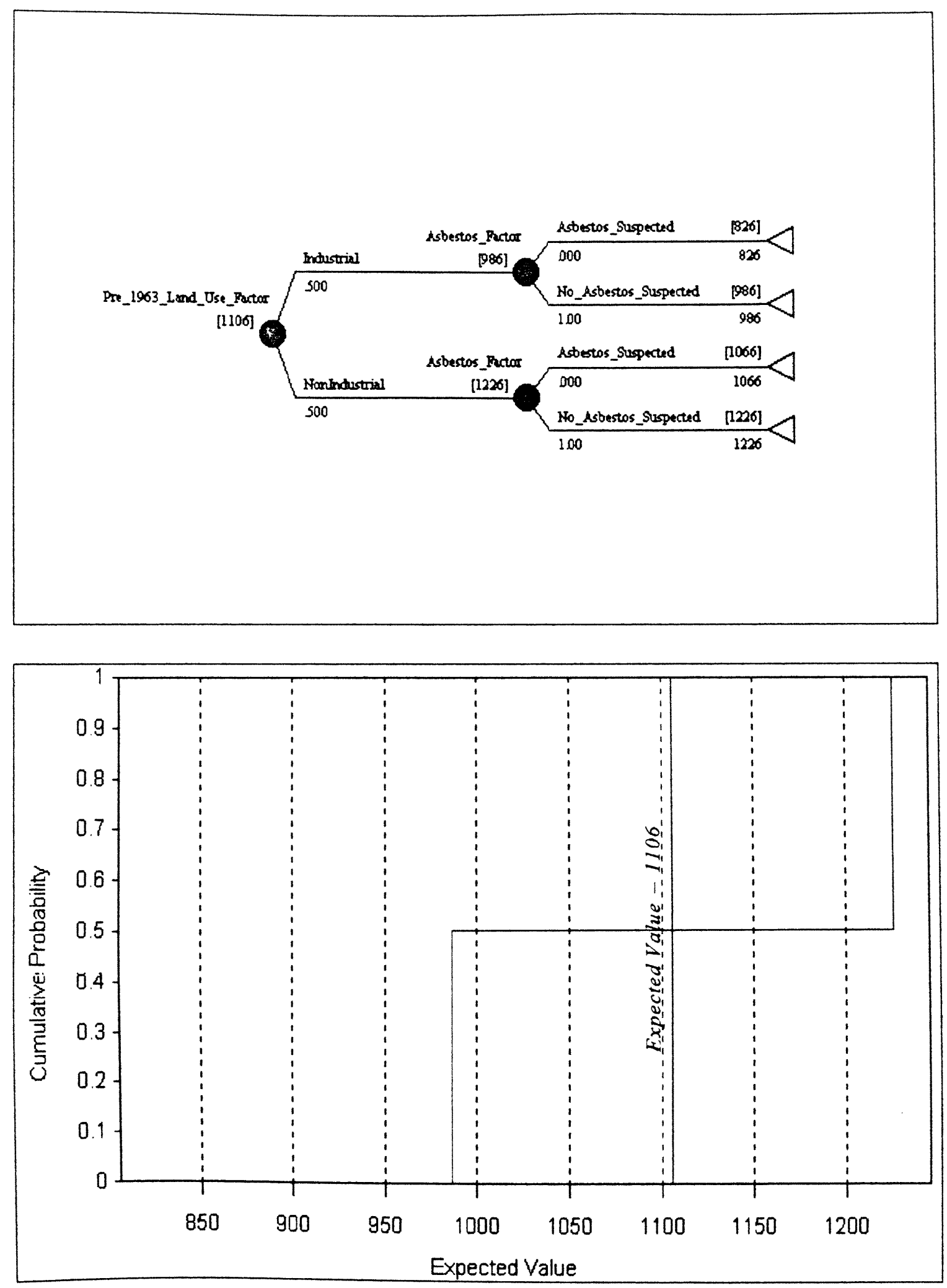

Figures 5.5.1A: Expected Value and Risk Profile for Site 1 [Case 1 Scenario] 

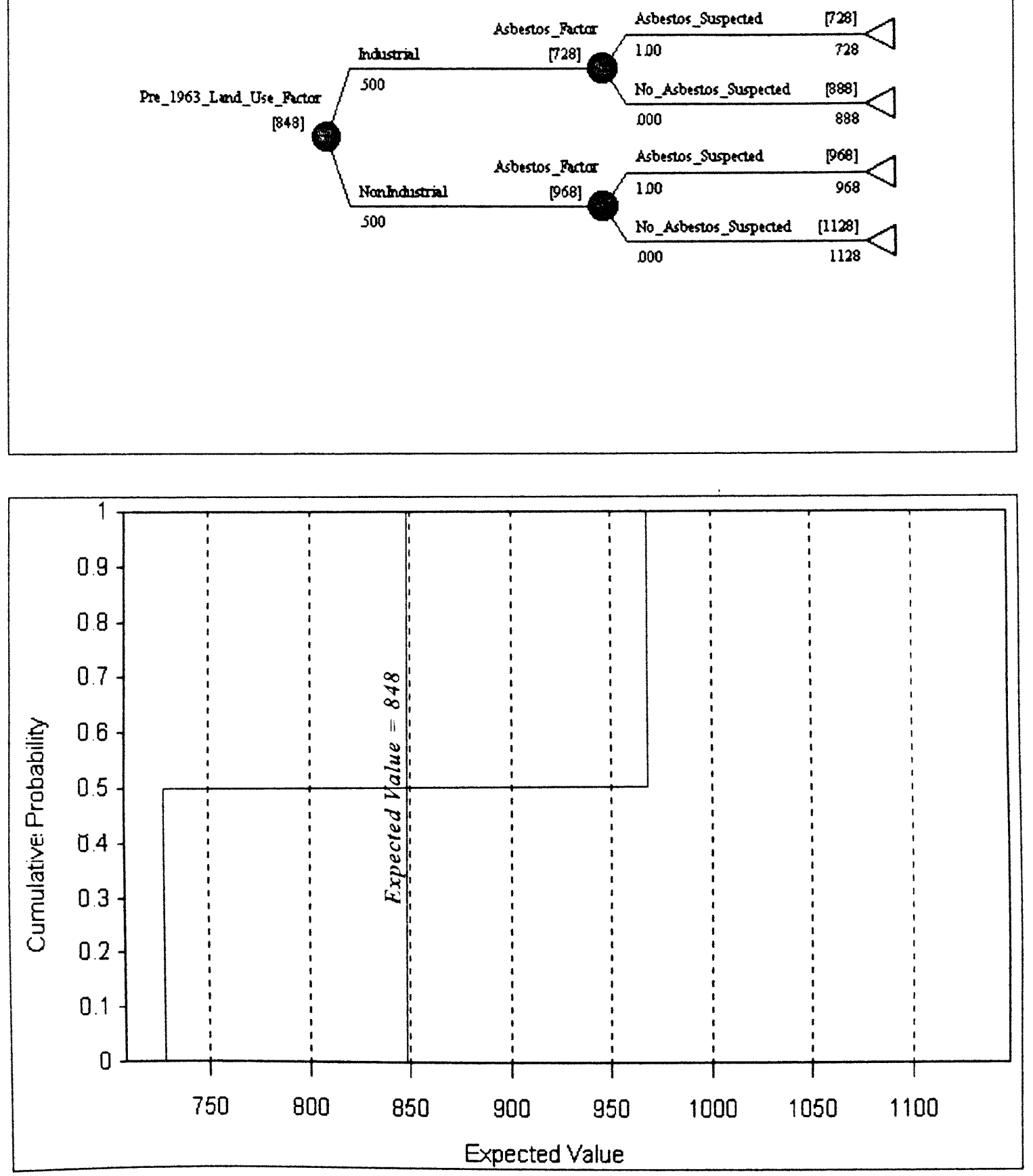

Figures 5.5.2A: Expected Value and Risk Profile for Site 2 [Case 1 Scenario] 


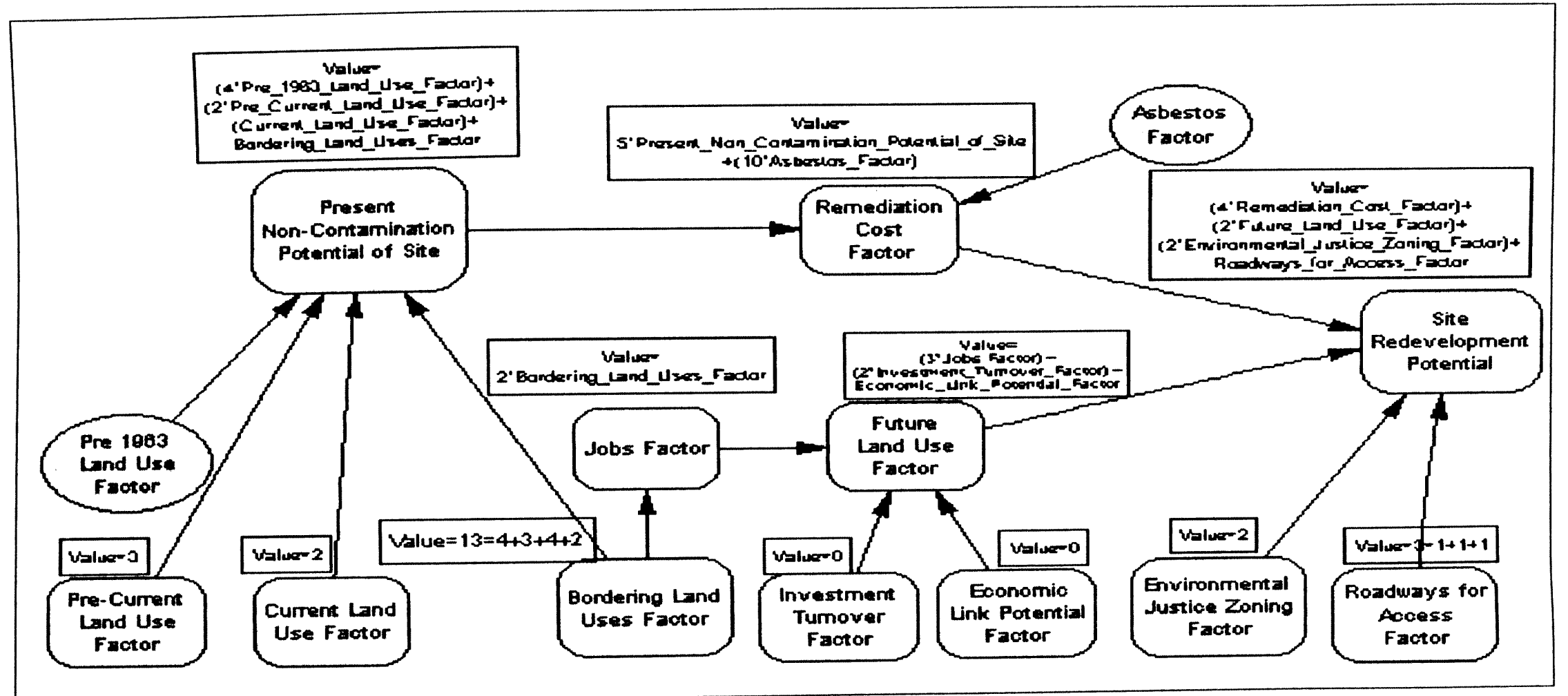

Pre_1963_Land_Use_Factor

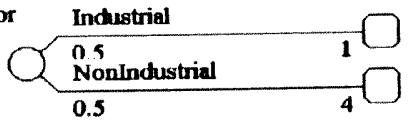

Astestos_factor Asbestos Sugpectod

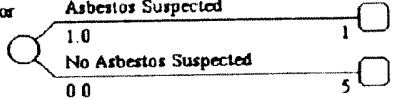

Figure 5.5.3:

Site 3 Information

[Case 1 Scenario] 

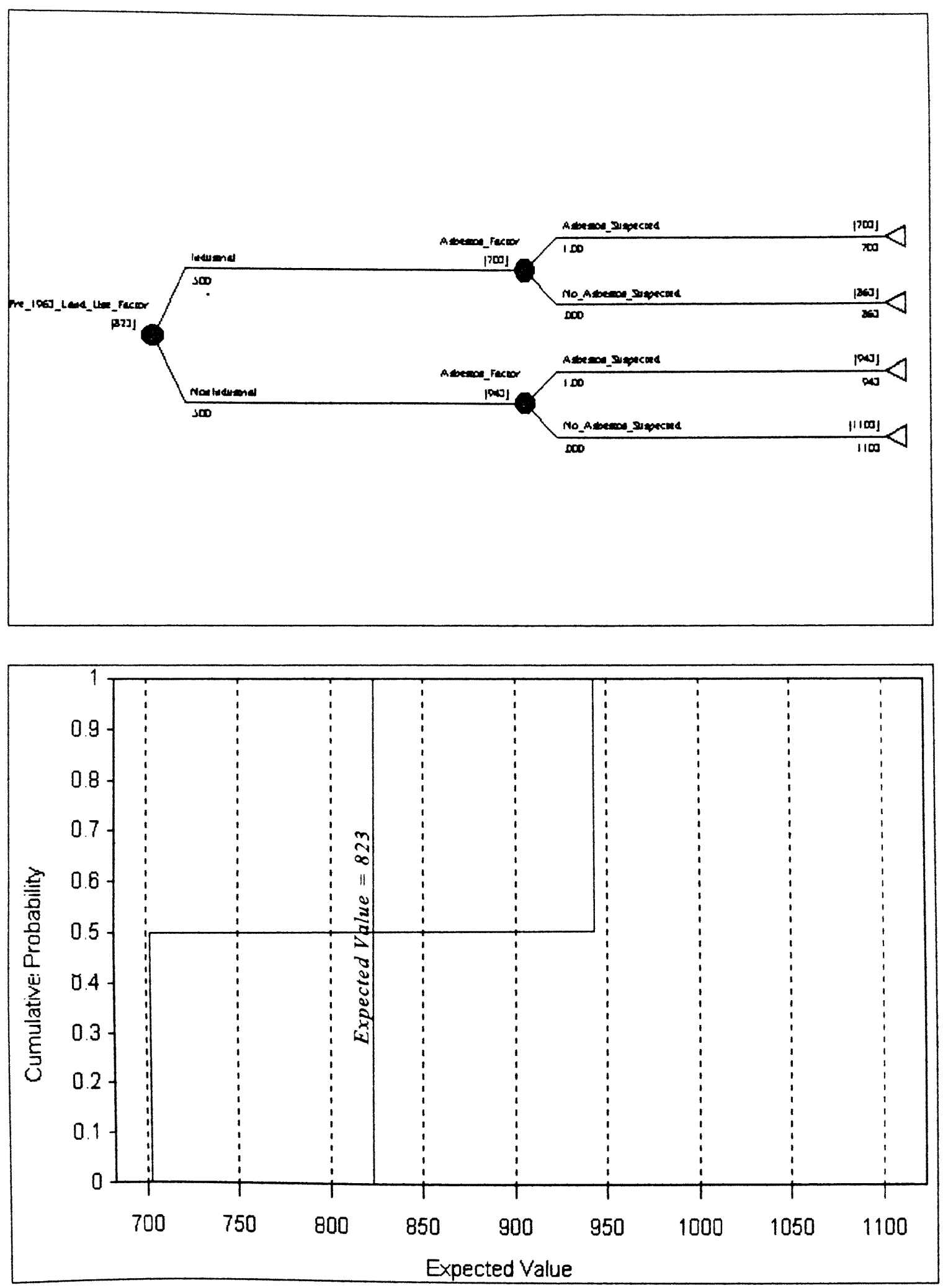

Figures 5.5.3A: Expected Value and Risk Profile for Site 3 [Case 1 Scenario] 


\subsubsection{Ranking the Sites (Case 2 Scenario)}

For our case two scenario, a hypothetical situation was assumed in which three separate private parties have approached the County with an interest in developing site 1 as a Publix (large scale grocery retail), site 2 as a Metal Recycling Facility, and site 3 as a Storage Warehouse. In our case 2 scenario, this information will be factored into the decision model for ranking the sites. Table 5.5 summarizes the additional ratings assigned to the individual sites based on the above information.

Table 5.5: Additional Land Redevelopment Information for Case 2 Scenario

\begin{tabular}{|c|c|c|c|}
\hline Site & Land Use & $\begin{array}{c}\text { Investment } \\
\text { Turnover Factor } \\
{[\boldsymbol{I T F}]}\end{array}$ & $\begin{array}{c}\text { Economic Link } \\
\text { Potential Factor } \\
{[\boldsymbol{E} \boldsymbol{L P F}]}\end{array}$ \\
\hline 1 & Publix & 3 & 2 \\
\hline 2 & Metal Recycling & 1 & 3 \\
\hline 3 & $\begin{array}{c}\text { Storage } \\
\text { Warehouse }\end{array}$ & 2 & 0 \\
\hline
\end{tabular}

\section{Investment Turnover Factor [ITF]}

The ITF [see Table 5.1] is a measure of the profitability of the proposed future land use of the site. Since Brownfields resources are usually limited, site redevelopments with high profitability are commensurately rated. Publix being a large and major retailer is expected to pay outright for site 1 , whose cost includes the remedial costs incurred in bringing the site up to the required County standards for reuse. Hence an ITF of 3 (the optimal value) is assigned for site 1. The Metal Recycler expects to pay 
the total cost for site 2 in two years which leads to a relative ITF value of 1, (from the perspective of the County which is interested in recouping the remediation investment as fast as possible in order to replenish its revolving fund and proceed with redeveloping its Brownfields). The County expects the Storage Warehouse to make good on its promise for a total payment in one year, hence an ITF of 2 is assigned for this alternative, indicating that the Storage Warehouse option is twice as attractive to the County from the point of view of remediation investment turnover, as is the Metal Recycling Facility.

\section{Economic Link Potential Factor [ELPF]}

The ELPF relates to the land use compatibility of the proposed land development with the City's already existing land uses [see Table 5.1]. The Publix is rated with a value of 2 because it is of utility to the surrounding residential areas; the Metal Recycling Facility gets an optimal rating of 3 because it will use metal crap facilities in the area as a resource, and the Storage Warehouse receives an ELPF value of zero since it has negligible linkages to the existing land uses in the PIC area.

This new information is used in updating the Influence Diagram models. The models are rerun and expected values for the three sites in the case 2 scenario are summarized in Table 5.6. Figures 5.6 show the expected value and risk -related outputs for each site in the case 2 scenario. 

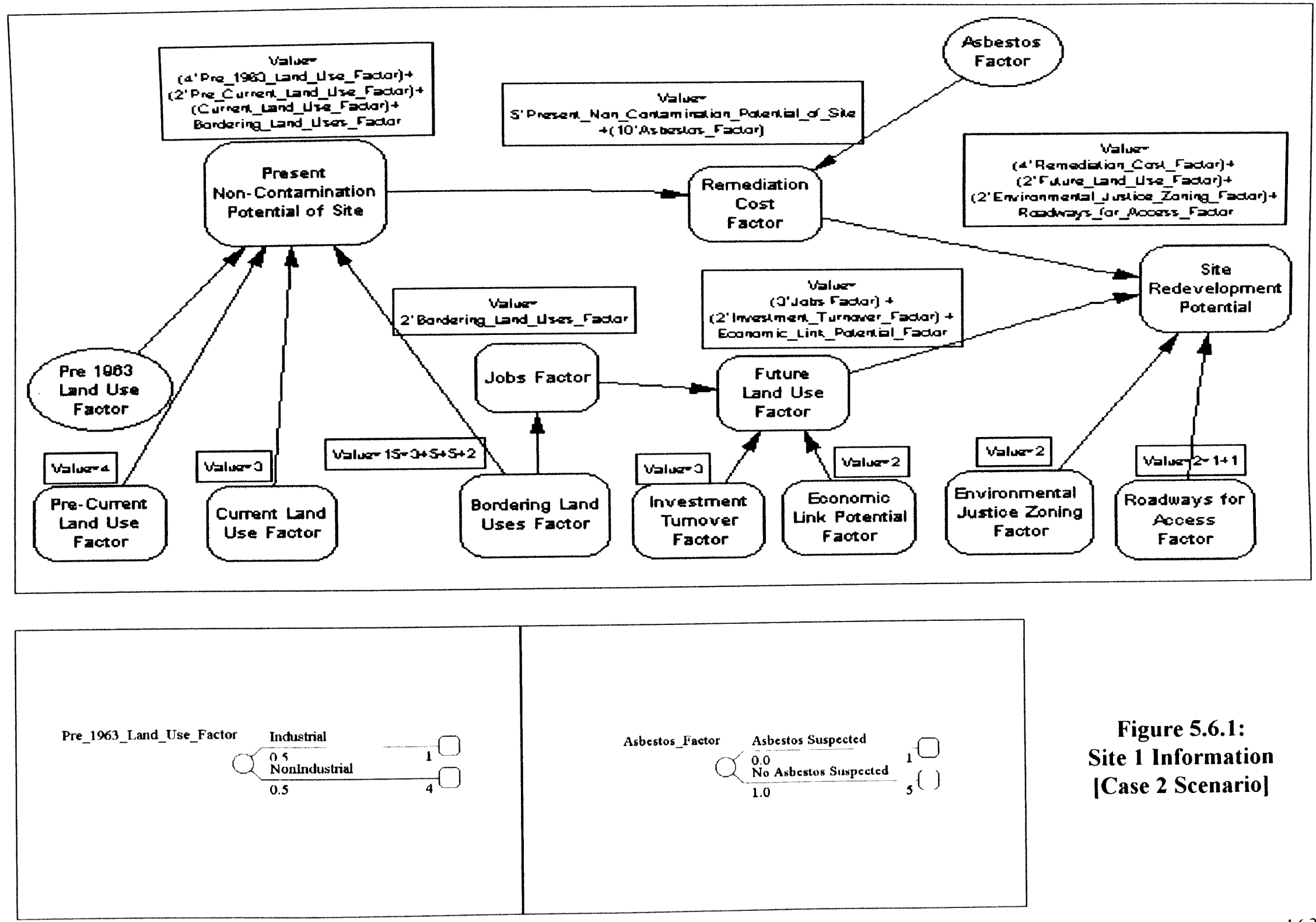

Figure 5.6.1:

Site 1 Information

[Case 2 Scenario] 


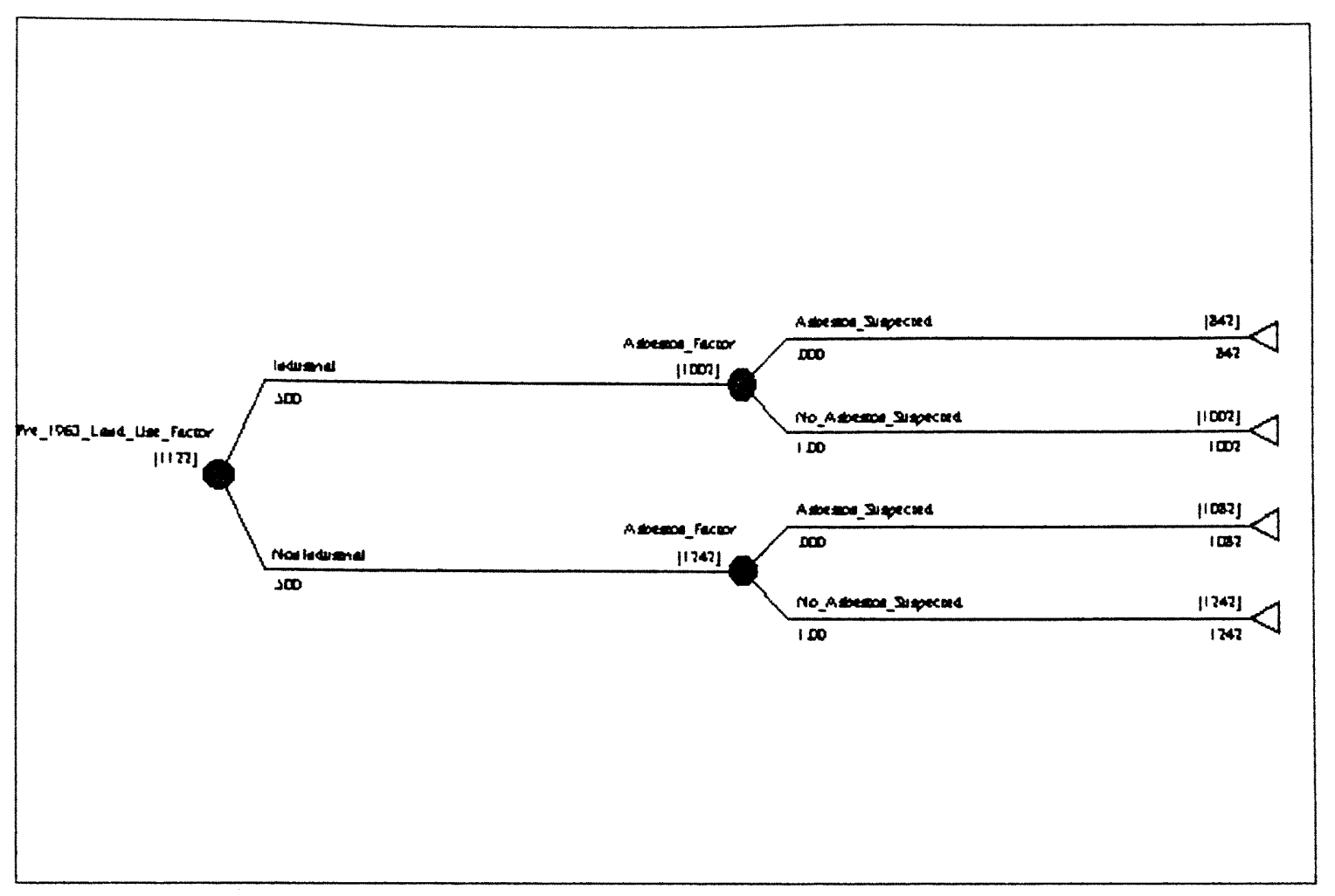

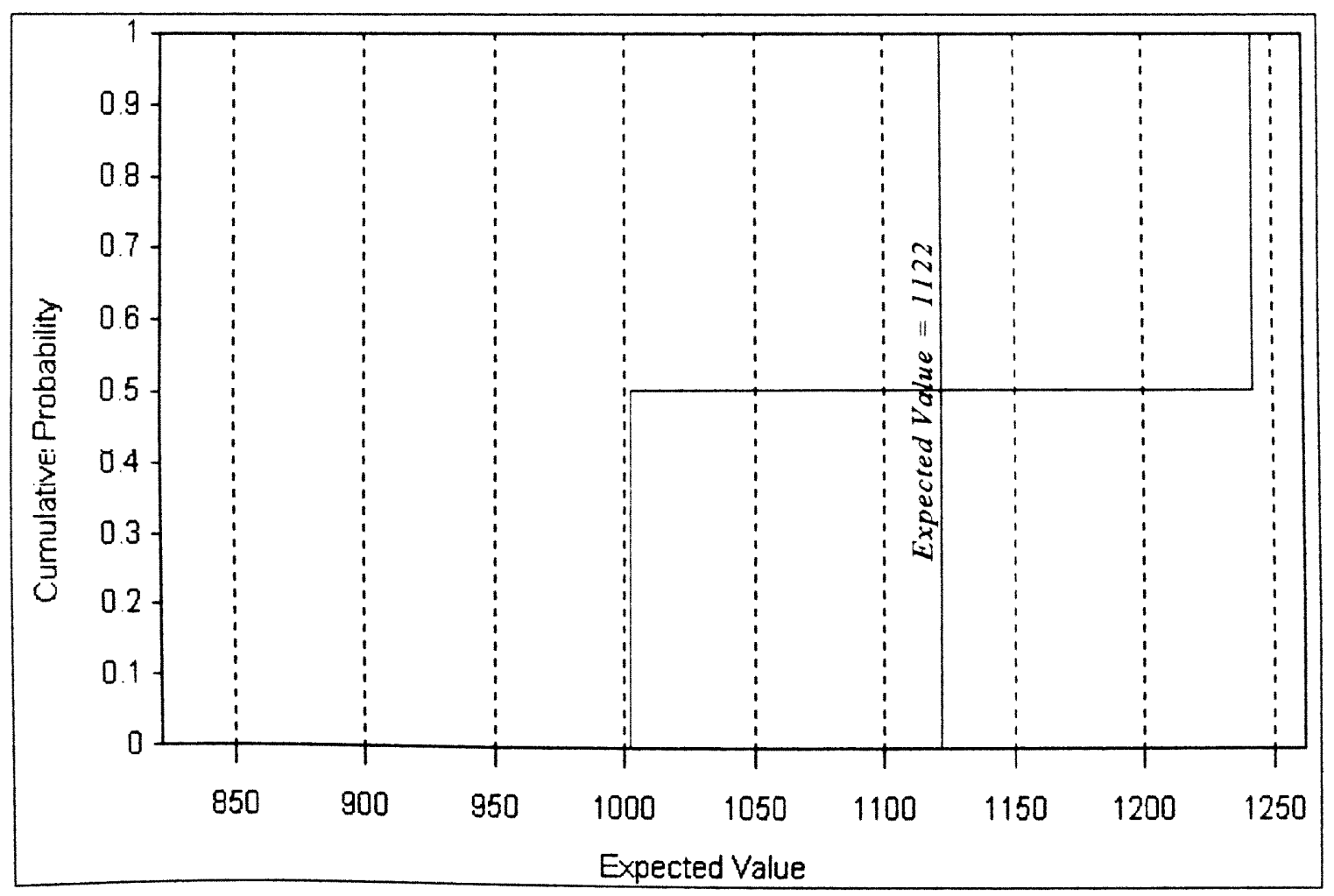

Figures 5.6.1A: Expected Value and Risk Profile for Site 1 [Case 2 Scenario] 


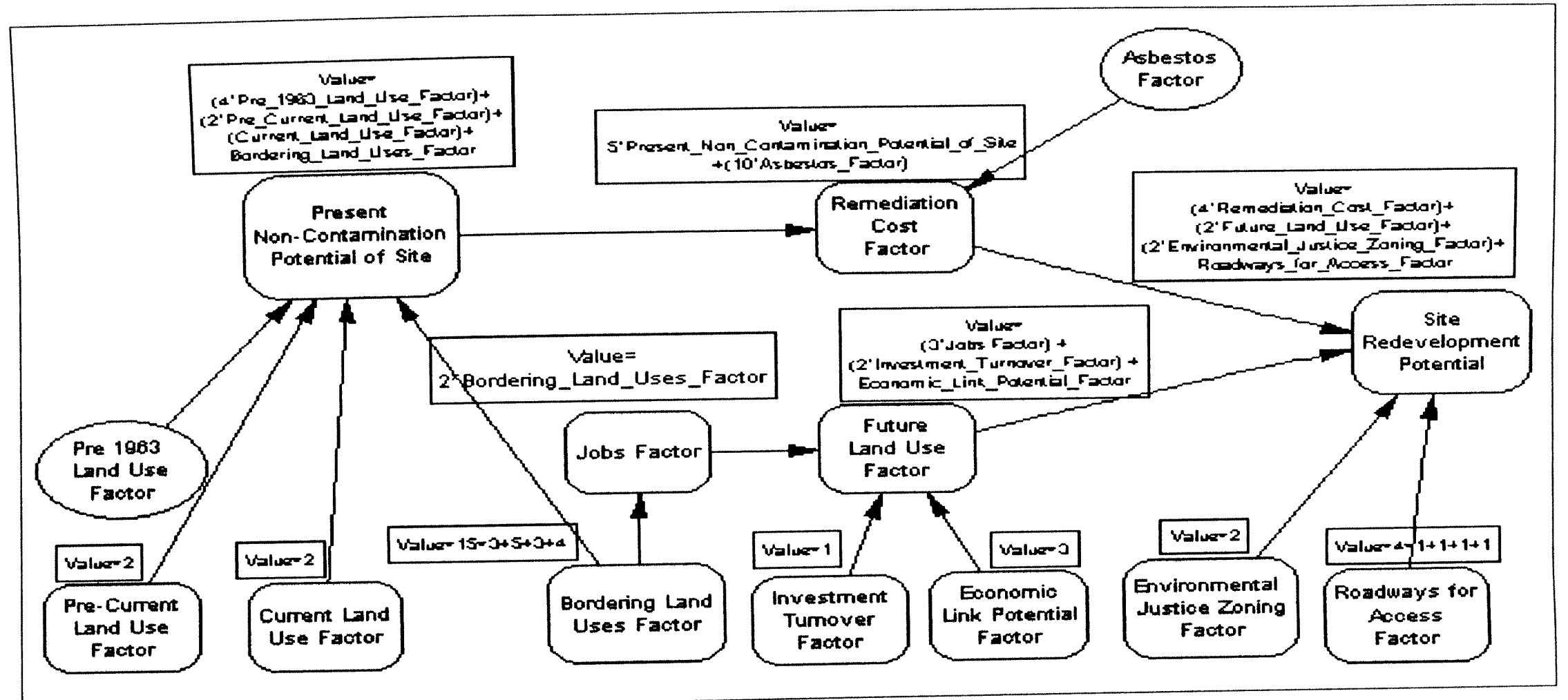

Pre_1963_Land_Use_Factor Industrial

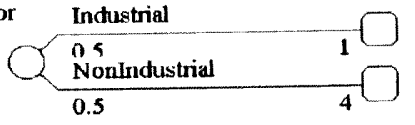

$\begin{array}{ll}\text { Asbestos_Factor } & \text { Asbestos Suspected } \\ 1.0 & \text { No Asbestos Suspected }\end{array}$

00
Figure 5.6.2:

Site 2 Information

[Case 2 Scenario] 


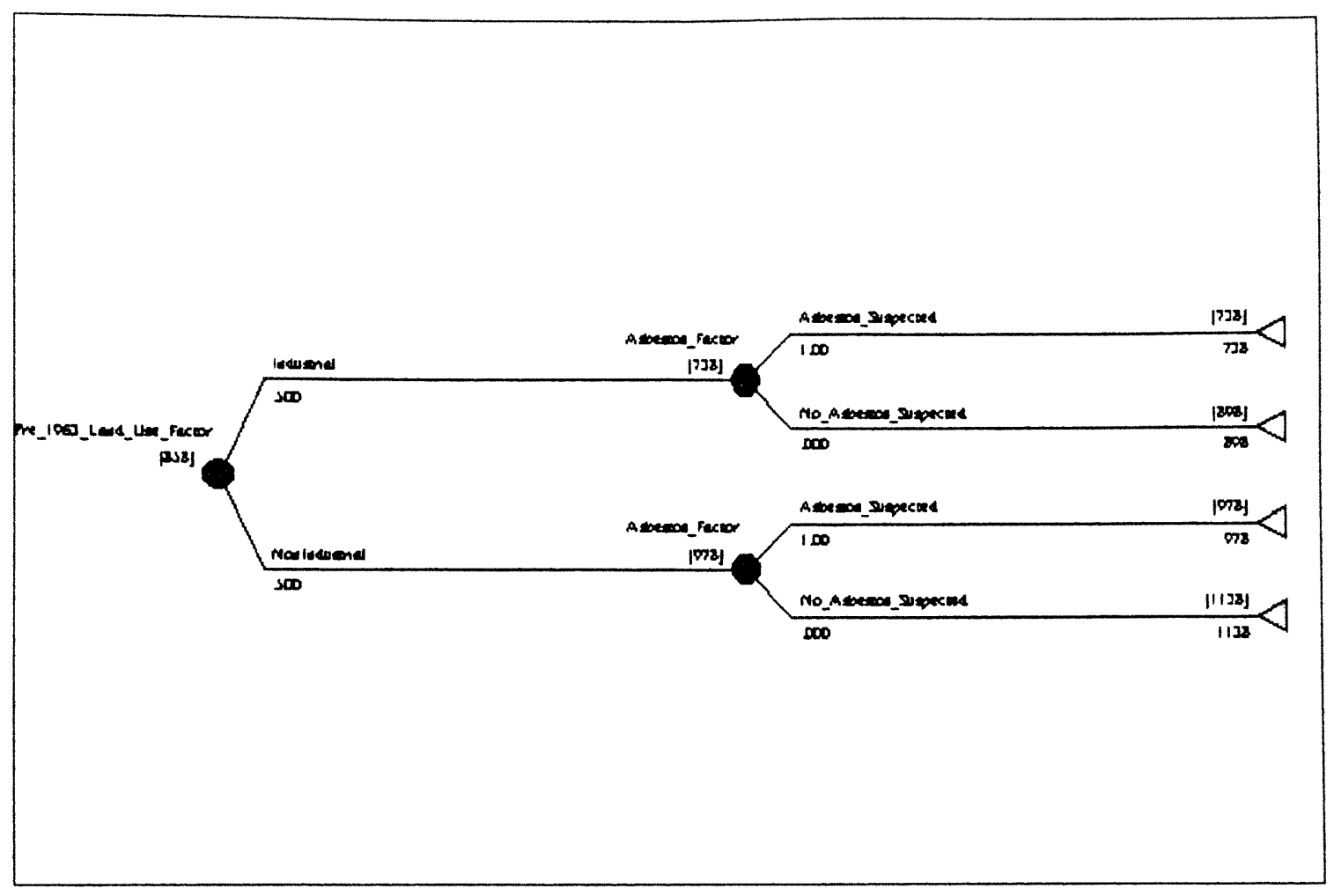

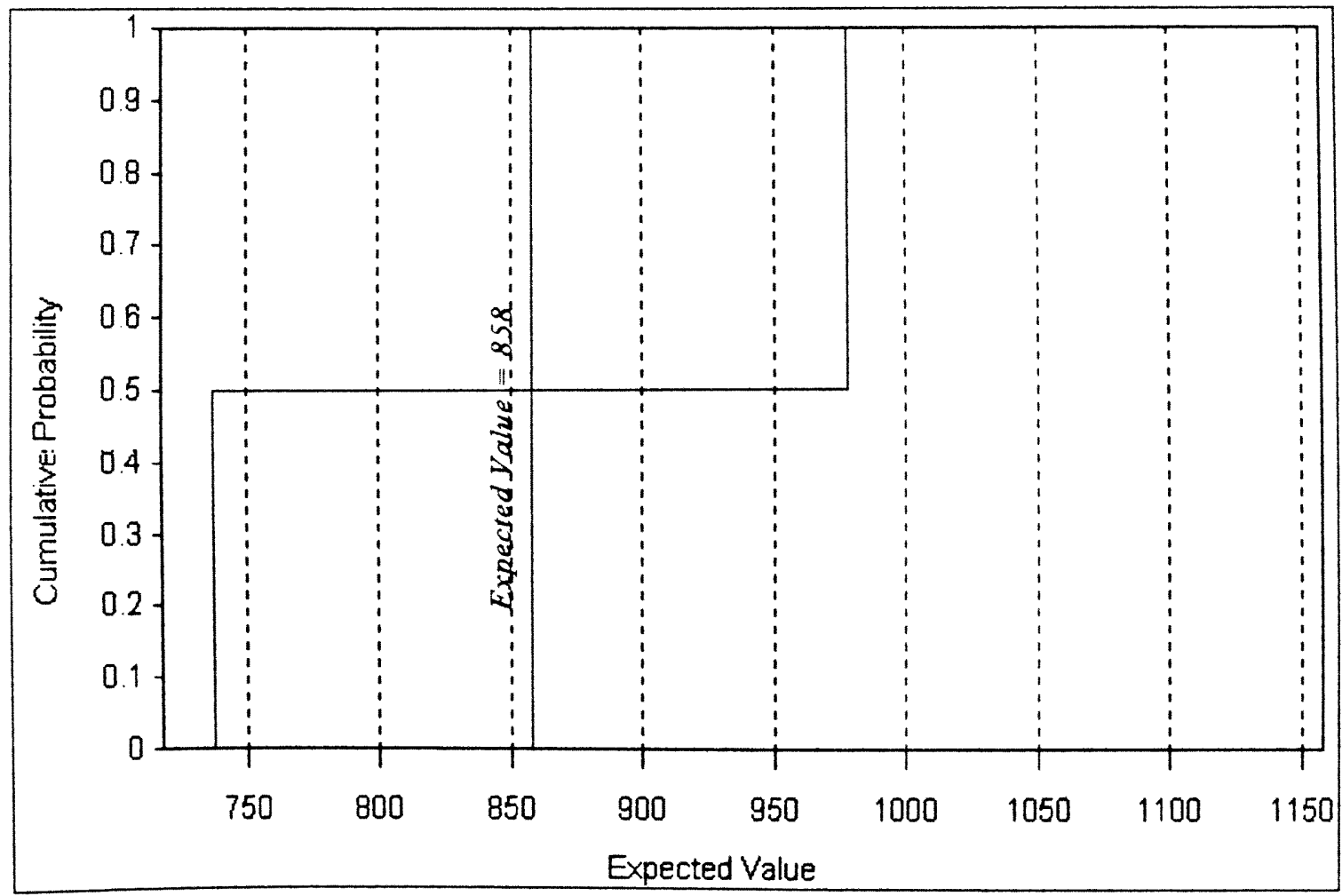

Figures 5.6.2A: Expected Value and Risk Profile for Site 2 [Case 2 Scenario] 

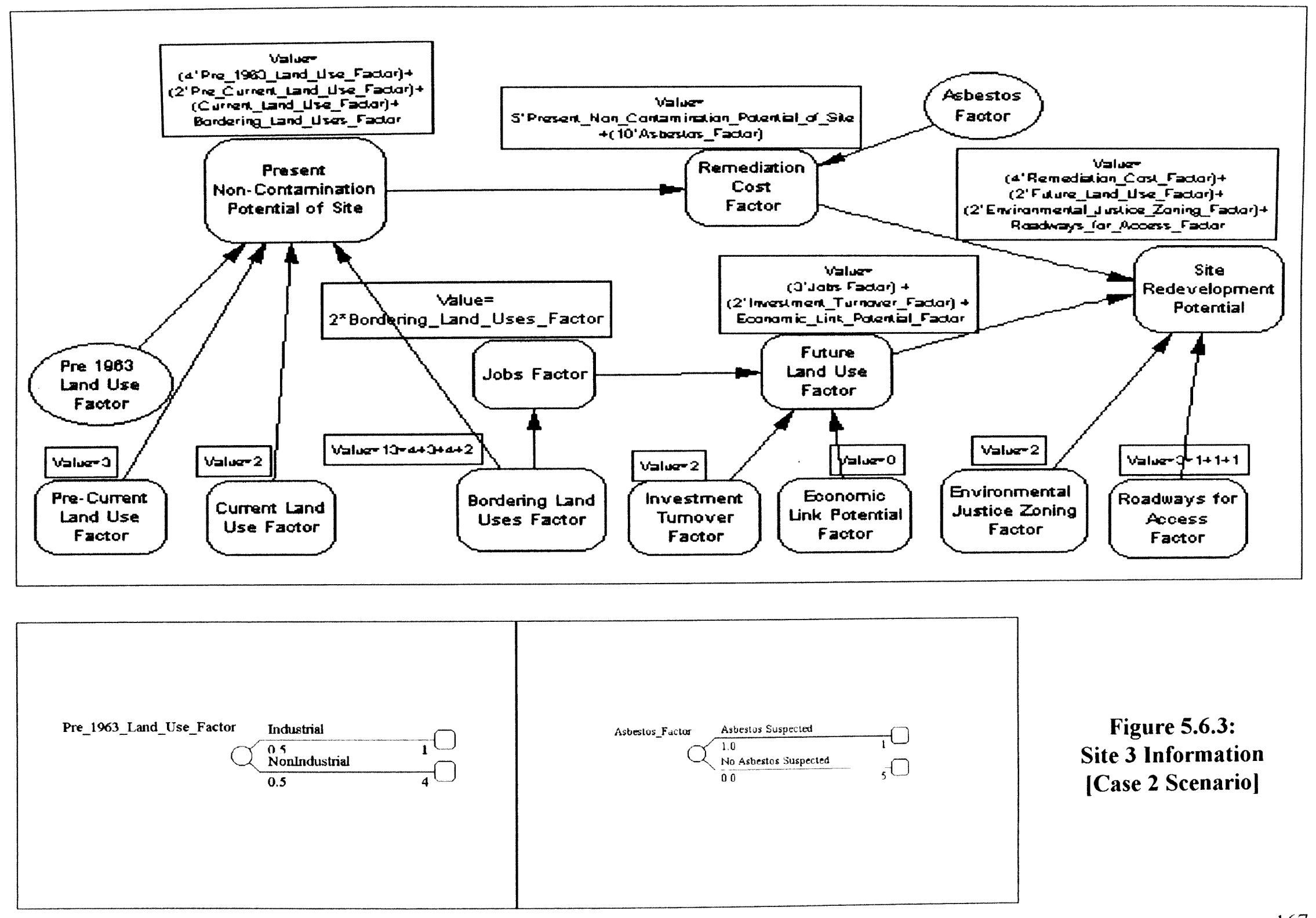

Figure 5.6.3:

Site 3 Information

[Case 2 Scenario] 


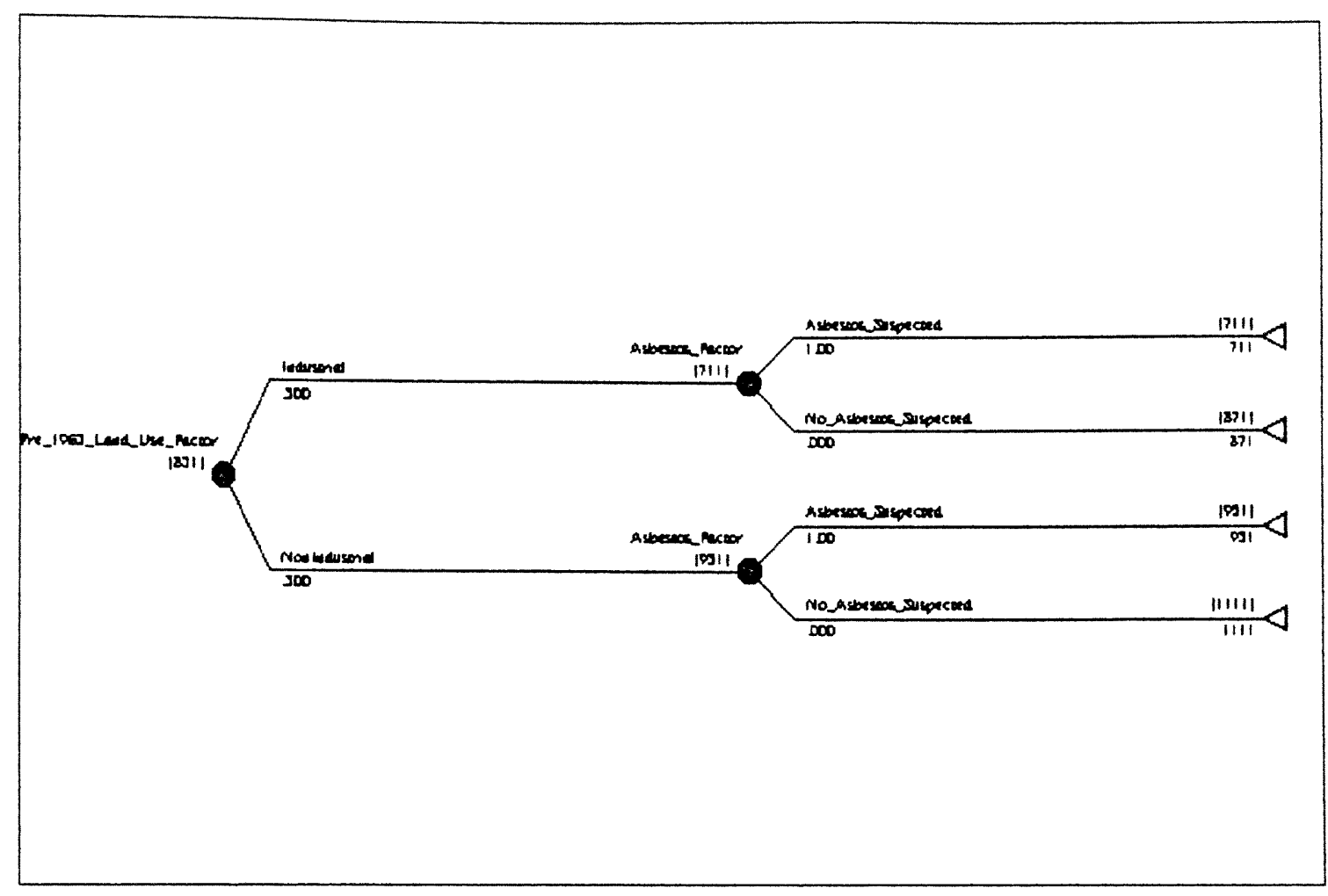

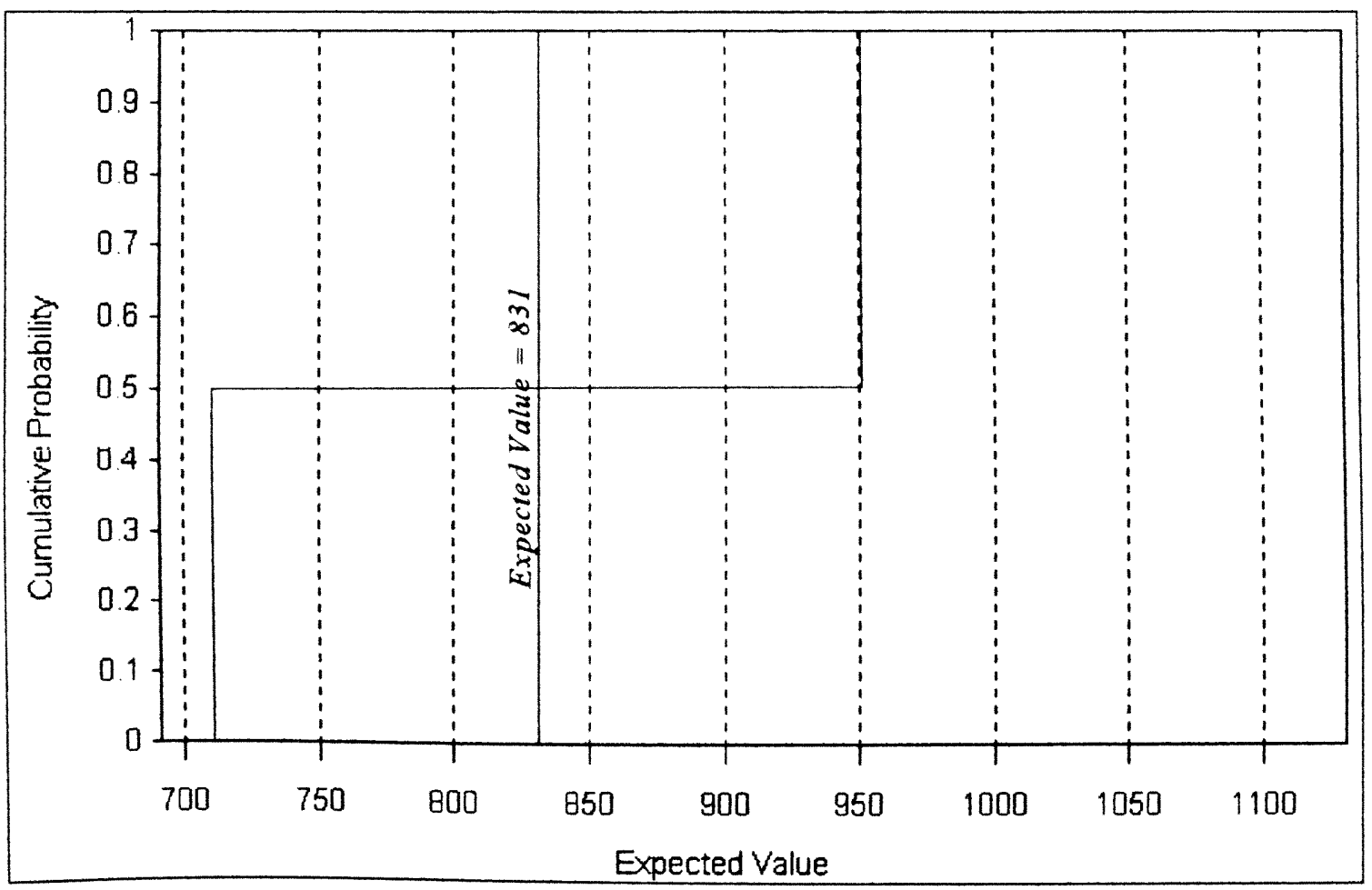

Figures 5.6.3A: Expected Value and Risk Profile for Site 3 [Case 2 Scenario] 
Table 5.6 Site Expected Values for Case 2 Scenario

\begin{tabular}{|c|c|}
\hline Site & Expected Value \\
\hline 1 & 1122 \\
\hline 2 & 858 \\
\hline 3 & 831 \\
\hline
\end{tabular}

Although the ranking order of the sites stays the same, site 1 becomes more attractive than site 2, with an expected value difference of 264 compared to the case 1 scenario where the expected value difference between the two sites was 258 . Likewise site 2 becomes more attractive than site 3 by a couple of points. Since no probability information is inputted for this scenario, the risk profiles for the three sites remain similar to the case 1 scenario and have no significant effect on site ranking [see Figures 5.6.1A, 5.6.2A and 5.6.3A].

\subsubsection{Ranking the Sites (Case 3 Scenario)}

In our case 3 scenario, we assume a hypothetical situation in which Dade County decides to fund land use research for the three sites prior to the year 1963, and this research reveals that site 1 was vacant prior to 1963 , site two has a high probability (80 percent) of industrial use in the late 1950s, and site 3 has a high probability ( 80 percent) of residential uses prior to 1963, as shown in Table 5.7. 
Table 5.7: Additional (Pre-1963) Land Use Information for Case 3 Scenario

\begin{tabular}{|c|c|c|c|}
\hline Site & Land Use & Value & $\begin{array}{c}\text { Associated Probability } \\
(\boldsymbol{\%})\end{array}$ \\
\hline 1 & Vacant & 4 & 100 \\
\hline 2 & Industrial & 1 & 80 \\
\hline 3 & Residential & 4 & 80 \\
\hline
\end{tabular}

Figures 5.7.1, 5.7.2 and 5.7.3 show how this information is inputted to update the existing models from the case 2 scenario. The Influence Diagram Models for the three sites are solved and give the expected value and risk information summarized in Table 5.8. Figures 5.7 show the details of the outputs for this run.

Table 5.8 Expected Value and Risk Information for Case 3 Scenario

\begin{tabular}{|l|l|l|l|}
\hline Site & Low Value (Probability) & Expected Value & High Value (Probability) \\
\hline 1 & N/A & 1242 & N/A \\
\hline 2 & $738(80 \%)$ & 786 & $978(20 \%)$ \\
\hline 3 & $711(20 \%)$ & 903 & $951(80 \%)$ \\
\hline
\end{tabular}

N/A - Not Applicable

Site 1 retains its lead and becomes even more attractive with respect to the other two sites because of its favorable land uses prior to 1963 , and the certainty associated with the site's information. The cases of sites 2 and 3 are slightly different. Purely from a standpoint of expected value, the order of sites 2 and 3 are reversed with site 3 becoming more attractive than site 2 . Site 3 leads site 2 with a total of 117 

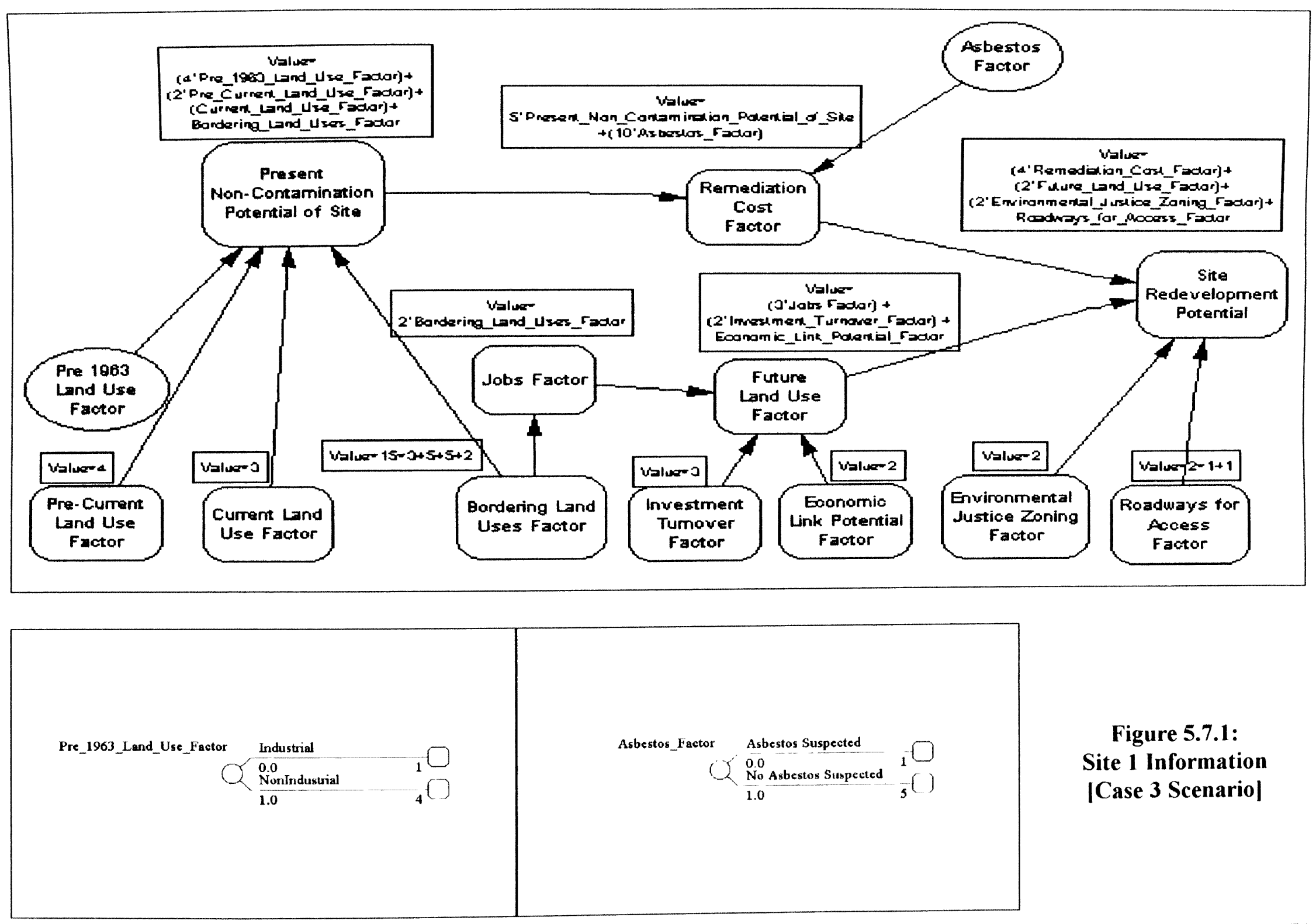

Figure 5.7.1:

Site 1 Information

[Case 3 Scenario] 


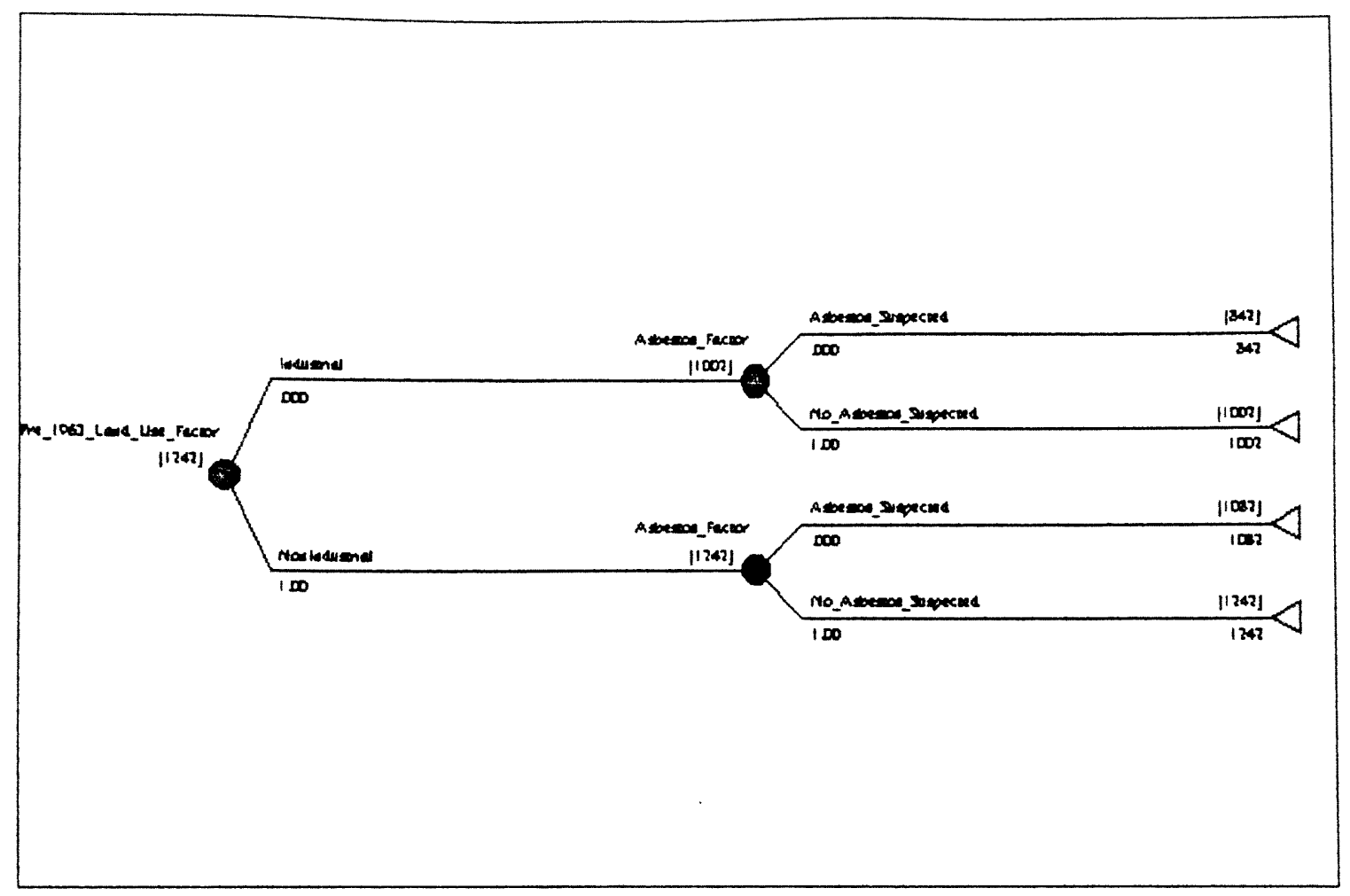

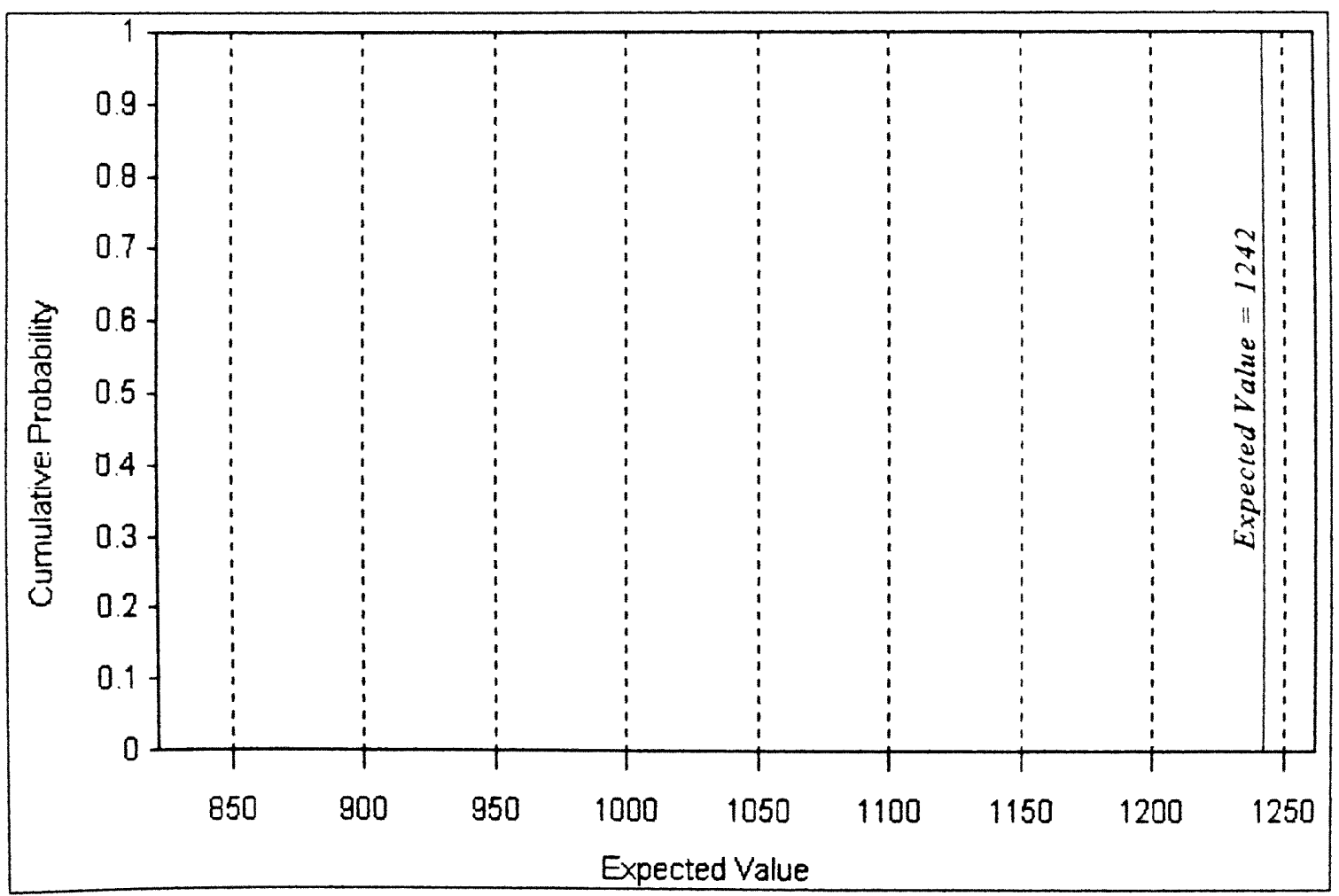

Figures 5.7.1A: Expected Value and Risk Profile for Site 1 [Case 3 Scenario] 

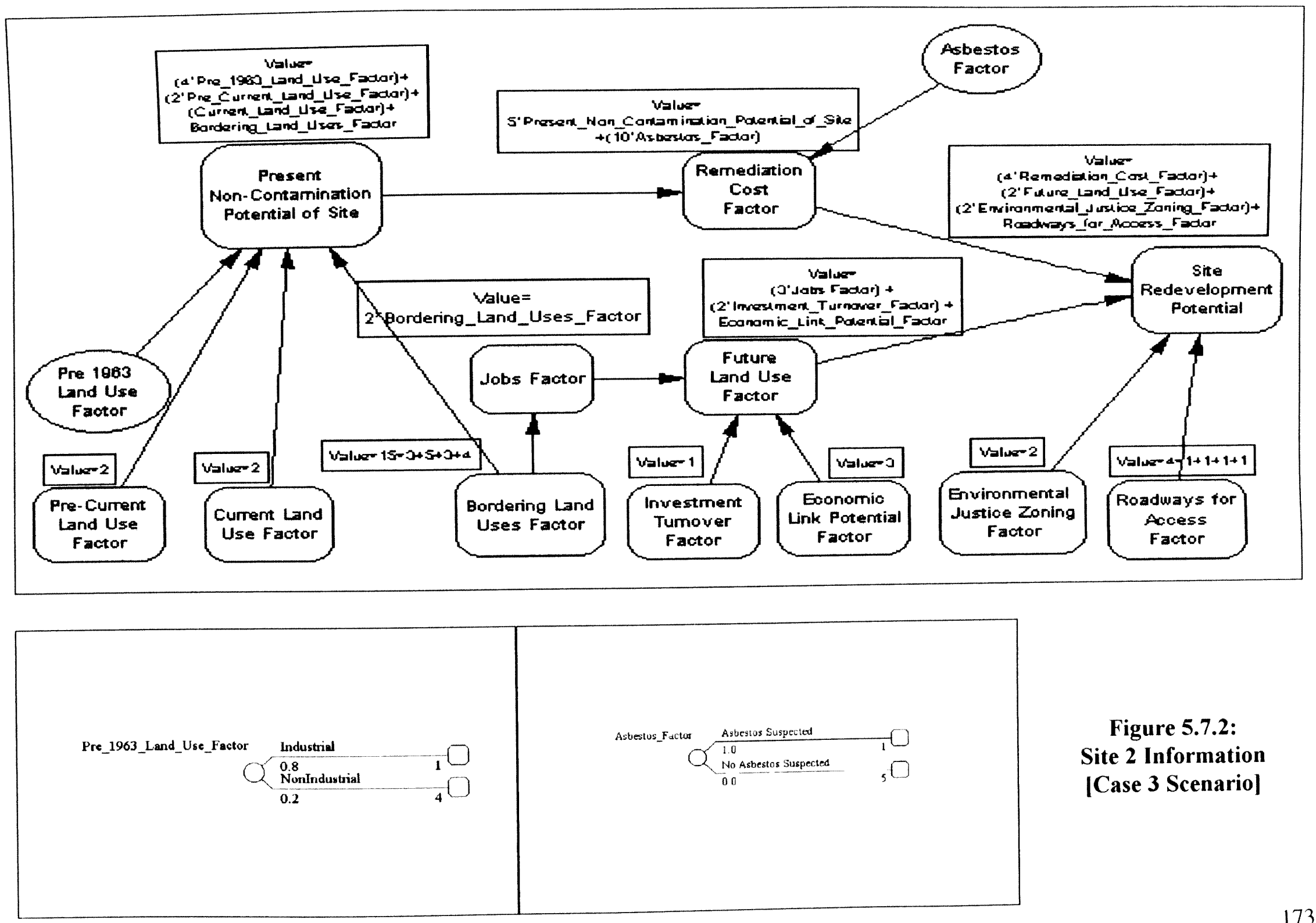

Figure 5.7.2:

Site 2 Information

[Case 3 Scenario] 

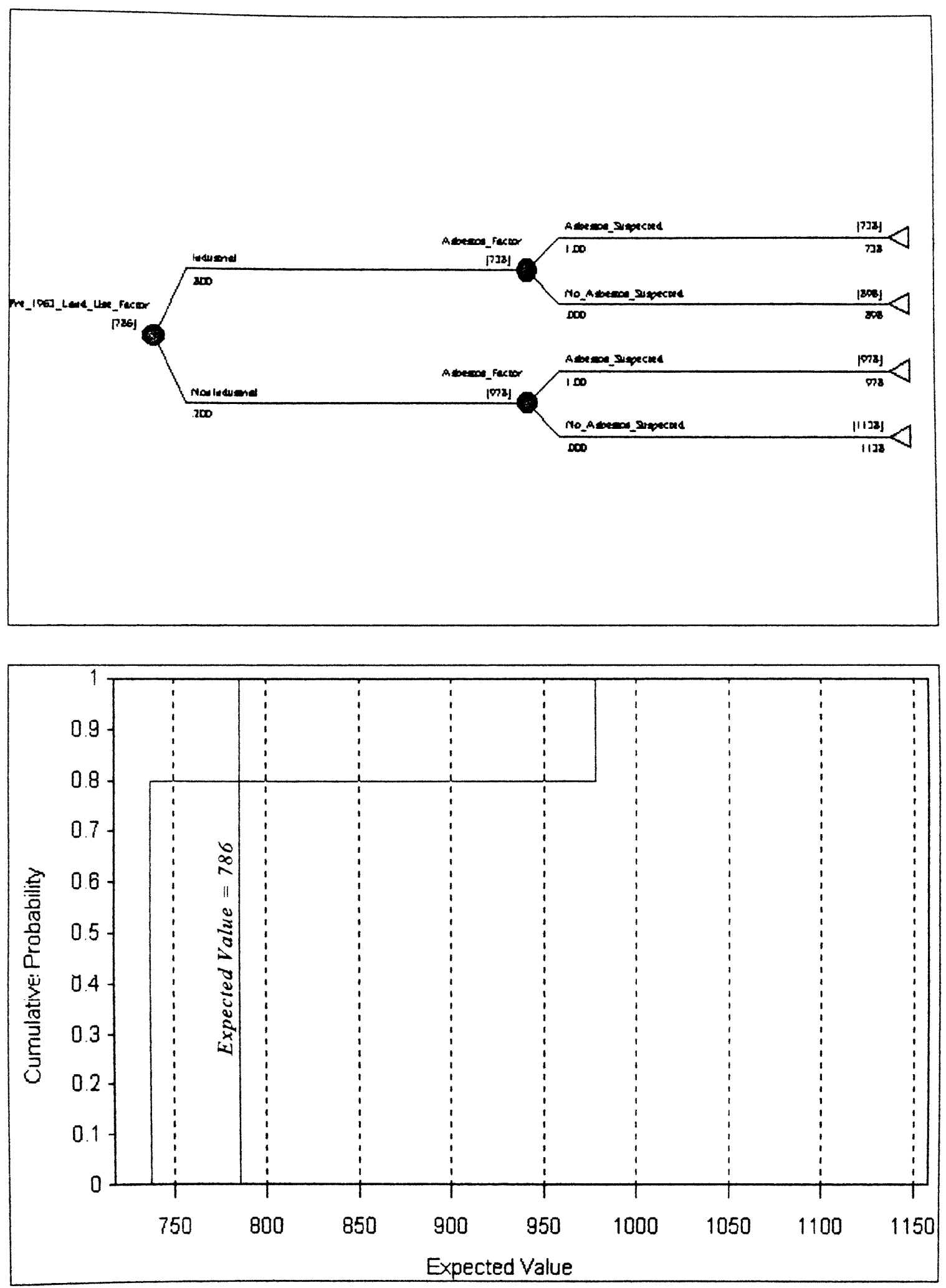

Figures 5.7.2A: Expected Value and Risk Profile for Site 2 [Case 3 Scenario] 

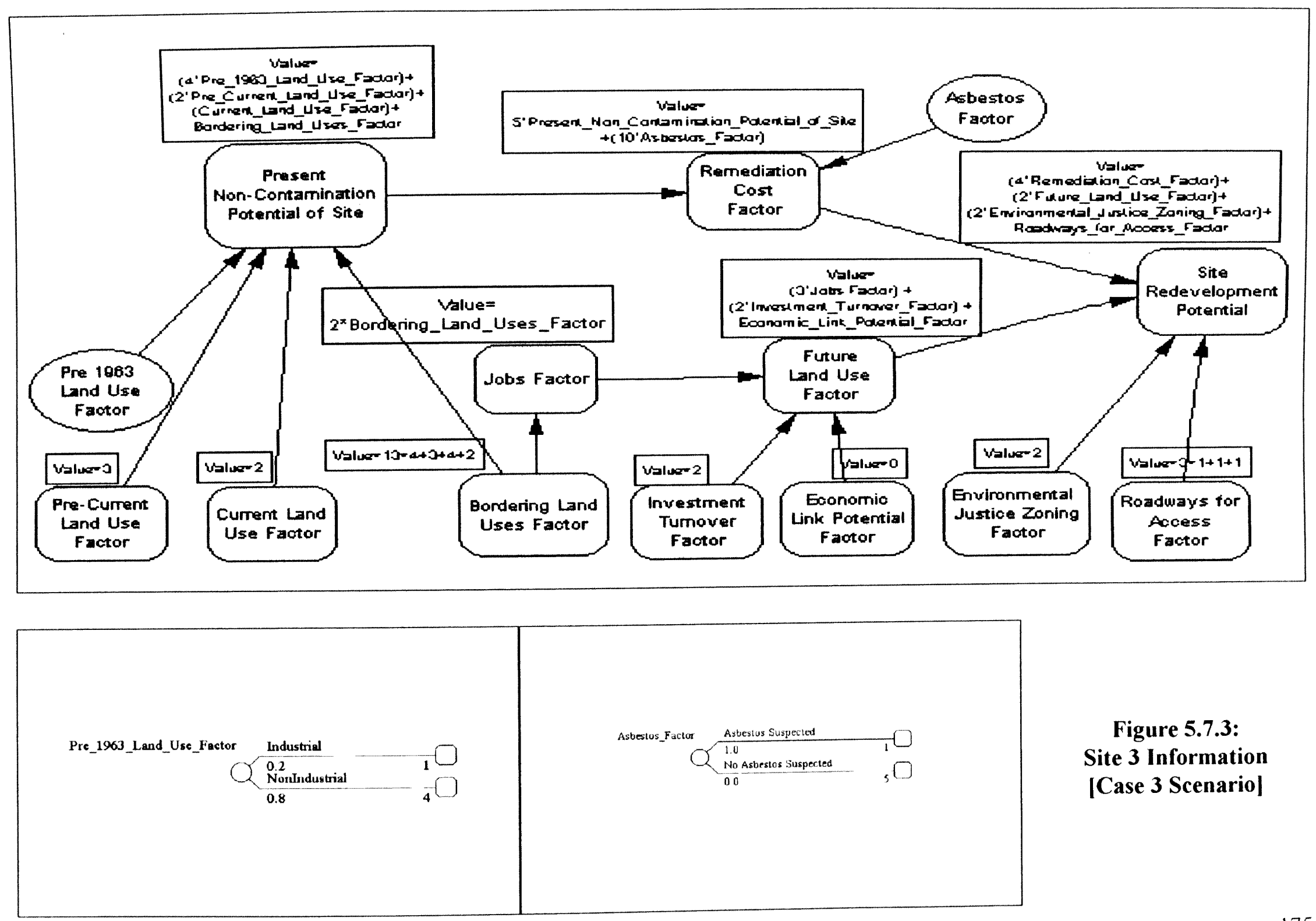

Figure 5.7.3:

Site 3 Information

[Case 3 Scenario] 

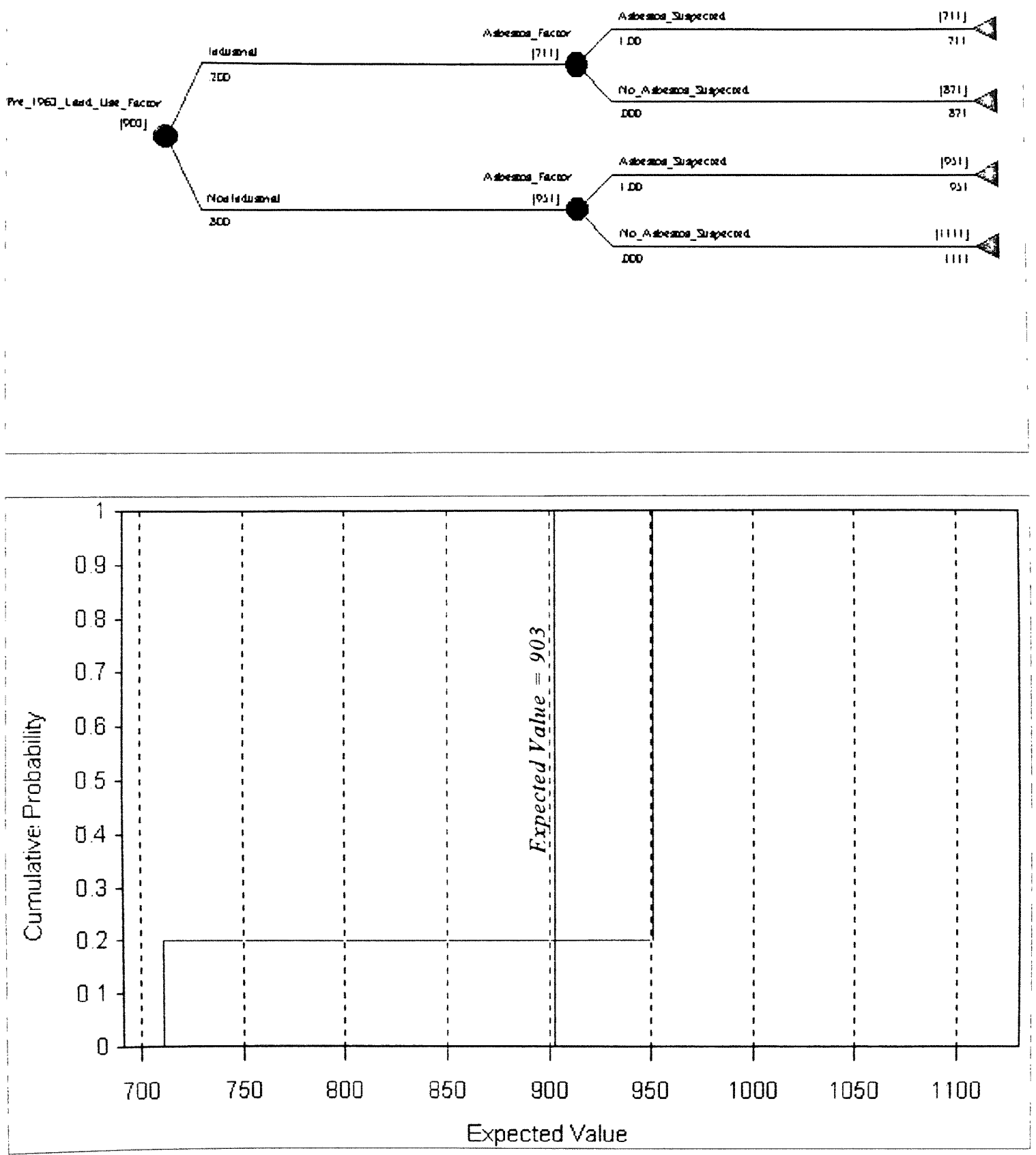

Figures 5.7.3A: Expected Value and Risk Profile for Site 3 [Case 3 Scenario] 
redevelopment potential points. Because the probabilities of these two sites are no longer symmetric, this run presents a neat opportunity for risk analysis. We observe that while site 3 has a higher expected value than site 2, the Highest Expected Value of site 2 is 27 points larger than that of site 3 . This information indicates that it is still probable that site 2 has a higher redevelopment potential than site 1 . So the question we ask ourselves then is how probable is this? What is the chance of site 2 having a higher redevelopment potential than site 3 ? The answer is 20 percent as is seen in Table 5.8 and Figures 5.7. Now a risk taking or risk prone decision-maker (one inclined to take whatever chances to maximize his or her utility) would rank site 2 higher than site 3 based on this information. A risk neutral decision-maker however, (one whose decision is purely based on the expected value and has no reference to risk), would rank site 3 higher than site 2 ; his or her decision would be solely based on the expected value of the sites. A risk averse decision maker, on the third hand, would like to minimize his or her losses whatever the outcome. This individual would also rank site 2 over site 3 because he or she would take a look at the first column of Table 5.8 and observe that the lowest expected value of site 2 is larger than that of site 3. Therefore he/she would rank site 2 above site 3 , as the lowest possible of site 2 is higher than that of site 3 . Based on this analysis, the final order of ranking is shown in Table 5.9 for the three sites. Assuming that the decision-maker is risk neutral, the final order of site remediation would be site 1 , then site 3 and finally site 2. Liberty City could begin to look forward to a new Publix at the PIC, a Storage 
Warehouse would be developed next, and the final Brownfields site would be developed as a Metal Recycling Facility.

Table 5.9: Order of Ranking for the Selected Sites

\begin{tabular}{|l|l|l|l|}
\hline \multicolumn{1}{|c|}{$\begin{array}{c}\text { Risk } \\
\text { Ortlook }\end{array}$} & Risk-Averse & Risk-Neutral & Risk-Prone \\
\hline First & Site 1 & Site 1 & Site 1 \\
\hline Second & Site 2 & Site 3 & Site 2 \\
\hline Third & Site 3 & Site 2 & Site 3 \\
\hline
\end{tabular}

\subsection{A Note on "Value of Information"}

It has been demonstrated in the analysis above that there is a definite information collection task for those inclined to use Influence Diagram Modeling for ranking sites. However Influence Diagrams may also save enormous resources in information elicitation by identifying variables which do not significantly influence the expected value of the utility function. In addition to this, Influence Diagrams may be used to determine the maximum resources that may be reasonably expended in obtaining information on a particular variable. To demonstrate the usefulness of Influence Diagrams in this regard, we solve our final Influence Diagram with the highest possible values inputted for every explanatory variable and obtain an expected value of 1426 points [Figures 5.8]. Assuming that we were lacking information on any number of variables at any point of our analysis, say for instance, the expected value 

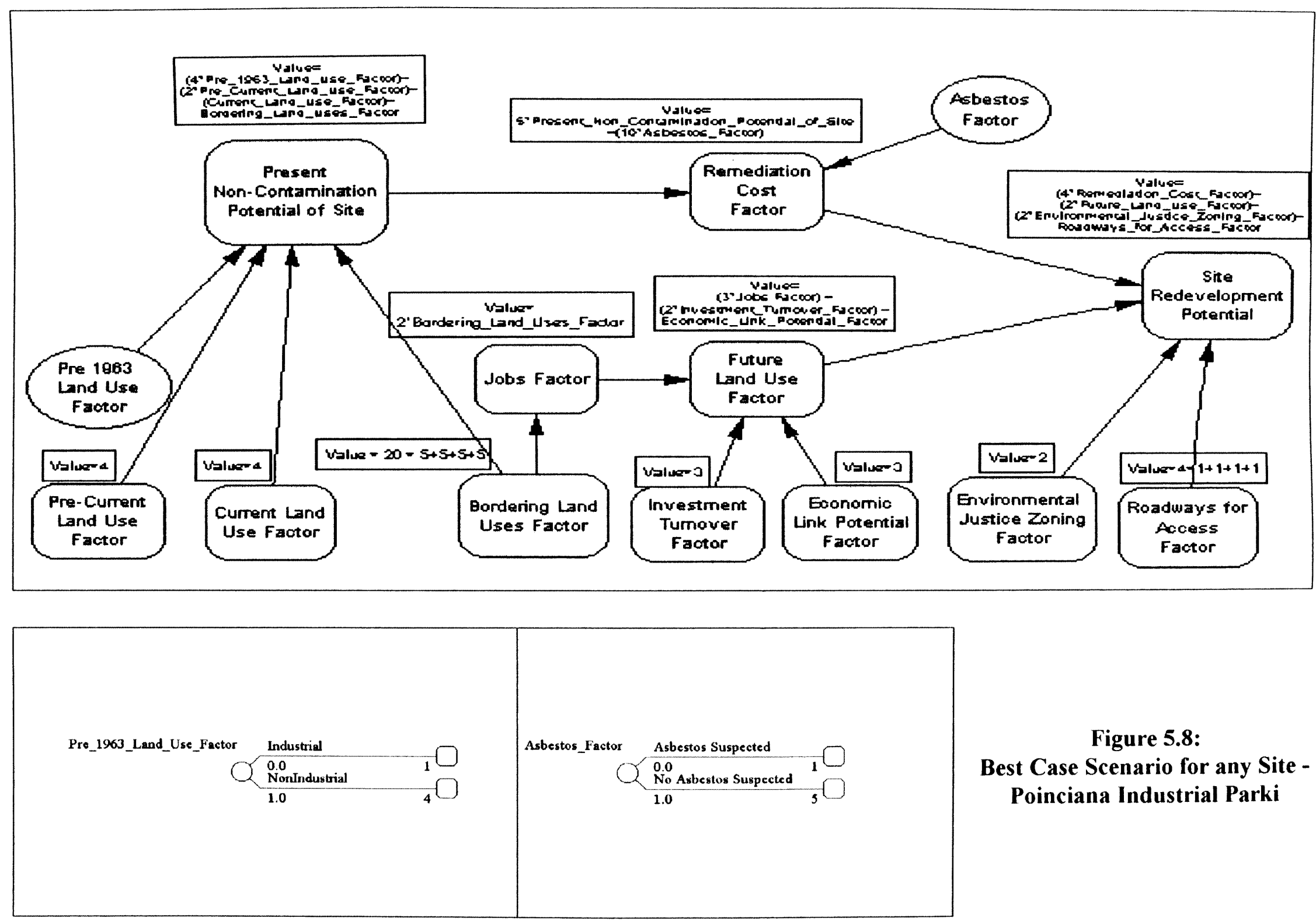

Figure 5.8:

Best Case Scenario for any Site Poinciana Industrial Parki 


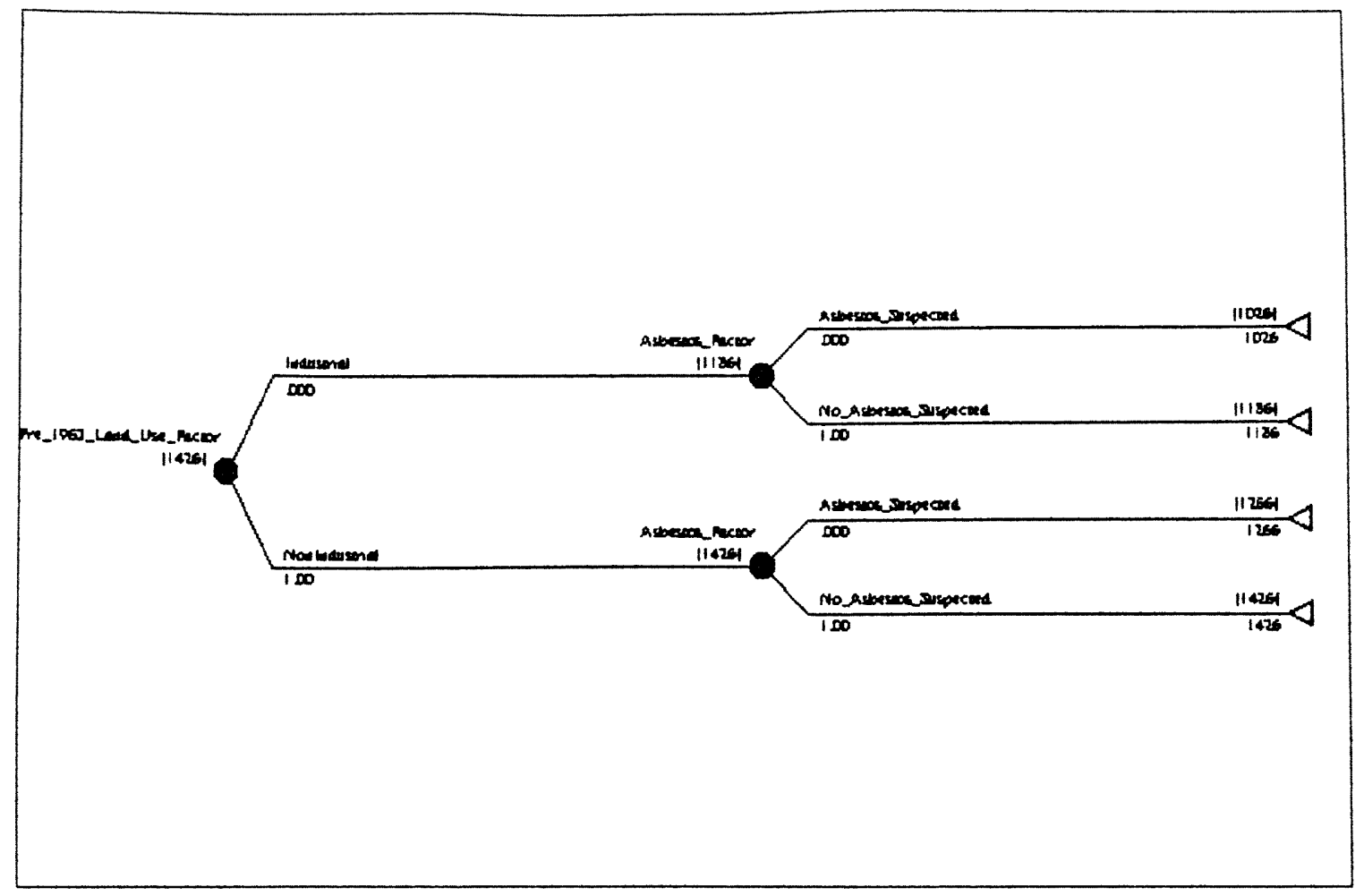

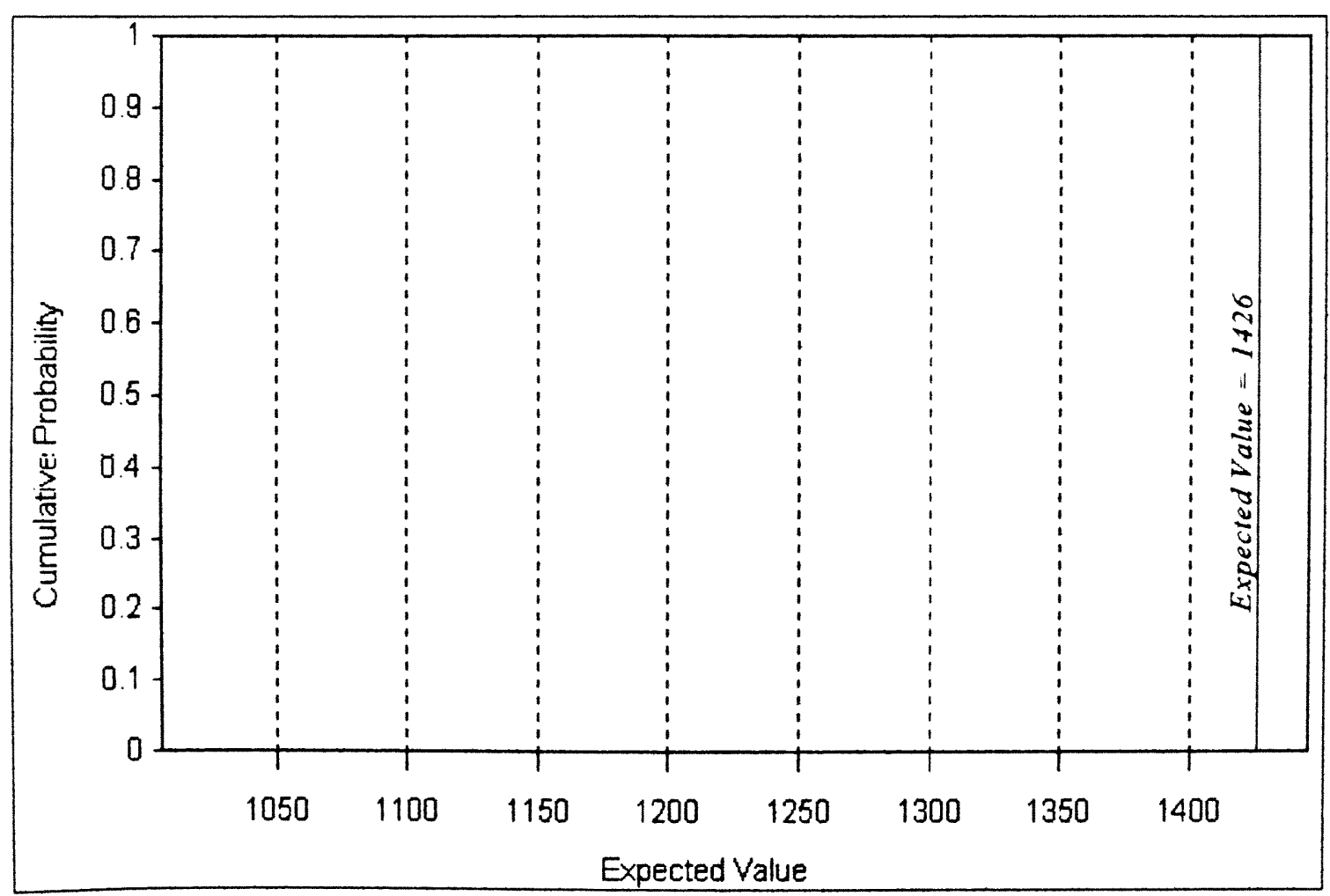

Figures 5.8A: Best Case Scenario for any Site (Poinciana Industrial Park) 
of the model for a particular site was say 1000 points, then this information implies that the maximum resources we should be willing to spend on obtaining site information should not exceed 426 redevelopment potential points. (Now studies could be performed to link redevelopment potential points to actual time and money resources. For instance, if for a variety of sites already developed by locality $\mathrm{X}$ over the past $\mathrm{X}_{1}$ years, it has been found that the average amount of money recouped per redevelopment potential point is $\$ 1,000$, then we may inclined to project that the maximum amount we may want to spend on information collection for this site must not exceed $\$ 426,000$ ).

\subsection{Summary}

Influence Diagrams have been demonstrated as a powerful decision modeling tool in Brownfields redevelopment optimization. Their versatility lies in their ability to capture the decision-maker's priorities with respect to competing objectives, their ability to forestall the expenditure of limited resources on information that is not indispensable to the decisionmaker's objectives, the ease with which they may be refined and updated, their ability to capture the decision problem from the decision-maker's perspective, the readiness with which they may be customized for different localities, their ability to model risk, their ability to make use of lower level information (explanatory variable type) to predict higher level information (derived variable type), their clarity and defensibility, and last but not least, their simplicity for communicating the decision-maker's thought process on a specific problem. Collectively, these advantages introduce Influence Diagrams as a strong support tool for site ranking and 
prioritization in Brownfields redevelopment. 
Chapter 6

CONCluding REMARKS 


\subsection{Summary}

The 1990s have taken off with extensive efforts nationwide to redevelop and reuse Brownfields, the vacant and under-used sites located in nation's older urban areas and suspected of contamination. The redevelopment of Brownfields is largely supported by federal and state level incentives and accomplished by local initiatives. While Brownfields redevelopment holds wonderful promises including the revitalization of inner-City neighborhoods, the creation of jobs and tax revenues, the renewal of old and under-used civil infrastructure, and the protection of public health, Greenfields and other natural resources, the process is also hindered by several obstacles. Brownfields redevelopment faces a variety of financial and legal liability concerns, technical and socio-economic constraints, competing objectives and uncertainties arising from inadequate site information. Since resources for the redevelopment of Brownfields are usually limited, redevelopment programs will benefit from creative techniques that sufficiently address the existing obstacles and help in optimizing available resources. To facilitate the best use of available resources, this thesis introduces and demonstrates the use of Influence Diagrams, with associated decision analytic tools, in an effective methodology for developing Brownfields ranking models to evaluate and rank sites for development.

The methodology demonstrated involves the following nine-step process for developing Brownfields Ranking Models for local Brownfields programs:

1. Defining decision objectives for determining the redevelopment potential of Brownfields; 
2. Defining associated variables to represent the decision objectives;

3. Defining the variable relationships that capture the existing and/or desired relationships between competing objectives;

4. Developing the Influence Diagram Model to capture these decision objectives, variables and variable relationships;

5. Refining the model as needed to reflect the varying degrees of uncertainty associated with available information for the model's independent variables;

6. Pre-processing site information into numeric based forms supported by the Influence Diagram model;

7. Inputting respective site information and solving the model for each site to determine expected value and risk outputs;

8. Analyzing the expected value and risk-related outputs of the model; and finally

9. Determining the final ranking of the sites based on the analysis of the model output.

This model is of potential use to local Brownfields initiatives that have plans to incorporate models for prioritizing their Brownfields sites for redevelopment, with the goal of optimizing the use of limited resources for Brownfields redevelopment.

\subsection{Conclusions}

\subsubsection{Model Benefits}

The model developed demonstrate several advantages for incorporating a decision 
analytic methodology in Brownfields ranking procedures. These are described below:

1. Influence Diagrams have been demonstrated as a useful tool for developing Brownfields ranking models that incorporate the fundamental issues, competing objectives and prevailing values and uncertainties in Brownfields redevelopment decision-making. These models will be especially useful in providing a effective means for incorporating the input of several different stakeholders and considering them simultaneously.

2. The demonstrated methodology is a useful one for determining which variables are significant for Brownfields decision-making and offers a strong potential for savings in resources for Brownfields redevelopment.

3. The models are defensible and the methodology is easily reproducible allowing for the use of actual site data to compare the redevelopment potential of different sites, to enable the optimal ranking of these sites.

4. The models are versatile: especially useful is the fact that Influence Diagram decision models may be tailored to suit the priority issues of different localities grappling with different issues, as is demonstrated in Chapters 4 and 5, as well as limited funds to allocate and a host of Brownfields to remediate and redevelop. The model may be easily updated as more site information becomes available. 


\subsubsection{Data Considerations}

While Influence Diagrams remain a powerful tool, this exercise has emphasized that the decision-maker is fully responsible for developing his or her decision objectives, variables and relationships for ranking Brownfields sites, collecting the necessary information to reflect the states of the different sites to be ranked, and reducing this information into a form that is meaningful for use in the model. This process is bound to involve an understanding of the pertinent socio-economic issues of the locality in which the sites are located. In this study, the site data obtained was reduced from case study format to a relative numeric value system for a number of defined measures that captured that area's overall socio-economic objectives, as well as the environmental state of the sites themselves.

Another useful observation that emerges relates to the quality of data used in the models. The models provide as good an output as the data that is fed into them. This is evident from the three scenarios that are presented in Chapter 5, where ranking changes to reflect the state of available information. It is true that if perfect information were available for every site to be ranked, the output of the model would be of a higher quality in terms of its accuracy, however the model's functionality would also be relegated to that of a spreadsheet model, i.e., the model would be only be needed for deterministic modeling which is perfectly done by such spreadsheet models as Microsoft Excel and Lotus. However, since it is usually uneconomical to obtain perfect information prior to Brownfields ranking, the Influence Diagram model 
is likely to serve a useful purpose in several cases in so far as care is taken to identify and provide meaningful data and variable relationships from the information that is readily or reasonably available.

\subsection{Suggestions for Further Research}

\subsubsection{Tradeoffs Between Detailed Structures and Resource Expenditure on Information Collection}

This thesis has developed a relatively simple model to rank sites for redevelopment in a particular locality. More detailed models may be developed for Brownfields ranking in this and other localities so long as the variables they contain are points of difference rather than similarity for the sites to be ranked. However, the more detailed the model structure, the more information is required for the model, and the less utility the model has with respect to minimizing available resources for redevelopment by using up large amounts for information collection. Hence there appears to be a trade off between the amount of detail incorporated in a model, the model's predictive accuracy, and the ultimate purpose of the model to optimize redevelopment resources. It may be of interest to the Brownfields redevelopment community to ascertain tradeoffs between the level of detail incorporated into the model, the corresponding accuracy of the model in predicting redevelopment potential, and the net effect of these two variables on resource savings. The author is of the opinion that identifying the significant redevelopment variables in any locality 
and understanding the true relationships between these may preclude the collection of extensive amounts of information and still provide adequate predictions of the potential values of sites for redevelopment. With this Influence Diagram Model, the emphasis seems to be more on the quality than on the quantity of information fed into the model, because the decision-maker must understand the relationships between all the different types of information inputted. This said however, further research on the tradeoffs between detailed modeling and the capacities of model prediction as well as the net effect of these two variables on resource expenditure, is likely to be useful those who intend to rank Brownfields sites for redevelopment using Influence Diagram and other decision analytic models.

\subsubsection{Local Standardization of Redevelopment Measures}

Redevelopment potential measures are likely to be different for different localities. The task of reducing these measures to a comprehensive value system is likely to be more complex than the methodology presented in this research. It may be useful to develop methodologies for determining the relative values of different measures. These procedures may be based on cost/benefit analyses of the variables in relation to the locality's long term objectives. They may also be based on prior experiences of the locality of interest or other localities with similar socio-economic characteristics. 
REFERENCES 
Agogino, Alice M, Nour-Omid, Ori, Imaino, Wayne, and Wang, Sherman S. (1992). "Decision-Analytic Methodology for Cost-Benefit Evaluation of Diagnostic Testers." IIE Transactions, Volume 24 (1), March 1992, pp 39-54.

Allardice, David R, Matton, Richard H, and Testa, Willam A. "Brownfield Redevelopment and Urban Economies." Found in Chicago Federal Letter; May 1995, No. 93, pp. 14.

Angelo, William J. "EPA and Cities see Green in Cleanup of 'Brownfields' Sites." ENR, Nov 6, 1995, Vol. 235, No. 19, pp. 31-34.

Baker, Nancy Croft. "EPA Loosens Lender Liability for UST." Environment Today, Oct 1995, Vol. 6, No. 9, pp. $1,8$.

Barnette, Curtis H. "Revitalizing Brownfields Sites." Iron Age New Steel, June 1995, Vol. 1 No. 6 , p. 88 .

Brownfields National Pilots. Office of Solid Waste and Emergency Response, USEPA. Accessed from USEPA Website - http://www.eap.gov/swerosps/bf/natl.htm, Updated: February 9, 1996. 
Brownfields Pilots. Office of Solid Waste and Emergency Response. Revised February 9, 1996. Accessed from Internet site http://www.eap.gov/swerosps/bf/pilot.htm.

Brownfields Regional Pilots. Office of Solid Waste and Emergency Response, USEPA. Accessed from USEPA Website - http://www.eap.gov/swerosps/bf/natl.htm, Updated: February 9, 1996.

Bryant, Bunyan. Environmental Justice. Issues, Policies and Solutions. Island Press, Washington, DC, Covelo California, 1995.

Bullard, Robert D. Unequal Protection. Environmental Justice and Communities of Color. Sierra Club Books, San Francisco, 1994.

Clemen, Robert T. Making Hard Decisions. An Introduction to Decision Analysis. PWSKent Publishing Company, Boston, 1991.

Connolly, Kathleen and Daddario, David. "How to find the Green in your City's Brownfields." American City \& County, Nov 1995, v110, No. 12, p. 28.

Cooke, Nancy J. "The Elicitation of Domain-Related Ideas: Stage One of the Knowledge Acquisition Process," in Expert Knowledge and Explanation, the Knowledge- 
Language Interface. Ed. Charlie Ellis. Ellis/Ellis Horwood Limited, 1989, pp 58-75.

Dade County Human Resources Deparment-Model City Program Division in cooperation with the Dade County Planning Department. The Proposed Model City Comprehensive Plan, Report I, Community Development, Undated.

Department of Environmental Resources. Brownfields Project Proposal for Metropolitan Dade County, March 1996.

DPL. Decision Analysis Software for Microsoft Windows. Student Edition. ADA Decision Systems, 1995.

Emerson, Jim. "Environmental Update." National Real Estate Investor, Jan 1996, v38, No. 1, p.2.

ENR. "Brownfield Incentives Aired.” ENR, March 18, 1996, p. 12.

Geltman, Elizabeth. Environmental Issues in Business Transactions. Michie Company, Charlottesville, VA, 1994, p. 340.

GTI [Ground Water Technology, Inc]. Phase I Environmental Site Assessment Report, 
Poinciana Industrial Park, April 1996.

Irwin, Laura. "Dade Task Force would make "Brownfields" Green. Miami Today, May 30, 1996.

Josi, Frank. “Minnesota’s Superfund Shield.” Planning, June 1996, Vol 61, No. 6, pp. 22-23.

Kendree and Sheperd Planning Consultants. Model City NDP, Dade County, Florida, Undated.

Kirkwood, Craig, W. (1992). "An Overview of Methods for Applied Decision Analysis." Interfaces 22 (6), Nov-Dec 1992, pp. 28-39.

Longman, Phillip. "Sprawl.” Florida Trend, December 1994, pp 40 - 47.

Maldonado, Monica. "Brownfields Boom.” Civil Engineering, May 1996, American Society of Civil Engineers, New York, pp. 36-40.

Maxwell, Daniel, T. "Three Packages for Processing Influence Diagrams: DPL ${ }^{\mathrm{TM}}, \mathrm{InDia}^{\mathrm{TM}}$ and Demos ${ }^{\mathrm{TM}}$." Journal of Multi-Criteria Decision Analysis, Vol 5, 1996, pp. 72-74. 
Metropolitan Dade County, Department of Housing and Urban Development, Neighborhood Development Program, Status Report, 1969-1974, December 1973.

Metropolitan Dade County. Human Resources Division. Model Cities Division. Model City Profile, January 1973.

Morris, Allen. The Florida Handbook, 1993-1994, 24th Biennial Edition. The Penninsular Publishing Company, Tallahassee, Florida, 1993.

NE-MW Economic Review, June 1995.

New State and Local Approaches to Environmental Protection. A contractor report prepared by the Environmental Law Institute for the Office of Technology Assessment, August 1993, p. 91.

Ohio Environmental Protection Agency. "Real Estate Cleanup and Re-use Program." Fact Sheet, June 1994, p. 2.

RMT Regulatory Updates. "Brownfields Programs: State Summary." RMT Website pages, Last Update: March 7, 1996. 
Shachter, Ross D. (1986). "Evaluating Influence Diagrams.” Operations Research, Vol 34 (6), November-December 1986, pp. 871-882.

Shachter, Ross D. (1988). "Probabilistic Inference and Influence Diagrams.” Operations Research, Vol 36 (4), July-August 1986, pp. 589-604.

Shafer, Glenn. (1992). “Influence Diagrams and Decision Trees.” Note for Business 876, University of Kansas.

Shanoff, Barry S. "EPA Forges Ahead with Brownfields Action Agenda." World Wastes, Oct 1995, Vol 38, No. 10, pp. 18-22.

The State of the States on Brownfields: Programs for Cleanup and Reuse of Contaminated Sites. Background paper produced by the United States Congress Office of Technology Assessment (OTA), June 21, 1995, Accessed from Internet site http://otabbs.ota.gov/E889T205.

Tebeau, Charlton W. A History of Florida. University of Miami Press, Coral Gables, 1971.

USEPA Guidance on Settlements with Prospective Purchases of Contaminated Properties. Office of Enforcement and Compliance Assurance. United States Environmental 
Protection Council, May 24, 1995. Accessed from Internet Site http://www.lawsite. com/BROWNFIELDS /usepa.html.

USEPA Policy Toward Owners of Property Containing Contaminated Aquifers. Office of Site Remediation Enforcement, United States Environmental Protection Council, May 24, 1995. Accessed from Internet Site http://www.lawsite.com/BROWNFIELDS /usepa.html. 
